\title{
Advances in the Stability of Halide Perovskite Nanocrystals
}

\author{
Maning Liu ${ }^{1}$, Anastasia Matuhina ${ }^{1}$, Haichang Zhang ${ }^{2}$ and Paola Vivo ${ }^{1, * \mathbb{C}}$ \\ 1 Faculty of Engineering and Natural Sciences, Tampere University, P.O. Box 541, FI-33014 Tampere, Finland; \\ maning.liu@tuni.fi (M.L.); nastia.matuhina@gmail.com (A.M.) \\ 2 Key Laboratory of Rubber-Plastic of Ministry of Education (QUST), School of Polymer Science and \\ Engineering, Qingdao University of Science and Technology, Qingdao 266042, China; \\ haichangzhang@hotmail.com \\ * Correspondence: paola.vivo@tuni.fi
}

Received: 7 October 2019; Accepted: 8 November 2019; Published: 12 November 2019

\begin{abstract}
Colloidal halide perovskite nanocrystals are promising candidates for next-generation optoelectronics because of their facile synthesis and their outstanding and size-tunable properties. However, these materials suffer from rapid degradation, similarly to their bulk perovskite counterparts. Here, we survey the most recent strategies to boost perovskite nanocrystals stability, with a special focus on the intrinsic chemical- and compositional-factors at synthetic and post-synthetic stage. Finally, we review the most promising approaches to address the environmental extrinsic stability of perovskite nanocrystals (PNCs). Our final goal is to outline the most promising research directions to enhance PNCs' lifetime, bringing them a step closer to their commercialization.
\end{abstract}

Keywords: perovskite nanocrystals; stability; lead-free; encapsulation; ligands; degradation; all-inorganic perovskites; lower dimensional perovskites

\section{Introduction}

In the last decade, metal halide perovskites semiconductors have received tremendous attention worldwide because of their outstanding optoelectronic properties, namely the high absorption coefficients, long charge-carrier diffusion lengths, exceptional high defect tolerance, tunable optical bandgaps, and moderately high charge-carrier mobility [1,2]. Such versatile characteristics of perovskites, together with their low formation energies, their suitability with high-volume manufacturing techniques, and their being made of low-cost and earth-abundant elements, make perovskites superstar materials for optoelectronic devices and particularly for photovoltaics, for which the certified power conversion efficiencies (PCEs) up to 25.2\% [3] have been recently achieved at a skyrocketing pace. On the other hand, the success of conventional chalcogenide nanocrystals and semiconductor quantum dots (QDs) (e.g., CdSe, CdS, ZnS) [4] has raised interest to develop perovskites at nanoscale. Their facile synthesis along with their exceptional optoelectronic properties, have significantly boosted their use for several applications, including light-emitting diodes (LEDs), photodetectors, and lasers [5]. The quantum confinement allows the tunability of the optoelectronic properties of perovskite nanocrystals (PNCs) according to the size, defined in terms of their Bohr radius [6]. This opens up an array of properties and possible applications. PNCs, with at least one dimension below $100 \mathrm{~nm}$ per unit crystal cell [6], have widely achieved enormous interests with more than 800 papers published in 2018 [7]. However, similarly as their parent perovskite materials, they also suffer from instability inherent to the ionic lead $(\mathrm{Pb})$-halide bond and the dynamic nature of the ligand binding [6]. Other bottlenecks of PNCs impeding their commercialization mainly include the toxicity of $\mathrm{Pb}$ and the challenge to integrate them into macroscopic devices $[8,9]$. 
PNCs' stability is mainly influenced by both composition (cations and halide anions) and atmospheric factors. The strong ionic bonding of halide PNCs inherently results in their easy reactivity with moisture, oxygen, temperature, and UV light, requiring severe conditions for their storage and further applications $[10,11]$. Over the past few years, many strategies have been developed and employed to improve PNCs stability during and/or after their synthesis. For instance, the synthesis of PNCs with low dimensionality of the inorganic part [8,9], surface treatment with hydrophobic and strong electron-withdrawing molecules [10], and capping perovskites with polymers or inorganic oxides [11,12], have been effectively used to enhance the environmental stability of as-formed colloidal PNCs and their corresponding optoelectronic devices.

In this review, we focus on the emerging new strategies to improve PNCs stability in such a dynamic and fast-moving field. While many good reviews have been published on PNCs so far $[5,6,12,13]$, a comprehensive overview with specific emphasis on their stability issues and the most recent approaches to address them is not yet thoroughly reported. We aim at filling this knowledge gap by surveying various strategies to boost PNCs stability, with a major highlight on the intrinsic chemical- and compositional- factors. In Section 2, we focus on the most recent trends in the colloidal synthesis and post-synthesis treatments to increase PNCs stability. Emphasis is put on the selection of organic ligands that greatly influence the size and the shape of PNCs and passivate the surface, thus strongly affecting PNCs stability. In Section 3, we examine each constituent of PNCs structure and its role in the overall stability. We also provide a brief overview on the most promising $\mathrm{Pb}$-free PNCs in terms of optoelectronic properties and PNCs inherent stability. In Section 4, we report about the recent advances on the approaches to address the environmental stability of PNCs, i.e., the effect of heat, moisture, oxygen, and UV light on PNCs degradation. Finally, we provide our views on future goals to advance the state-of-the-art on PNCs extrinsic stability. We believe that this work will be a useful reference for researchers working in the field, eventually promoting new insights and future studies to significantly enhance the stability of PNCs, thus bringing them closer to the commercialization.

\section{Synthesis and Post-Synthesis Treatments}

In this section, we will briefly discuss the advances towards stability improvement upon the significant synthetic routes that have been developed within injection methods. Moreover, we provide an overview of several key strategies for post-synthesis treatments to improve the stability of as-synthesized colloidal PNCs, mainly including surface passivation, phase transition, and ions exchange.

\subsection{Key Synthesis Methods}

The widely used colloidal synthesis approaches in solution process provide an effective route for the manufacturing of uniform and high-quality PNCs. To date, the most employed synthetic routes for PNCs are the injection methods, which can be divided into hot injection route and low temperature injection process $[14,15]$. Upon different synthesis approaches, by controlling reaction temperature, capping ligands and other reaction conditions, various halide PNCs can be achieved with variable components (e.g., organic/inorganic hybrid or fully inorganic), morphological dimensionalities from zero to three dimension (0D-3D), sizes and optical properties, which are closely in relation to the stability issue of the as-prepared colloidal PNCs.

\subsubsection{Hot-Injection Method}

The high temperature hot-injection procedure has been commonly employed for the synthesis of conventional metal chalcogenide (e.g., CdSe, CdS, PbS) nanocrystals [16], and is also widely used to synthesize metal halide PNCs, particularly for fully inorganic ones due to the high temperature reaction. Kovalenko et al., firstly fabricated lead-based $\mathrm{CsPbX}_{3}(\mathrm{X}=\mathrm{Cl}, \mathrm{Br}$, I and the mixture) PNCs with a typical hot-injection method [17]. In general, the formation of $\mathrm{CsPbX}_{3} \mathrm{NCs}$ is initiated by the swift injection of Cs-oleate into a precursor (e.g., an octadecene solution) containing $\mathrm{PbX}_{2}$ and 
long-chain alkyl acid and amine, i.e., oleic acid (OA) and oleylamine (OAm), at high temperatures normally in the range of $140-200^{\circ} \mathrm{C}$. The function of the mixture of $\mathrm{OA}$ and $\mathrm{OAm}$ is to solubilize $\mathrm{PbX}_{2}$ in precursor and accordingly to stabilize the as-formed PNCs [14]. Instead of the very common source of cesium oleate, i.e., cesium carbonate in $\mathrm{OA}$, some other Cs-containing compounds such as cesium stearate and cesium acetate can produce improved processability and smaller sizes for PNCs due to the higher solubility of acetate or stearate based precursor $[18,19]$. The overall formation process of $\mathrm{CsPbX}_{3}$ can be expressed by Equation (1):

$$
\text { 2Cs-oleate }+3 \mathrm{PbX}_{2} \rightarrow 2 \mathrm{CsPbX}_{3}+\mathrm{Pb}(\text { oleate })_{2}
$$

Basically, $\mathrm{PbX}_{2}$ is the only source of $\mathrm{X}^{-}$ions and thus one third of $\mathrm{Pb}^{2+}$ in precursor is consumed for the byproduct of lead oleate. In this case, lead-to-cesium molar ratio $\left(\mathrm{R}_{\mathrm{Pb}-\mathrm{Cs}}\right)$ is one key factor to influence the formation of desired $\mathrm{CsPbX}_{3} \mathrm{NCs}$, which generally requires the value of $\mathrm{R}_{\mathrm{Pb}-\mathrm{Cs}}$ to be 1.5 [14,17]. As shown in Equation (1), the formation of $\mathrm{CsPbX}_{3} \mathrm{NCs}$ is performed with excess halide while Cs-oleate is the limiting reagent. Prior to separation and purification, besides $\mathrm{CsPbX}_{3} \mathrm{NCs}$, the byproducts of lead oleate and oleylammonium halide and unreacted OA and OAm coexist in the reaction system, and act as surface binding components. Due to the nature of ionic $\mathrm{CsPbX}{ }_{3} \mathrm{NCs}$, even more ionic interactions with capping ligands can result in the easy dissociation of binding ligands from the surface of PNCs during separation and purification [20]. Some reports show that, by adding small excess of OA and OAm before precipitating PNCs, the photoluminescence quantum yield (PLQY) and the colloidal integrity of NCs can be effectively preserved for their improved stability $[14,20]$. In addition, the variety of aliphatic carboxylate and amine ligand pairs can modify the morphological dimensionality and size of PNCs. It has been observed that the increase in nanocube size corresponds a decrease in acid chain lengths ranging from acetic to oleic acid and hexyl- to oleylamine, respectively (Figure 1a) [19]. Meanwhile, shorter alkyl-amines and OA can break the inherent cubic crystal structure and induce the 2D growth of PNCs, i.e., nanosheets or nanoplatelets [21]. The thickness of nanoplatelets shows an amine chain-length dependence. Pan et al., reported the thinnest nanoplatelet of $1.8 \mathrm{~nm}$, obtained by using hexylamine [19]. Furthermore, as another key parameter, the reaction medium such as ether solvents (e.g., ethylene glycol dibutyl ether (EGDBE), diethylene glycol dibutyl ether (di-EGDBE), and tetraethylene glycol dibutyl ether (tetra-EGDBE)) can also affect the nucleation and growth of $\mathrm{CsPbX}_{3} \mathrm{NCs}$ due to their different polarity at different temperatures (Figure 1b,c) [22]. $\mathrm{Li}$ et al., reported that the size and morphology of $\mathrm{CsPbBr}_{3}$ QDs can be well tuned into the solvent with low polarity, which also relates to the stability of as-synthesized PNCs [22]. 

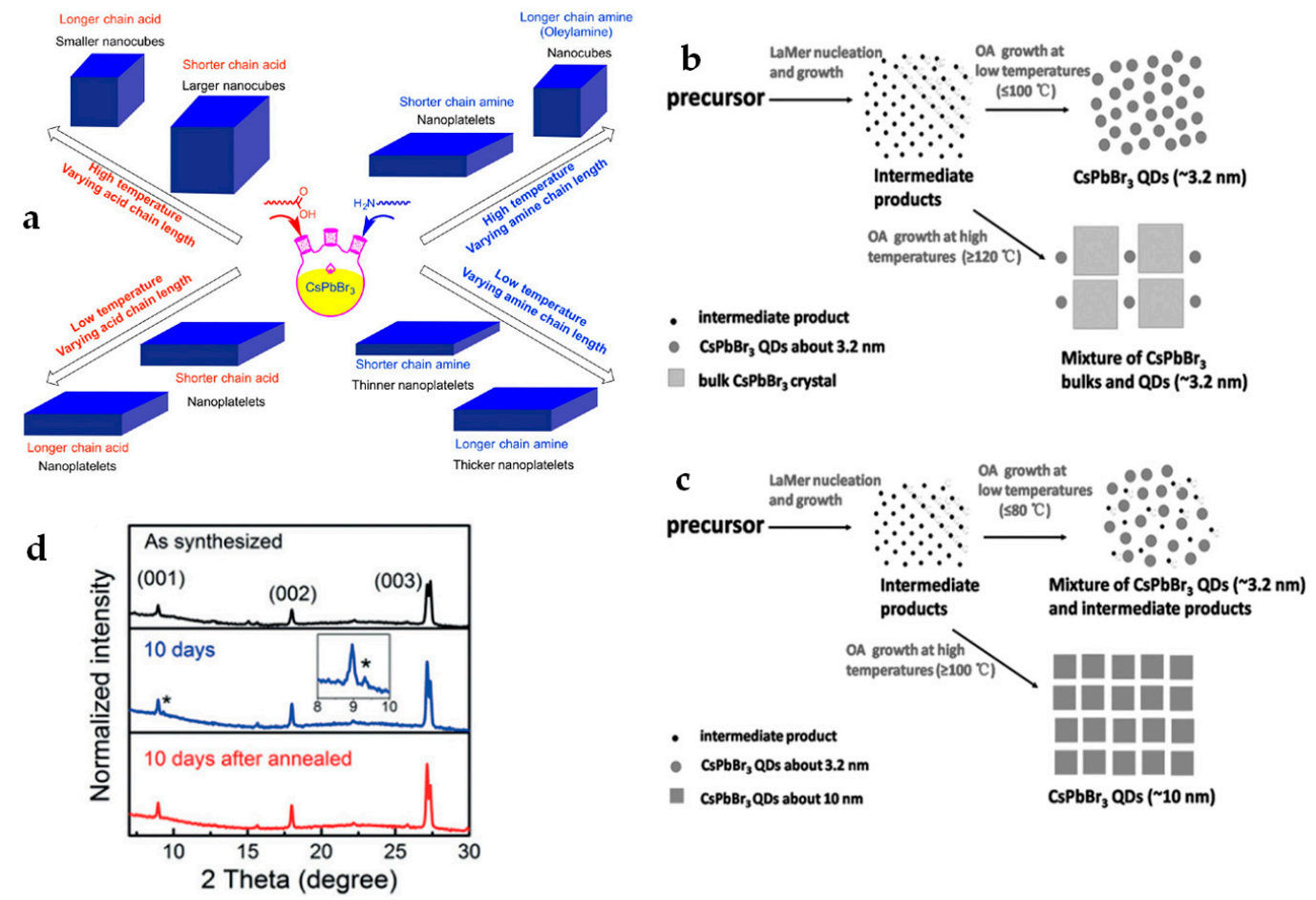

Figure 1. (a) Summary of the shape and size dependence on the chain length of carboxylic acids and amines. Reproduced with permission [19]. The growth processes of $\mathrm{CsPbBr}_{3}$ quantum dots (QDs) in (b) tetra-ethylene glycol dibutyl ether (EGDBE) with the high polarity, and (c) EGDBE with the low polarity at different temperatures. Reproduced with permission [22]. (d) X-ray diffraction (XRD) patterns of as-synthesized $\mathrm{Cs}_{3} \mathrm{Bi}_{2} \mathrm{X}_{9} \mathrm{NCs}$ (black), $\mathrm{Cs}_{3} \mathrm{Bi}_{2} \mathrm{X}_{9} \mathrm{NCs}$ stored in open air for 15 days before (blue) and after annealing (red). There is no other observed peak at $2 \theta$ higher than $30^{\circ}$ in the complete pattern. Reproduced with permission [23].

Lead-free PNCs based on tin ( $\mathrm{Sn}$ ), $\mathrm{CsSnX}_{3}$, with a size of $\sim 10 \mathrm{~nm}$ can be readily obtained within the hot-injection synthesis by using $\mathrm{SnX}_{2}$ as the metal halide source instead of $\mathrm{PbX}_{2}$ [24]. However, due to the easy oxidation of $\mathrm{Sn}^{2+}$ to $\mathrm{Sn}^{4+}$ in ambient conditions, the stability of as-prepared CsSnX PNCs is extremely low in air, which becomes a critical issue for their application. Alternatively, by employing $\mathrm{SnI}_{4}$ as a precursor within the same hot-injection synthesis, much more air-stable $\mathrm{Cs}_{2} \mathrm{SnI}_{6}$ PNCs can be achieved [25]. Interestingly, the reaction time ranging from $1 \mathrm{~min}$ to $1 \mathrm{~h}$ for the initial

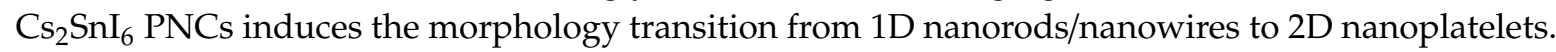
Some other metal substitutions, i.e., bismuth (Bi) or antimony ( $\mathrm{Sb}$ ), have been investigated towards achieving lead-free stable PNCs via the hot-injection procedure. However, those Bi- or Sb-based PNCs generally show relatively low PLQY (e.g., $<5 \%$ ), mainly due to their large size and different phase or deep faults originating from their electronic orbitals (e.g., Sb 5p-orbital splitting) [26,27].

Currently, as the most widely employed method for the synthesis of PNCs, the high temperature hot-injection procedure is a very promising route to obtain high-quality PNCs. Due to the dissociation of the nucleation and growth stages within the hot-injection synthetic route, a high level of monodispersity can be realized with no need of further size-selective skills [28]. However, the stability optimization of PNCs at the stage of reaction is limited, and depends to a large extent on the separation and purification of post-reaction system and post-synthesis treatments [29], which will be discussed in Section 2.2.

\subsubsection{Ligand Assisted Reprecipitation (LARP) Method}

One critical issue of the hot-injection method is that the precise reaction temperature is hard to control due to the injection of cold solution (e.g., Cs-oleate precursor), causing low reproducibility from batch to batch and inhibiting large-scale manufacturing [30]. Therefore, some other alternative 
synthesis methods have been developed to tackle these problems. The low temperature ligand assisted reprecipitation method (LARP) is a representative strategy to be readily scaled up, while obtaining high production yield of stable PNCs [31,32].

Prior to the formal establishment of the LARP method, a so-called "non-template" (NT) method was initially developed to synthesize both hybrid (e.g., methylammonium(MA)PbBr 3 PNCs) [33] and fully inorganic (e.g., $\mathrm{CsPbBr}_{3}$ QDs) [34] PNCs in large-scale mode. In a typical NT synthesis, the soluble precursor salts (e.g., $\mathrm{MAX}$ or $\mathrm{CsX}$, and $\mathrm{PbX}_{2}$ ) dissolved in a DMF solution are mixed with a ligand solution which contains OA and alkyl-chain amine in ODE at low temperature $\left(<100^{\circ} \mathrm{C}\right)$. By adding an anti-solvent such as acetone in the mixture precursor, the PNCs can be precipitated due to the reduced solubility. A very high PLQY of $>90 \%$ and large volume (up to $900 \mathrm{~mL}$ ) of PNCs per batch can be achieved via NT synthetic route [35]. As a derivative of the NT method, Zhang et al., initially developed the LARP method to fabricate $\mathrm{MAPbX}_{3}$ QDs at room temperature (RT) [36]. Instead of the separated ligand solution in the NT method, all precursor salts and ligands were dissolved in a polar solvent such as DMF or DMSO. With the addition of an anti-solvent (e.g., toluene), the precipitation of $\mathrm{MAPbBr}_{3} \mathrm{NCs}$ with a size of $3.3 \mathrm{~nm}$ was initiated, showing a PLQY of $\sim 70 \%$. The synthesis of functional cubic $\mathrm{CsPbI}_{3} \mathrm{PNCs}_{\mathrm{N}}$ via the LARP method has been challenged by employing CsX as Cs source due to the large particle sizes in colloidal route, reducing the phase instability [31,32]. Alternatively, by using Cs-oleate precursors, a controllable small size $(\sim 5 \mathrm{~nm})$ of $\mathrm{CsPbI}_{3}$ QDs can be obtained while stabilizing the cubic phase [37]. As another key parameter in the LARP method, the DMF reaction method can seriously degrade and even dissolve as-prepared PNCs, resulting in a reduced production yield [36]. A homogeneous reaction process at RT has been developed by Wei et al., for synthesizing $\mathrm{CsPbBr}_{3}$ QDs in a mode of gram-scale production under ambient condition [32]. A series of non-polar solvents (e.g., chloroform, dichloromethane, hexane or toluene) were used to mix all $\mathrm{Cs}^{+}, \mathrm{Pb}^{2+}$ and $\mathrm{Br}^{-}$precursors. Eventually, they found that fatty acids, i.e., long-chain carboxylate acid, such as butyric acid, hexanoic acid, octanoic acid or OA, play a significant role in the RT homogeneous synthetic route to $\mathrm{CsPbBr}_{3} \mathrm{NCs}[14,32]$.

The LARP method is also suitable to synthesize lead-free and fully inorganic PNCs. $\mathrm{Cs}_{3} \mathrm{Bi}_{2} \mathrm{X}_{9}$ QDs have been successfully synthesized by injecting a DMSO solution consisting of CsX and BiX precursors into 2-propanol (IPA) as an anti-solvent [23]. Interestingly, without any capping ligands in the reaction, $6 \mathrm{~nm}$-size $\mathrm{Cs}_{3} \mathrm{Bi}_{2} \mathrm{Br}_{9}$ QDs can still be formed but showing a low PLQY of $0.2 \%$. After involving some aliphatic ligands such as $\mathrm{OA}$ and octylamine, smaller size QDs (e.g., $3.9 \mathrm{~nm}$ ) were obtained with a largely improved PLQY of $19.4 \%$ [38]. By substituting Bi with $\mathrm{Sb}$ at $\mathrm{B}$ site of their $\mathrm{ABX}_{3}$ structure and using a similar synthetic route, $\mathrm{Cs}_{3} \mathrm{Sb}_{2} \mathrm{Br}_{9}$ QDs in size of $3.1 \mathrm{~nm}$ were also fabricated with a dramatically enhanced PLQY of $46 \%$ [39]. All these fully inorganic PNCs showed improved thermal and chemical stabilities compared to their hybrid analogues based on storage-time dependent X-ray diffraction (XRD) study (Figure 1d) $[23,38]$. The main drawback of the LARP method is that it is hard to precisely control PNCs size and morphology, which can be instead easily achieved via the hot-injection method. Besides the above-discussed colloidal injection synthetic routes, non-injection methods such as convection, solvothermal, microwave, and ultrasonication methods, have also been developed for the preparation of stable metal halide PNCs. In this review, we will not discuss those non-injection methods further, but an interest reader can refer to $[14,40]$ for a deep overview.

\subsection{Post-Synthesis Modification}

To be competitive with the high performance of bulk perovskite solar cells, it is crucial to understand the degradation mechanism of current metal halide PNCs particularly at post-synthesis stage, and then further improve the stability of PNCs for potential commercialization. Recently, several significant post-synthetic treatments have been investigated and developed to not only tune the structural and optical properties of PNCs but also to increase their stability in both solution and solid phases [41,42]. These treatments, that are closely in relation to the surface chemistry of colloidal 
PNCs, can be classified according to three criteria: surface passivation, phase transformations, and ions exchange, including cation exchange and anion exchange.

\subsubsection{Surface Passivation}

Owing to the strong ionic character of both internal and external bondings, PNCs are readily formed while it is also easy to break them during the isolation and purification steps (Figure 2a) [43]. The surfactants for surface passivation, i.e., capping ligands, are therefore the key to preserve the structure of PNCs and further influence their stability and PLQY. Since straight-chain aliphatic ligands with a terminal group of $-\mathrm{NH}_{2} / \mathrm{NH}_{3}{ }^{+}$, i.e., oleylamine and octylamine, are used to dissolve B-site metal cation in the precursor during the synthesis, it is reasonable for amino capping ligands to originally passivate the surface of the as-formed PNCs. Due to the modest constants of ligands binding to the surface of PNCs, the ligand density at the surface typically decreases after several required cycles of isolation and purification [44]. It has been reported that, by adding a small amount of organic acid and amine ligands, the acid-base equilibrium can be maintained as a prerequisite to achieve good colloidal stability $[45,46]$. However, the excess of amine has also been proved to destabilize the PNCs into an irreversible degradation with a transition shown by Equation (2) [47]:

$$
4 \mathrm{CsPbBr}_{3} \stackrel{\text { amine }}{\rightarrow} \mathrm{Cs}_{4} \mathrm{PbBr}_{6}+3 \mathrm{PbBr}_{2}
$$

Instead of straight-chain ligands, Li et al., developed a passivation mechanism in terms of a so-called dissolution-precipitation model (shown in Figure 2b) by employing branched capping ligands, i.e., (3-aminopropyl) triethoxysilane (shortened as APTES) [48]. The re-dissolution of the as-synthesized PNCs in DMF solvent can be effectively hindered upon the strong steric hindrance and the silica formation through the function of APTES hydrolysis, which is favorable for maintaining their original properties and improving the stability.

Compared to those conventional alkyl amino and acid ligands, other surface agents containing phosphoric or fluoro group can also be beneficial for the enhancement of both stability and PLQY of PNCs. Shen et al., found that trioctylphosphine (TOP) can interact with $\mathrm{PbI}_{2}$, achieving a stable and quite reactive $\mathrm{PbI}_{2}$-based precursor. As-treated $\mathrm{CsPbI}_{3}$ QDs showed nearly 100\% PLQY and improved chemical stability [49]. Deng et al., demonstrated novel lead-free hollow nanocrystals capped with perfluorooctonoic acid (PFOA) after the ligand exchange, i.e., $\mathrm{CsSnBr}_{3}$ cubic nanocages, exhibiting excellent oxygen resistibility and high stability against moisture and light in ambient conditions (Figure 2c) [50]. They attributed this highly improved stability to two effects from used PFOA ligands that contain strong electron-withdrawing groups with large steric hindrance.

Considering those long-chain aliphatic ligands with insulating nature, short-chain ligand exchange procedure particularly in solid state has been proposed and investigated to achieve efficient charge transfer into the device application. It has been known that PNCs are unstable in most polar anti-solvents, which makes the selection of a proper solvent for the ligand exchange in film state difficult. Short aromatic ligands such as benzoic acid and 4-phenylbutylamine recently have been able to induce the precipitation of PNCs in a suitable solvent, i.e., benzene or octane, while removing the long-chain aliphatic ligands on the surface of as-formed PNCs [51]. Pan et al., demonstrated enhanced stability of $\mathrm{CsPbI}_{3} \mathrm{NCs}$ in the desired cubic phase with the surface treatment of 2,2'-iminodibenzoic acid (IDA), meanwhile exhibiting a high PLQY of 95\% [52]. In addition to conventional organic surfactant ligands, inorganic ligands could also perform as capping ligands to stabilize PNCs. For instance, with $\mathrm{PbSO}_{4}$-oleate capping, Kamat et al., found that as-synthesized $\mathrm{CsPbX}_{3} \mathrm{PNCs}$ can be effectively protected to preserve their native structure for several days, which can restrain the reactions of anion exchange [53]. Potassium-oleate (K-oleate) has also been employed to passivate the surface of PNCs, resulting in enhanced photo- and thermal-stability [54]. Further exploitation of effective capping ligands during post-synthesis modification will be crucial to obtain highly stable and optimal optoelectronic properties of PNCs. 

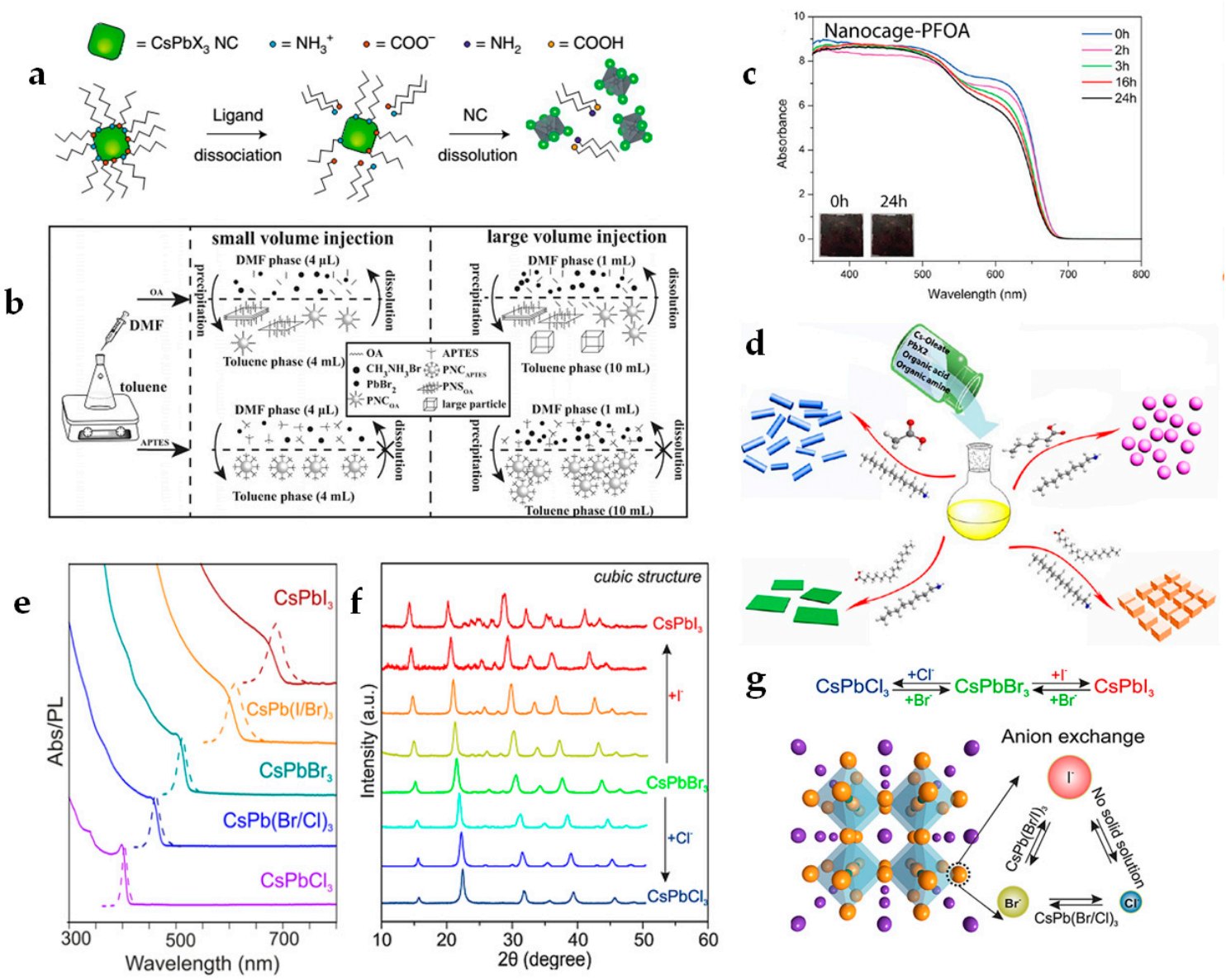

Figure 2. (a) Structural lability of $\mathrm{CsPbX}_{3}$ nanocrystals (NCs) due to the desorption of weakly bound ligands. Reproduced with permission [43]; (b) Precipitation quantities influenced by oleic acid (OA) and (3-amino-propyl)triethoxysilane (APTES) ligand capping effects. Reproduced with permission [48]; (c) Comparison of absorption spectra of $\mathrm{CsSnBr}_{3}$ nanocages after treatment with perfluorooctonoic acid (PFOA) at different exposure time. Inset: films were prepared by drop-casting the solution on a glass slide and exposure in air $\left(25^{\circ} \mathrm{C}\right.$, RH 60\%). Reproduced with permission [50]; (d) Schematic illustrating the formation process for different $\mathrm{CsPbX}_{3}(\mathrm{X}=\mathrm{Cl}, \mathrm{Br}$, I) nanocrystals mediated by organic acid and amine ligands at room temperature. Reproduced with permission [37]; (e) Typical optical absorption and PL spectra of $\mathrm{CsPbX}_{3} \mathrm{NCs}$ after post-synthetic anion exchange reactions. Reproduced with permission [17]; (f) XRD patterns of the parent $\mathrm{CsPbBr}_{3} \mathrm{NCs}$ and anion-exchanged samples in cubic phase. The top pattern for purely $\mathrm{CsPbI}_{3} \mathrm{NCs}$ shows some secondary phase (e.g., orthorhombic) in addition to the parent cubic phase; (g) Schematic of the anion-exchange within the cubic perovskite crystal structure of $\mathrm{CsPbX}_{3}$. Reproduced with permission [55].

\subsubsection{Phase Transition}

During the post-synthesis treatment, not only the surface of as-formed PNCs is effectively modified and passivated by capping ligands, but also the phase transition of PNCs can be induced, which is generally accompanied with the change of morphologies (0D-3D). The phase identity and phase transformation are thus the key factors to evaluate the phase stability of PNCs. For the native formation of PNCs in terms of synthesis procedure, the classic micellar transition mechanism can be the dominant scheme to shape the PNCs upon various organic acid and amine ligands [37]. One typical example of phase transformation is $3 \mathrm{D} \mathrm{CsPbr}$ nanocubes converting into $2 \mathrm{D} \mathrm{CsPb}_{2} \mathrm{Br}_{5}$ nanosheets, triggered by either $\mathrm{PbBr}_{2}$-rich conditions $\left(\mathrm{CsPbBr}_{3}+\mathrm{PbBr}_{2} \rightarrow \mathrm{CsPb}_{2} \mathrm{Br}_{5}\right)[56,57]$ or by breaking down the initial 3D PNCs with ligands $\left(2 \mathrm{CsPbB}_{3} \rightarrow \mathrm{CsPb}_{2} \mathrm{Br}_{5}+\mathrm{CsBr}\right)$ [58]. Several groups have found a direct transition from $3 \mathrm{D} \mathrm{CsPbBr}$ to $0 \mathrm{D} \mathrm{Cs}_{4} \mathrm{PbBr}_{6}$ by adding the excess of amines to extract $\mathrm{PbBr}_{2}$ from the parent 
PNCs [59-61]. As-transformed 0D Cs $\mathrm{PbBr}_{6}$ PNCs showed improved size homogeneity and chemical stability with the addition of alkyl-thiol ligands [62]. Deng et al., systematically investigated the relationship between the type and length of organic acids and amines and the formed PNCs in variable phases and morphologies [37]. For instance, hexanoic acid and octylamine can modify the PNCs into 0D QDs while the oleic acid and octylamine are able to shape the PNCs into few-unit-cell-thick nanosheets (Figure 2d) [37]. Other factors such as heat [63,64], light [65], and moisture [66,67] can also trigger the phase transition of PNCs into the solid state. The transformation of $\mathrm{Cs}_{4} \mathrm{PbBr}_{6} \rightarrow$ $\mathrm{CsPbBr}_{3}$ can be achieved via thermal annealing by physically removing $\mathrm{CsBr}$ [63]. Further exploration of multi-factor driving phase transformation during post-synthesis process will be still required to obtain optimized and phase-stable properties of PNCs.

\subsubsection{Ions (Anion and Cation) Exchange}

It is known that the optical properties of PNCs can be tuned in the spectrum ranging from blue to red light by varying the halide composition. Due to its highly ionic character, PNCs undergo a post-synthetic anion exchange reaction $\left(\mathrm{Cl}^{-} \leftrightarrow \mathrm{Br}^{-}\right.$and $\left.\mathrm{Br}^{-} \leftrightarrow \mathrm{I}^{-}\right)$(Figure 2e) [17]. By adding the halide source, such as $\mathrm{PbX}_{2}$ solution or an ammonium halide solution, a swift halide exchange can be achieved because of the precise cationic sub-lattice and the high diffusivity of halide vacancies [55]. The monodispersity of colloidal PNCs can be preserved during the anion exchange process, and it exhibits similar optical properties as those of directly formed PNCs with the same composition $[55,68]$. Most importantly, the phase feature of PNCs, i.e., morphology and shape, can be independently maintained, which has been proved with 1D nanowires- and 2D nanoplatelets-shaped PNCs [34,69].

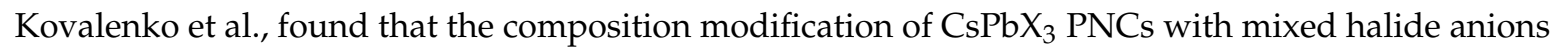
show the limited influence on the change of the cationic sub-lattice, and the cubic phase is still effectively retained after the anion exchange reaction (Figure 2f,g) with an exceptional case that the purely $\mathrm{CsPbI}_{3}$ PNCs also exhibits a secondary phase (e.g., orthorhombic) in addition to the parent cubic phase [55]. However, Yang et al., demonstrated that the phase transformation can occur from cubic to orthorhombic by increasing the ratio of $\mathrm{I}^{-}$anions in $\mathrm{CsPbBr}_{3-x} \mathrm{I}_{x}$ PNCs composition [70]. This contradiction indicates that further experimental investigations and deep understanding of structure-composition relationships for PNCs are relatively urgent to better clarify the phase identity issue upon the halide anion exchange process.

As an analogous process to anion exchange, the cation exchange reaction on both the A-site and B-site of PNCs $\mathrm{ABX}_{3}$ structure (see Section 3) can also effectively tune and improve the optical properties and the stability of PNCs. It has been known that A-site cations weakly influence the band gaps of PNCs due to their very limited contributions to the density of states near the Fermi level [13]. Nevertheless, the symmetry of the PNCs compounds can be effectively determined by the character of A-site cations. Several reports demonstrated that for $\mathrm{CsPbX}_{3} \mathrm{PNCs}_{1} \mathrm{~A}$-site $\mathrm{Cs}^{+}(1.67 \AA)$ can be replaced by the larger $\mathrm{MA}^{+}(2.17 \AA)$ cation [71], while $\mathrm{Cs}^{+}$and $\mathrm{FA}^{+}(2.53 \AA)$ can be cross-exchanged to achieve $\mathrm{Cs}_{1-\mathrm{x}} \mathrm{FA}_{\mathrm{x}} \mathrm{PbI}_{3}$ PNCs [72]. Manna et al., have reported that exchanging the A-site cations in PNCs can result in a variation in the tolerance factor and accordingly in the stability of PNCs [13]. For instance, the partial or complete exchange of $\mathrm{Cs}^{+}$in $\mathrm{CsPbI}_{3} \mathrm{PNCs}_{\text {by FA }}^{+}$cations, using FA-oleate as a precursor, leads to a long-term stability and a near-IR emission of resulting PNCs [72]. The first report on the partial exchange of the B-site $\mathrm{Pb}^{2+}$ cation in $\mathrm{CsPbBr}_{3}$ PNCs was published by Van der Stam at al., in which they mixed as-formed PNCs solution and $\mathrm{M}^{2+}$ cation precursors in toluene, i.e., $\mathrm{M}=\mathrm{Sn}^{2+}$, $\mathrm{Zn}^{2+}$ and $\mathrm{Cd}^{2+}$ [73]. However, this method led to only limited (10\%) substitution of the $\mathrm{M}^{2+}$ cation exchanged into the native PNCs, although a large excess of $\mathrm{M}^{2+}$ was applied. This observation can be attributed to the required higher activation energies at the B-site compared to anion exchange at X-site [55]. Alternatively, Mondal et al., employed the ultrasonication method to improve the alloying level (up to $40 \%$ ) of $\mathrm{CsPbCl}_{3}$ PNCs with $\mathrm{Cd}^{2+}$ by using a saturated $\mathrm{CdCl}_{2}$ solution in ethanol [74]. The increased doping level of $\mathrm{Cd}^{2+}$ in $\mathrm{Cd}: \mathrm{CsPbCl}_{3}$ PNCs enhanced their photo-stability while keeping the PLQY up to $90 \%$ of the initial value after several months of storage. Post-synthetic $\mathrm{Mn}^{2+}$ doping in 
$\mathrm{CsPbX}_{3} \mathrm{PNCs}$ has also been employed for the cation exchange at B-site. Huang et al., employed a simultaneous halide exchange method by adding $\mathrm{MnCl}_{2}$ solution into as-synthesized $\mathrm{CsPBBr}_{3} \mathrm{PNCs}_{\text {so }}$ alloy the sensitized $\mathrm{Mn}: \mathrm{CsPbCl}_{3-x} \mathrm{Br}_{x}$ [75]. However, those alloyed PNCs showed an unstable feature from photo-oxidation and thermo-degradation. To overcome this stability issue, $\mathrm{Xu}$ et al., prepared $\mathrm{CsPbMn}{ }_{1-x} \mathrm{Cl}_{x}$ by embedding as-formed $\mathrm{CsPbBr}_{3}$ PNCs in a mixture of $\mathrm{MnCl}_{2}$ and $\mathrm{KCl}$ matrix for a simultaneous cation and anion exchange [76]. With this approach, several unique phenomena were observed, including the formation of intermediate core-shell structures and composition-dependent doping processes upon long reaction times (e.g., $>40 \mathrm{~h}$ ).

Additional applied strategies on cation exchange had negative effects on stabilizing the original PNCs, as in the case of the decomposition of native $\mathrm{CsPbX}_{3}$ PNCs upon the substitutions of $\mathrm{Cs}^{+}$cations by $\mathrm{Rb}^{+}, \mathrm{Ag}^{+}$or $\mathrm{Cu}^{+}$at A-site, and of $\mathrm{Pb}^{2+}$ cations by $\mathrm{Ge}^{2+}$ or $\mathrm{Bi}^{3+}$ at B-site $[40,55]$. Several possible factors can affect the decomposition, including incompatible ion sizes, oxidation induced instability, or thermodynamics dependent phase competition [10]. Therefore, it is necessary to further explore and optimize the techniques of post-synthetic ions exchange to acquire stable phases of PNCs with tunable optoelectronic properties.

\section{Perovskite Nanocrystals Structure}

Metal halide perovskites have a general crystal structure of $\mathrm{ABX}_{3}$, in common with calcium titanium oxide $\left(\mathrm{CaTiO}_{3}\right)$ mineral discovered in 1839 by the mineralogist Lev Perovskite, and after him named as 'perovskite'. In $\mathrm{ABX}_{3}, \mathrm{X}$ is anion while $\mathrm{A}$ and $\mathrm{B}$ are cations, $\mathrm{A}$ being larger than $\mathrm{B}$. The $\mathrm{A}$ cation occupies a cubo-octahedral site coordinated with twelve $\mathrm{X}$ anions while the $\mathrm{B}$ cation is stabilized in an octahedral site coordinated with six $\mathrm{X}$ anions.

\subsection{A-Cation}

Due to the large cavity between the octahedra in $\mathrm{ABX}_{3}$ structure of PNCs [14], A-site can be occupied by a single type of cations, typically $\mathrm{Cs}^{+}, \mathrm{MA}^{+}$, and/or formamidinium $(\mathrm{FA})^{+}$, or by a mixture of them. A-site engineering offers multiple possibilities for fine-tuning structure-property-stability relationships within PNCs. If the large $\mathrm{Pb}^{2+}$ or $\mathrm{Sn}^{2+}$ cation (most common choices for $\mathrm{B}$ cation) occupies the B-site, the A-site cation should be large enough to meet the structural requirements predicted by the tolerance factor [15]. For PNCs, there are three most common 3D polymorphs at ambient conditions, i.e., cubic, tetragonal, and orthorhombic phases, similarly as for the bulk perovskite crystals. The relative stabilities of the different polymorphs in PNCs can be modified by surface chemistry effects [15]. Since $\mathrm{MA}^{+}$is volatile, it may be desirable to avoid it in PNCs composition for ensuring long-term stability [77]. Two MA-free $\mathrm{PNCs}, \mathrm{FAPbI}_{3}$ and $\mathrm{CsPbI}_{3}$, have recently attracted wide attention for their near-infrared emission properties. However, both of those MA-free PNCs are not highly stable due to the suboptimal A-site cations, i.e., too large $\mathrm{FA}^{+}$and too small $\mathrm{Cs}^{+}$, which is defined as "perovskite red wall" [15,72]. To address this issue, an effective way is to synthesize a mixture of A-cations based PNCs such as $\mathrm{Cs}_{1-x} \mathrm{FA}_{x} \mathrm{PbX}_{3}$. Protesescu et al., demonstrated a modified hot-injection method for mixing $\mathrm{FA}^{+}$

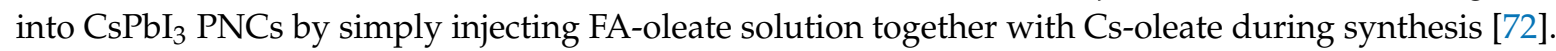
As-synthesized $\mathrm{FA}_{0.1} \mathrm{Cs}_{0.9} \mathrm{PbI}_{3}$ PNCs showed a relatively high PLQY (>70\%). Their cubic phase, stable for several months in ambient conditions, was responsible for the retention of their initial PLQY in a colloidal state (still more than $70 \%$ after a few months storage) [72]. Recently, Rubidium (Rb) or Potassium (K) have also been considered as alternative A-cations for all-inorganic PNCs with improved stability $[77,78]$. Lee et al., synthesized orthorhombic $\mathrm{RbPbI}_{3}$ nanowires for the first time, by simply replacing $\mathrm{Cs}_{2} \mathrm{CO}_{3}$ with $\mathrm{Rb}_{2} \mathrm{CO}_{3}$ upon the typical hot-injection method [79]. However, the tolerance factor of $\mathrm{RbPbX}_{3}(\mathrm{X}=\mathrm{Br}$ or $\mathrm{Cl}) \mathrm{NCs}$ is $\sim 0.8$, which implies a limitation in perovskite formation [80]. To solve this problem, by mixing A-site cations, the tolerance factor of as-synthesized $\mathrm{Rb}_{1-x} \mathrm{Cs}_{x} \mathrm{PbX}_{3} \mathrm{PNCs}$ can be effectively enhanced. However, these PNCs still exhibited comparable PLQYs to that of $\mathrm{CsPbX}_{3}$ NCs [40]. In addition, tuning the A-site with larger cations reduces the morphological dimensionality 
of PNCs to 2D sheets or platelets, 1D rods or wires, or 0D dots or clusters [81]. The morphological dimensionality related stability of PNCs will be discussed in detail in Section 3.5.

\subsection{B-Cation: Lead-Free PNCS}

The crystal structure of PNCs is mostly affected by the choice of B cation. When B in $\mathrm{ABX}_{3}$ is $\mathrm{Pb}$, depending on the tolerance factor the perovskite structure can e.g., be cubic, consisting of a three-dimensional (3D) network of corner-sharing $\left[\mathrm{PbX}_{6}\right]^{4-}$ octahedra, with $\mathrm{Pb}^{2+}$ cations located at the center of the octahedra, and with the large cavity between adjacent octahedra occupied by $\mathrm{A}^{+}$cations. When $\mathrm{Pb}$ is replaced by other elements, for example those of group- 14 in the periodic table like $\mathrm{Sn}$ and germanium $(\mathrm{Ge})$, adjacent kin elements like $\mathrm{Sb}$ and $\mathrm{Bi}$, or double elements in the so-called double perovskites, a great variety of crystal structures for PNCs can be obtained [82].

The $\mathrm{B}$ cation of the $\mathrm{ABX}_{3}$ perovskite structure is also the main responsible of the perovskite toxicity, a major critical problem of traditional halide perovskites with $\mathrm{B}=\mathrm{Pb}^{2+}$ that makes this technology still not ready for commercialization [83]. In fact, the presence of hazardous heavy metals (like lead) in electronics is regulated in the European Union, and similar restrictions are expected to be reinforced in other countries as well. This has recently driven an intense research worldwide toward environmentally benign $\mathrm{Pb}$-free perovskite materials, both in bulk and as nanocrystals, for different applications [82,84]. The development of chemically robust $\mathrm{Pb}$-free halide PNCs alternatives with similar outstanding characteristics as the original lead halide PNCs has, however, so far led to materials with significantly lower performances in optoelectronic devices with respect to those based on Pb-containing analogues [85-87]. Therefore, it is paramount to identify new synthetically accessible $\mathrm{Pb}$-free materials (both in bulk or in nanocrystal phase) that are environmentally stable and friendly while retaining the outstanding properties of $\mathrm{Pb}$ halide perovskites to allow perovskite technology entering the consumer electronics market [43].

While many reports exist on lead-free bulk perovskites, only a handful of them refer to lead-free perovskite nanocrystals, each focusing on different aspects $[12,82,88,89]$. In this Section, we look at available Pb-free PNCs systems from stability point of view. As follows, we report the key elements employed to replace $\mathrm{Pb}$ when aiming at perovskites with lower toxicity. When selecting elements to form $\mathrm{Pb}$-free perovskite structures, several chemical design rules, both structural and electronic, can guide us to screen potential candidates [90]. As for the structural criteria, Goldschmidt tolerance $(t)$ and octahedral $(\mu)$ factors, together with the cation/anion radius ratio can help to predict stable perovskite phases. It is important to note that some phases not stable in bulk are only accessible at nanoscale. One well-known $\mathrm{Pb}$-based case is the $\alpha-\mathrm{CsPbI}_{3}$ phase [89]. As for the electronic criteria, compositions resulting in PNCs with direct band gap and strongly allowed lowest optical transition for efficient absorption and emission processes are required for materials with good optoelectronic behavior [90]. Nanocrystals offer a wide composition flexibility, often serving as model systems to achieve compositions impossible to achieve in any other way thanks to the cation exchange, alloying, or doping. Furthermore, quantum confinement effects also affect the electronic structure and thus the optical transitions of the perovskites, thus possibly tuning their properties for more efficient optoelectronic devices [89].

The key examples of Pb-free PNCs are summarized in Table 1. 
Table 1. Key examples of reported lead-free perovskite nanocrystals.

\begin{tabular}{|c|c|c|c|c|}
\hline Material & Crystal Structure & Optical Transition & Bandgap, eV & Ref. \\
\hline $\begin{array}{c}\mathrm{CsSnX}_{3} \\
(\mathrm{X}=\mathrm{Br}, \mathrm{Cl}, \mathrm{I})\end{array}$ & $\begin{array}{c}\text { Cubic }(\mathrm{Cl}), \\
\text { orthorhombic (Br, I) }\end{array}$ & $\begin{array}{l}\text { Hot injection or } \\
\text { anion exchange }\end{array}$ & $\begin{array}{c}\text { High hole mobility; Tunable } \\
\text { bandgap through Vis/NIR }\end{array}$ & {$[24,91-93]$} \\
\hline $\mathrm{Cs}_{2} \mathrm{SnI}_{6}$ & $\begin{array}{l}\text { Defect-variant of } \\
\mathrm{ABX}_{3} \text { perovskite } \\
\text { structure }\end{array}$ & $\begin{array}{l}\text { Phosphine-free hot } \\
\text { injection }\end{array}$ & $\begin{array}{l}\text { Stable films; direct bandgap } \\
(1.48 \mathrm{eV}) ; \text { high absorption } \\
\text { coefficient; tunable morphology; } \\
\text { tested in solar cells and FETs }\end{array}$ & {$[25,94]$} \\
\hline $\begin{array}{c}\mathrm{MA}_{3} \mathrm{Bi}_{2} \mathrm{X}_{9} \\
(\mathrm{X}=\mathrm{Cl}, \mathrm{Br}, \mathrm{I})\end{array}$ & $\begin{array}{l}\text { Distorted-layered } \\
\text { structure }\end{array}$ & $\begin{array}{l}\text { Collaborative } \\
\text { solvent LARP } \\
\text { (Co-LARP) }\end{array}$ & $\begin{array}{l}\text { PLQY }=15 \%(X=B r) \text {; tunable PL } \\
\text { peaks from } 360 \text { to } 540 \mathrm{~nm} \text {; good } \\
\text { ethanolic stability; minor } \\
\text { re-absorption effect }\end{array}$ & [95] \\
\hline $\begin{array}{c}\mathrm{Cs}_{3} \mathrm{Bi}_{2} \mathrm{X}_{9} \\
(\mathrm{X}=\mathrm{Br}, \mathrm{Cl}, \mathrm{I})\end{array}$ & $\begin{array}{l}\text { Vacancy-ordered } \\
\mathrm{ABX}_{3} \text { perovskite } \\
\text { structure }\end{array}$ & $\begin{array}{l}\text { Hot injection [96] } \\
\text { or room T } \\
\text { synthesis [97] }\end{array}$ & $\begin{array}{l}\text { Widely-tunable absorbance; } \\
\text { air stable }\end{array}$ & {$[96,97]$} \\
\hline $\begin{array}{l}\mathrm{Cs}_{3} \mathrm{Sb}_{2} \mathrm{X}_{9} \\
(\mathrm{X}=\mathrm{Cl}, \mathrm{I})\end{array}$ & $\begin{array}{l}\text { Trigonal and } \\
\text { orthorhombic } \\
\text { phases }\end{array}$ & $\begin{array}{l}\text { Ionic metathesis } \\
\text { process }(\mathrm{X}=\mathrm{Cl})\end{array}$ & $\begin{array}{l}\text { Band-edge emission in the } \\
\text { yellow-red }(\mathrm{X}=\mathrm{I}) \text {; Sharp } \\
\text { band-edge excitonic emission }\end{array}$ & {$[27,98]$} \\
\hline $\mathrm{Cs}_{2} \mathrm{InSbCl}_{6}$ & - & - & Direct bandgap $(1.0 \mathrm{eV})$; stable & [99] \\
\hline $\begin{array}{l}\mathrm{Cs}_{2} \mathrm{AgBiX}_{6} \\
(\mathrm{X}=\mathrm{Cl}, \mathrm{Br}, \mathrm{I})\end{array}$ & $\begin{array}{l}\text { Elpasolite }(\mathrm{X}=\mathrm{Cl}, \\
\mathrm{Br})\end{array}$ & $\begin{array}{l}\text { Hot injection }(\mathrm{X}= \\
\mathrm{Cl}, \mathrm{Br}) \text {, anion } \\
\text { exchange reaction } \\
\quad(\mathrm{X}=\mathrm{I})\end{array}$ & $\begin{array}{l}\text { Stable, strong absorption } \\
\text { throughout the visible region. } \\
\text { Indirect bandgap }\end{array}$ & - \\
\hline $\mathrm{Cs}_{2} \mathrm{InSbCl}_{6}$ & - & - & Direct bandgap $(1.0 \mathrm{eV})$; stable & [99] \\
\hline $\begin{array}{l}\mathrm{Cs}_{2} \mathrm{AgIn}_{x} \mathrm{Bi}_{1-x} \mathrm{Cl}_{6} \\
(x=0.75 \text { and } 0.9)\end{array}$ & $\begin{array}{l}\text { Fm3m cubic } \\
\text { space group }\end{array}$ & $\begin{array}{l}\text { Anti-solvent } \\
\text { recrystallization }\end{array}$ & $\begin{array}{c}\text { Direct bandgap; PLQY }=36.6 \% \text {; } \\
\text { bright dual color (violet and } \\
\text { orange) emission }\end{array}$ & [100] \\
\hline
\end{tabular}

Sn and Ge halide perovskites are the structurally and electronically closest to $\mathrm{Pb}$ halide counterparts. The most promising alternative to $\mathrm{Pb}$ is $\mathrm{Sn}$ because of its efficient absorption and emission, suitable bandgaps with direct nature and narrower than their $\mathrm{Pb}$ analogues, low exciton binding energies, long carrier diffusion lengths, and defect tolerance [50,101]. To date, the highest efficiency for Pb-free perovskite solar cells is obtained with Sn-based perovskites [102]. However, Sn-based PNCs have debatable toxicity [103], and are also more unstable than the lead counterparts towards moisture, light, and heat. A unique example of Sn-based PNCs with outstanding stability against moisture, oxygen, and light are hollow $\mathrm{CsSnBr}_{3}$ nanocages treated with perfluorooctanoic acid, reported by Wang et al. [50]. This work demonstrates the already underlined importance of selecting and fine-tuning the synthetic methods when aiming at stable yet highly performing PNCs.

Ge is fairly rare and pricey element, which is also poorly stable [6]. Hence, Sn or Ge are not the best substitutions for $\mathrm{Pb}$ at $\mathrm{B}$-site when targeting high stability. However Padture et al., reported a brilliant example of surface passivation with a Sn-Ge bulk perovskite, which induces the formation of an ultrathin $(\sim 5 \mathrm{~nm})$ native-oxide layer on the bulk perovskite surface, responsible of a significant enhancement in the stability [104]. Inspired by this work, very recently we have successfully pioneered the synthesis of $\mathrm{CsSn}_{0.5} \mathrm{Ge}_{0.5} \mathrm{I}_{3}$ nanocubes with improved stability compared to $\mathrm{CsSnI}_{3} \mathrm{NCs}$ in ambient conditions, as the result of the reduction of high trapping density $\mathrm{Sn}$ vacancies upon partial replacement of Sn with Ge atoms in the nanostructures [105].

Cations from group 15 elements, $\mathrm{Bi}^{3+}$ and $\mathrm{Sb}^{3+}$, form $1 \mathrm{D}$ perovskite crystals with formula $\mathrm{A}_{3} \mathrm{~B}_{2} \mathrm{X}_{9}$, namely $\mathrm{Cs}_{3} \mathrm{Bi}_{2} \mathrm{I}_{9}$ and $\mathrm{Cs}_{3} \mathrm{Sb}_{2} \mathrm{I}_{9}$. However, reducing the morphological dimensionality from $3 \mathrm{D}$ to $1 \mathrm{D}$ increases the bandgaps and leads to anisotropic properties, not ideal when considering photovoltaic applications [106,107].

Another approach to overcome the toxicity of $\mathrm{Pb}$ in perovskites is to design materials with $\mathrm{A}_{2} \mathrm{~B}^{\prime} \mathrm{B}^{\prime \prime} \mathrm{X}_{6}$ structure, i.e., the so-called double perovskites (DPs), where two $\mathrm{Pb}^{2+}$ in the $\mathrm{ABX}_{3}$ crystal lattice are replaced with a pair of monovalent and trivalent metal cations $\mathrm{B}^{\prime}$ and $\mathrm{B}^{\prime \prime}$. Their structure is referred to as elpasolite. DPs are very promising materials due to the compositional flexibility of 
their $\mathrm{A}_{2} \mathrm{~B}^{\prime} \mathrm{B}^{\prime \prime} \mathrm{X}_{6}$ crystalline structure. Moreover, in spite their optoelectronic properties inferior to $\mathrm{Pb}$ or Sn perovskites, DPs are the best materials when aiming at highly stable perovskites that are also $\mathrm{Pb}$-free. Theoretically, thousands of DP compositions are possible. To identify the most promising materials to be synthesized a combined computational and machine learning approach is paramount. The most promising and widely explored DPs rely on silver $(\mathrm{Ag})$ and $\mathrm{Bi}$, though most of the reported double PNCs have indirect bandgap, being thus not ideal for photovoltaics or light-emitting diodes applications. On the other hand, $\mathrm{Cs}_{2} \mathrm{AgBiBr}_{6} \mathrm{PNCs}$ exhibited outstanding photoconversion of $\mathrm{CO}_{2}$ for solar fuels production, and it has also been used for water splitting applications, together with $\mathrm{Cs}_{2} \mathrm{AgBiCl}_{6}, \mathrm{Cs}_{2} \mathrm{AgSbBr}_{6}$, and $\mathrm{Cs}_{2} \mathrm{AgInCl}_{6}$ [108]. It is interesting to note that, while $\mathrm{Cs}_{2} \mathrm{AgBiI}_{6}$ is not stable in bulk form (single crystals or thin films) [109,110], yet it can be stable in nanostructures [111]. As far as degradation is concerned, a decrease in chemical stability from $\mathrm{Cs}_{2} \mathrm{AgInCl}_{6}$ to $\mathrm{Cs}_{2} \mathrm{AgBiCl}_{6}$ has been observed [112].

Copper $(\mathrm{Cu})$ is another promising material when aiming at humidity-stable, heat-stable, and UV light-stable lead-free perovskites. A Cu-based 2D perovskite $\left(\mathrm{C}_{6} \mathrm{H}_{5} \mathrm{CH}_{2} \mathrm{NH}_{3}\right)_{2} \mathrm{CuBr}_{4}$ [113] has been reported by Li et al., showing a low bandgap of $1.81 \mathrm{eV}$ and high absorption coefficient of $\sim 1 \times 10^{5}$ $\mathrm{cm}^{-1}$ at $539 \mathrm{~nm}$, making it a suitable light-harvester for solar cells, and particularly suitable for tandem photovoltaics. Finally, Solis-Ibarra et al. [114]. proposed a stable $\mathrm{Cu}-\mathrm{Sb} \mathrm{DP}$ with direct bandgap (hence suitable for photovoltaics) of $1 \mathrm{eV}$ [114].

\subsection{Halides}

Halide composition engineering is recognized as a major approach to tune the structural and optical properties of both Pb-based and Pb-free PNCs. As one key parameter, the elemental ratio of halide/metal (X/B) severely influences the synthesis to obtain high quality and stable PNCs. Typically, for Pb-based PNCs, the ratio of $\mathrm{X} / \mathrm{Pb}$ ranging from 2:1 to 4:1 has been verified to achieve higher PLQYs, longer PL lifetimes, and more stabilized NCs, as reported by Wang et al. [115]. The enhancement of overall optoelectronic properties upon the above-mentioned halide-rich synthesis could be attributed to the reduced traps on the surface halide vacancies of as-formed PNCs [115]. The same authors proposed a scheme of $\mathrm{CsPbBr}_{3}$ PNCs synthesis in halide-poor and halide-rich circumstances (Figure 3a) [115]. Due to the ligands easily peeled off from the surface of PNCs during the purification in a halide-poor circumstance, the PLQY of as-formed PNCs was dramatically decreased. On contrast, by adding more amount of oleylammonium bromide that surrounds the PNCs, the halide can effectively remain on the surface of PNCs, preserving the condition for self-passivation. The Br-rich capping can occupy the surface vacancies while passivating the surface where the electron traps allocate, resulting in improved structural stability and PLQY of $\mathrm{CsPbBr}_{3}$ PNCs [15]. In addition, the durability of PNCs during the purification and device manufacturing can be enhanced in the halide-rich stoichiometry [13]. Woo et al., used inorganic $\mathrm{ZnBr}_{2}$ as an additional source of bromide into the $\mathrm{PbBr}_{2}$ precursor for synthesis [116]. The resulting PNCs showed more halide-rich stoichiometric compositions ( $\mathrm{Cs}: \mathrm{Pb}: \mathrm{Br}=1.0: 1.2: 3.4)$ than that produced from the standard synthetic method without metal bromide ( $\mathrm{Cs}: \mathrm{Pb}: \mathrm{Br}=1.0: 1.0: 2.8)$. With this so-called "inorganic passivation", the stability and initial PLQY of as-synthesized CsPbBr PNCs were considerably improved (Figure 3b,c) [116]. Instead of $\mathrm{PbX}_{2}$ as the standard halide source, Imran et al., employed benzoyl halides to synthesize a whole family of fully inorganic and hybrid $\mathrm{PNCs}$, i.e., $\mathrm{CsPbX}_{3}, \mathrm{FAPbX}_{3}$, and $\mathrm{MAPbX}_{3}$, demonstrating a good phase purity and stability with the precise size control [117]. With a similar concept, Creutz et al., utilized silyl halides as the halide sources to synthesize the $\mathrm{Pb}$-free $\mathrm{DP} \mathrm{Cs}_{2} \mathrm{AgBiX}_{6}$, resulting in highly stable PNCs specifically tuned for a halide-rich ambient [118]. 

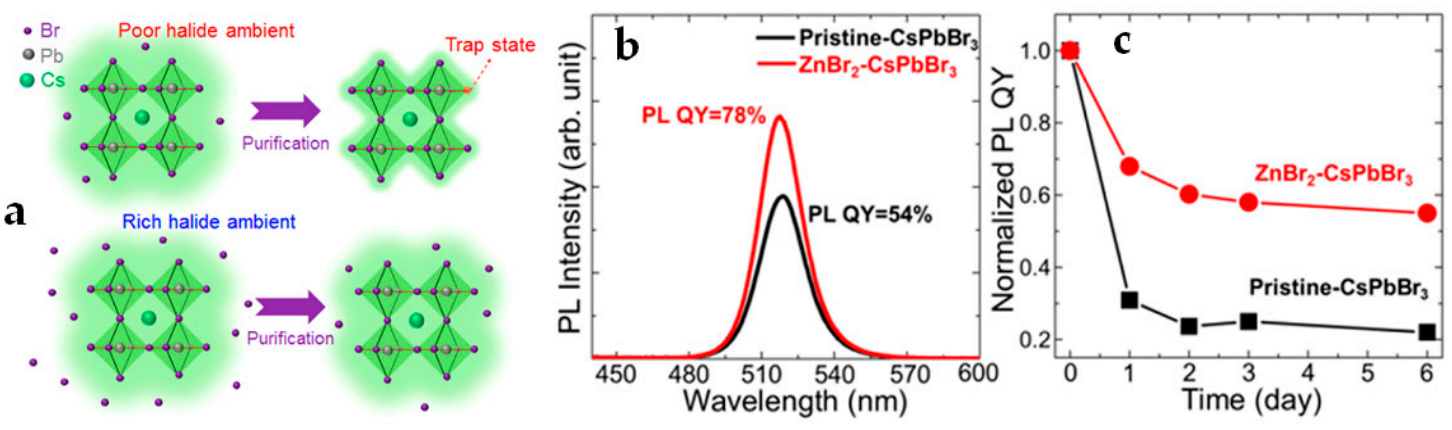

Figure 3. (a) Scheme for halide-poor and halide-rich circumstances for synthesis of PNCs. Reproduced with permission [115]. (b) PL spectra and (c) photoluminescence quantum yield (PLQY) of $\mathrm{CsPbBr}_{3}$ before and after self-passivation with $\mathrm{ZnBr}_{2}$. Reproduced with permission [116].

\subsection{Role of Dopants in Degradation}

Recent studies show that doping is an effective strategy to enhance the PNCs stability [6,91]. Seok's group introduced $\mathrm{Br}$ anion into $\mathrm{MAPbI}_{3} \mathrm{PNCs}$ via halide exchange, leading to the formation of $\mathrm{MAPb}\left(\mathrm{I}_{1-x} \mathrm{Br}_{x}\right)_{3}$ [119]. $\mathrm{MAPb}\left(\mathrm{I}_{1-x} \mathrm{Br}_{x}\right)_{3}$ PNCs were more stable than $\mathrm{MAPbI}_{3}$ counterparts. Compared to the iodide-based PNCs, the bromide-doped ones had improved stability due to the higher symmetry in the nanostructure. As a consequence, while the solar cells fabricated with the undoped PNCs had power conversion efficiency rapidly decreasing and their color changing from dark brown to yellow when exposed to the humidity over 55\%, once PNCs were doped with bromide anion (for $x>0.2$ in $\mathrm{MAPb}\left(\mathrm{I}_{1-x} \mathrm{Br}_{x}\right)_{3}$ composition), the stability of the corresponding devices significantly improved (Figure 4a).

In addition to anion-doping, doping at A or B site with other cations can also improve PNCs stability. Protessescu et al., doped $\mathrm{CsPbI}_{3} \mathrm{PNCs}_{\text {with }} \mathrm{FA}^{+}$cations. The insertion of approximately $10 \% \mathrm{FA}^{+}$cations into the $\mathrm{CsPbI}_{3} \mathrm{PNCs}$ marginally affected the cell parameters and did not change the relative intensities of the $\mathrm{X}$-ray diffraction peaks [72]. As a result of the doping, the $\mathrm{FA}_{0.1} \mathrm{Cs}_{0.9} \mathrm{PbI}_{3}$ PNCs structure had prolonged stability compared to $\mathrm{CsPbI}_{3}$ PNCs (from several days to few months) in colloidal suspension as well as in films. The enhanced stability may partially originate from lattice expansion.

For the $\mathrm{B}$ site, currently the most used metal $\mathrm{Pb}$ is not only toxic but also responsible for the ionic labile $\mathrm{Pb}$-halide bonds. To this aim, doping at $\mathrm{Pb}$ site with e.g., $\mathrm{Mn}^{2+}$ resulted in effectively increased structural PNCs stability derived from the high formation energy of $\mathrm{Mn}^{2+}: \mathrm{CsPb}_{3}$ with respect to the pristine materials [120-125]. The degradation of drop-cast films of $\mathrm{CsPbI}_{3}$ and $\mathrm{CsPb}_{x} \mathrm{Mn}_{1-x} \mathrm{I}_{3} \mathrm{PNCs}$ stored in ambient conditions was monitored by the evolution of their XRD patterns. $\mathrm{CsPbI}_{3}$ showed the sign of degradation from $\alpha$-phase to $\delta$-phase of $\mathrm{CsPbI}_{3}$ within one day and the transition was completed within 5 days, while $\mathrm{CsPb}_{x} \mathrm{Mn}_{1-x} \mathrm{I}_{3}$ PNC film did not exhibit any visible degradation during the first 2 weeks, and it mainly remained in the same phase after about one month of storage (Figure $4 \mathrm{~b}$ ) [120]. In solution, $\mathrm{CsPbI}_{3}$ totally degraded and turned white yellow with no photoluminescence (PL) after 1 month of storage even in nitrogen-filled glovebox, while the doped PNCs kept their color and strong PL after the same period under identical storage conditions. The improved stability can be attributed to the shrinkage of the lattice parameters upon alloying, with the shortening of the metal- $\mathrm{X}$ bonds (from $3.14 \AA$ for Pb-I to $2.97 \AA$ for Mn-I). Zhou et al., using different ratio of $\mathrm{Mn}^{2+}$ dopant in $\mathrm{CsPbBr}_{3}$ PNCs, synthesized $\mathrm{CsPb}_{x} \mathrm{Mn}_{1-x} \mathrm{Br}_{3}$ PNCs $(x=0 \%, 2.0 \%, 2.6 \%, 3.4 \%, 3.8 \%, 4.3 \%, 5.1 \%, 5.6 \%, 6.2 \%)$ [121]. As shown in Figure $4 c$, the green PL brightness of pure $\mathrm{CsPbBr}_{3}$ PNCs turned into non-luminescent PNCs within 30 days in ambient conditions. On contrast, much slower degradation was observed for $\mathrm{Mn}^{2+}$-doped PNCs, which still showed high fluorescence even after 120 days of storage. It should be noticed that the increase in $\mathrm{Mn}^{2+}$ doping concentration above $5.6 \%$ was detrimental to stability, thus it is important to fine-tune the optimal doping ratio when designing new nanocrystals. In addition to $\mathrm{Mn}^{2+}$, other metals have also been used for B-site doping, such as $\mathrm{Sn}^{2+}, \mathrm{Zn}^{2+}$, and $\mathrm{Cd}^{2+}[73,126]$. 

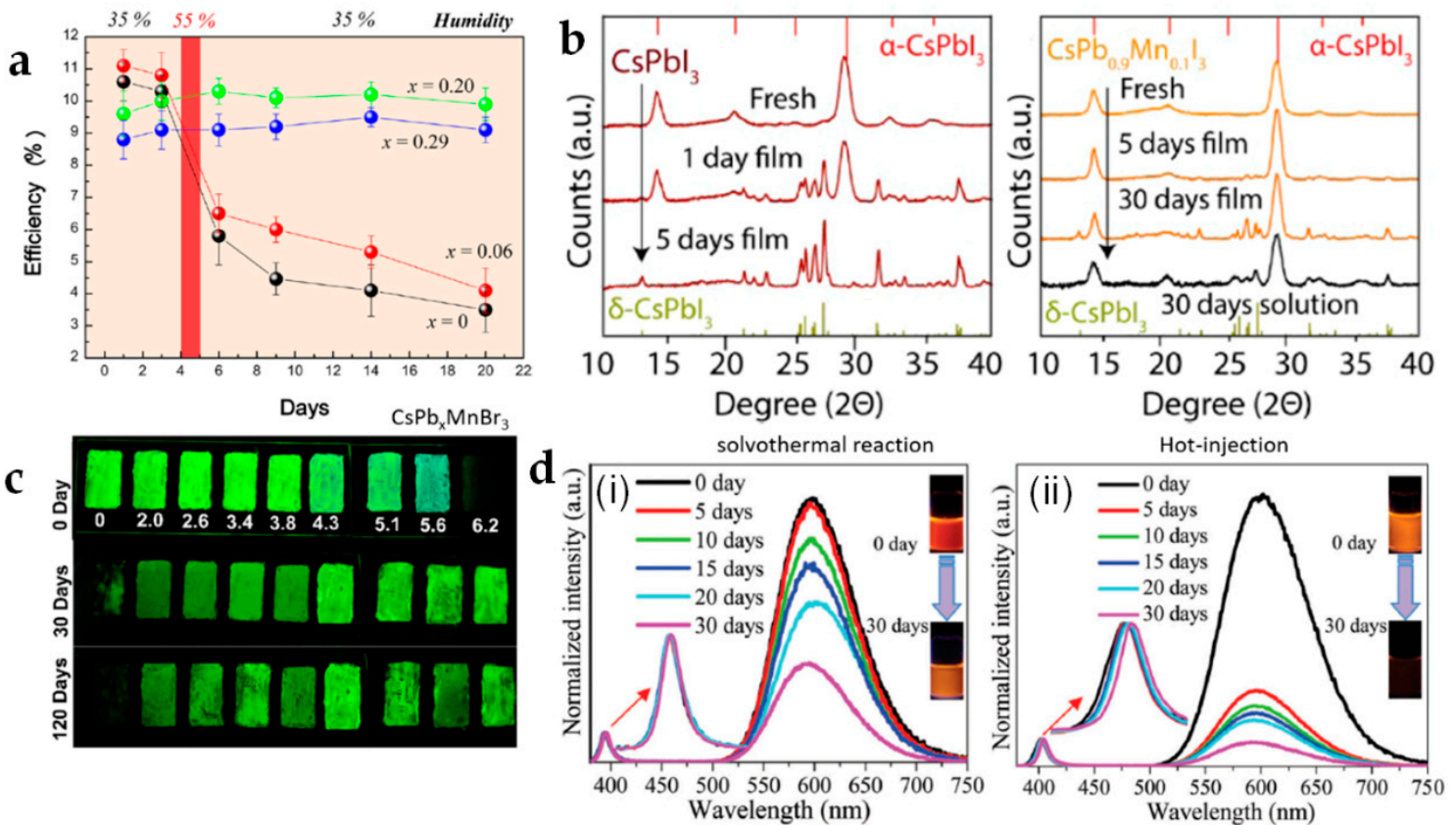

Figure 4. (a) Power conversion efficiency variation of the heterojunction solar cells based on $\operatorname{MAPb}\left(\mathrm{I}_{1-x} \mathrm{Br}_{x}\right)_{3}(x=0,0.06,0.20,0.29)$ with time stored in air at room temperature without encapsulation. Reproduced with permission [119]; (b) Stability of $\mathrm{CsPbBr}_{3} \mathrm{PNCs}_{\text {and }} \mathrm{CsPb}_{\mathrm{x}} \mathrm{Mn}_{1-\mathrm{x}} \mathrm{Br}_{3}$ PNCs. Reproduced with permission [120]; (c) PL emission photographs for $\mathrm{CsPbBr}_{3}: \mathrm{Mn} \mathrm{PNCs}$ QDs coated on the surface of a glass slide with different $\mathrm{Mn}^{2+}$ contents from 0 to $6.2 \mathrm{~mol} \%$ taken under UV irradiation at indicated time periods. Reproduced with permission [121]; (d) Variation of photoluminescence (PL) spectra of the $\mathrm{Mn}$-Doped $\mathrm{CsPbCl}_{3}$ samples prepared by (i) solvothermal reaction and (ii) hot injection method with the extension of preservation time (0-30 days). Reproduced with permission [127].

When doping PNCs with the same anions, different synthesis approaches can result in different properties. Chen et al., prepared $\mathrm{Mn}$-doping $\mathrm{CsPbX}_{3}$ by solvothermal reaction and hot injection approach, separately [127]. In this study, the PNCs obtained by solvothermal reaction showed quite stable even upon storage for 30 days in air, and the decay lifetime almost did not change. For the hot injection method, the relative emission substantially decreased after exposure to air, indicating that the loss of $\mathrm{Mn}^{2+}$ ions from the $\mathrm{CsPbCl}_{3}$ host with prolonged storage time was significant (Figure $4 \mathrm{~d}$ ). In addition, the decay lifetime for the sample exposed to air for 5-30 days (2.12-2.65 ms) was far longer than the one exposed to fresh air $(1.31 \mathrm{~ms})$. The solvothermal PNCs were more stable than those prepared by hot injection, which can be due to the former ones conducted under high-temperature and pressure environments leading strong bonding of $\mathrm{Mn}^{2+}$ in the ligand-field of the PNCs host.

As discussed above, each site $(\mathrm{A}, \mathrm{B}, \mathrm{X})$ of $\mathrm{ABX}_{3}$ PNCs can be doped. Generally, going towards fully inorganic PNCs gives better stability perspectives compared to hybrid organic-inorganic ones. Combining the doping at different sites into the same PNCs should be explored in near future as an attempt to further enhance the PNCs stability.

\subsection{Morphological Dimensionality of PNCS}

Various chemical approaches have so far been reported to synthesize PNCs with sizes in the range from tens of micrometers to several nanometers and with variable morphologies, such as nanocubes (3D), nanoplatelets (2D), nanorods and nanowires (1D) and spherical quantum dots (0D) $[6,40,128]$. Using the hot-injection method, Deng's group synthesized single-crystalline $\mathrm{Cs}_{2} \mathrm{SnI}_{6}$ nanocrystals with variable shapes [25]. As shown in Figure 5A, after the first 1 min of reaction, the PNCs were spherical QDs with an average diameter of $\sim 2.5 \mathrm{~nm}$, which further changed into a dominance of nanorods 
with length/diameter ratio of $3 \mathrm{~nm}$ after $5 \mathrm{~min}$. Subsequently, the nanorods grew into nanowires and the length/diameter ration went up to 28 after $10 \mathrm{~min}$. After $30 \mathrm{~min}$, the nanowires assembled and finally formed nanobelts, which were still not stable and finally transformed into nanoplatelets with a thickness of around $8 \mathrm{~nm}$ after $1 \mathrm{~h}$ reaction. Hence, by increasing the reaction time, the size of the PNCs increased, and the shape changed from 0D to 1D and finally to 2D. This study indicates that the 2D PNCs are more morphologically stable than 1D and 0D.
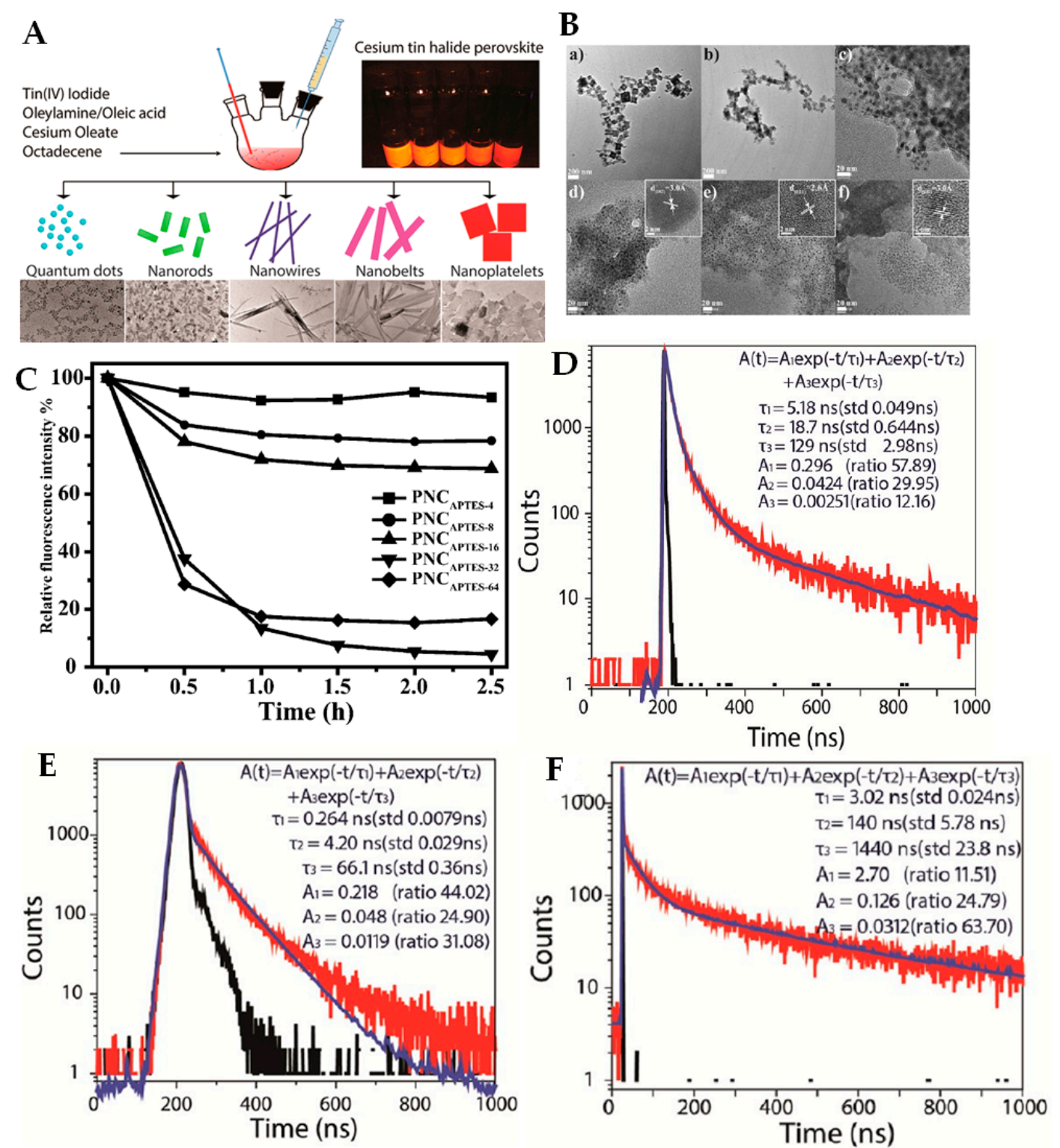

Figure 5. (A) Overview of the procedures for the synthesis of perovskite $\mathrm{Cs}_{2} \mathrm{SnI}_{6}$ nanocrystals with controlled morphology and TEM images of the PNCs with different shapes. Reproduced with permission [25]; (B) TEM images of PNCs with different sized prepared with different concentrations of APTES capping ligands; $(\mathbf{C})$ The relative fluorescence intensity of $\mathrm{PNC}_{\mathrm{APTES}}$ precipitate as a functional of time in isopropanol. Reproduced with permission [48]; (D-F) Time-resolved PL decay and fitting curves of the light emission at $515 \mathrm{~nm}$ (D, nanocubes), 514 (E, nanorods) or 510 (F, nanoplatelets) from different shaped $\mathrm{CsPbr}_{3} \mathrm{NCs}$ with a 375-pulse laser. Reproduced with permission [37].

Due to the surface defects and the dynamic stability of the PNCs surface, the size and morphology of the PNCs significantly influence the overall PNCs stability. Akkerman et al., fabricated 3 to 5 monolayers (MLs) of $\mathrm{CsPbBr}_{3}$ PNCs at room temperature, by controlling the amount of added $\mathrm{HBr}$ 
during the synthesis [34]. In this study, the stability of the 2D PNCs was related to the number of the layers: 4 MLs were only stable for one day, while 3 and 5 MLs of 2D PNCs were more stable at least for one month. Unfortunately, the reasons for the peculiar trend in stability have not been pointed out and remained unclear. However, this work demonstrates that the size of the PNCs directly influences the stability of the PNCs.

Simulation studies have shown that the surface defects may accelerate PNCs degradation [129]. Therefore, the small-sized and low dimensional PNCs are most likely the best candidates for any future application. $\mathrm{FAPbI}_{3}$ nanowires with tenths of micrometers in diameter exhibited phase stability up to several weeks [130]. However, once the size was reduced down to $\sim 10 \mathrm{~nm}$, the $\alpha-\mathrm{FAPbI}_{3} \mathrm{PNCs}$ with a cubic shape did not show any detectable conversion upon an extended storage after several months [72]. The higher stability of perovskites with low morphological dimensionality and their corresponding devices can be correlated to the enhanced crystallinity of the smaller clusters. Recent studies involving 1D perovskite nanowires additionally support this argument [131]. Furthermore, the results of Yong et al., regarding the small clusters of cuboids $\mathrm{MAPbI}_{3} \mathrm{PNCs}_{\mathrm{N}}$ with the higher stability compared to the large ones, also confirm the importance of low morphological dimensionality on the enhancement of stability [132].

In many cases, the small-sized PNCs showed improved photo-stability compared to the large-sized ones. However, in some cases, the conclusion reverses. Using different amounts of branched capping ligands such as (3-amino-propyl)triethoxysilane (APTES), Luo et al., obtained a tunable size of PNCs in cubic shape with an average length of $80 \mathrm{~nm}$ (PNC PPTES-2 $), 7.8 \pm 1.6 \mathrm{~nm}\left(\mathrm{PNC}_{\text {APTES-8 }}\right), 5.1 \pm 0.6 \mathrm{~nm}$

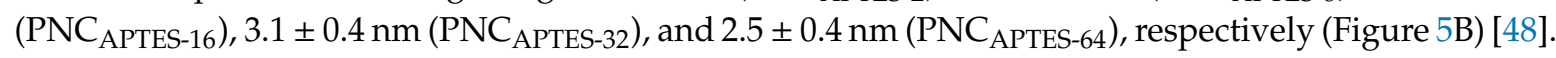
The stability of PNC ${ }_{\text {APTES }}$ with a larger size of PNCs was enhanced. After $2.5 \mathrm{~h}$, the PNC $\mathrm{PNTES}_{\mathrm{A}-2}$ kept almost the same PL intensity as the initial value while for $\mathrm{PNC}_{\mathrm{APTES}-6 / 16}$ the PL intensity slightly decreased to only around $20 \% \sim 30 \%$. In contrast, the PL intensity of the small-sized PNCs, e.g., PNC APTES-32 and PNC APTES-64 with a cubic length less than $3.5 \mathrm{~nm}$ decreased quickly, even down to $20 \%$ of the initial value just after $1 \mathrm{~h}$ of storage (Figure 5C). In this work, the branched capping APTES ligands passivated the PNCs surface, and this is the key reason why the larger PNCs led to the improved stability as a result of their more effective surface passivation.

Using different ligands, Deng's group synthesized $\mathrm{CsPbX}_{3}$ PNCs in various shapes, for which the long-lived lifetimes $\left(\tau_{3}\right)$ of PL decays were tens to thousands of nanoseconds, and the intermediate-lifetimes $\left(\tau_{2}\right)$ were several to hundreds of nanoseconds [37]. The PL decays were shape-dependent and among them the longest PL lifetime was achieved with 2D nanoplatelets $\left(\tau_{3}\right.$ $=1440 \mathrm{~ns}$ and $\tau_{2}=140 \mathrm{~ns}$ ). For the 3D nanocubes, the $\tau_{3}$ and $\tau_{2}$ were much faster, i.e., $129 \mathrm{~ns}$ and $18.7 \mathrm{~ns}$, respectively, while $\tau_{3}$ and $\tau_{2}$ of $2 \mathrm{D}$ nanorods were even more accelerated, i.e., only $66.1 \mathrm{~ns}$ and $4.2 \mathrm{~ns}$, respectively (Figure 5D-F). Among those three shapes of PNCs, due to the atomically flat in-plane surface, the nanoplatelets had less defects and surface states than other shaped nanocrystals. The longest PL lifetime of 2D nanoplatelets can be ascribed to the increased in-plane single-crystalline geometry, with the PL decay mainly occurring via the exciton radiative recombination in the large nanocrystals. This work also suggests that the short and intermediate-lifetime can originate from trap and/or surface-state assisted PL decays.

By combining the key findings in this section, we can outline the key characteristics of stable PNCs, i.e., the small size and low morphological dimensionality, combined with good crystallinity and low defect density, and the effective passivation of the perovskite surface.

\section{Environmental Stability (Heat, Moisture, Oxygen, UV Light) of PNCs}

When the environmental stability of PNCs is targeted, i.e., the extrinsic stability towards heat, moisture, oxygen, and UV light, different approaches can be adopted depending on the specific targeted properties (e.g., resilience to heat) and applications. Several criteria in selecting one or another approach need to be evaluated, such as the cost of the materials and manufacturing process, and the environmental friendliness of the involved components. 


\subsection{Encapsulation}

Encapsulation is the term usually referred to the technique of incorporating nanocrystals or QDs into a protective media during the manufacturing process. The main goal is to obtain a homogeneous dispersion of emitting particles into the protective matrix to avoid agglomeration and quenching of the luminescence. The encapsulation techniques (Figure 6) adopted for producing composite materials based on PNCs can be classified into four methods, namely integration into mesoporous particles, direct embedding in ready-made solid porous matrix, cold-flow technique, and glass encapsulation.

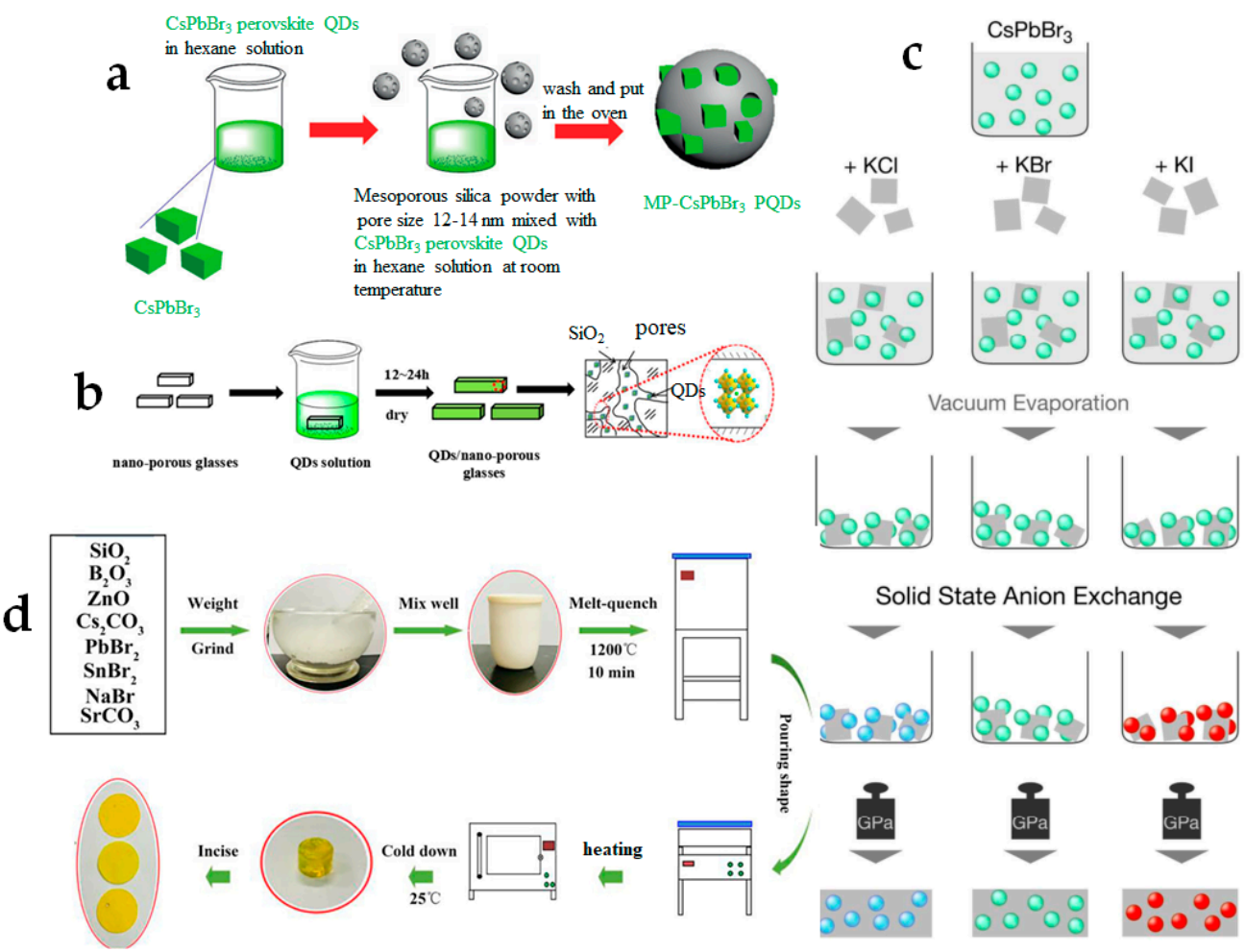

Figure 6. Encapsulation methods. (a) Integration into mesoporous particles. Modified from the original figure. Reproduced with permission [133]; (b) Direct embedding in ready-made porous matrix. Reproduced with permission [134]; (c) "cold-flow" method. Reproduced with permission [135]; (d) Modified from the original figure. Reproduced with permission [136].

The first approach is based on mixing the PNCs solution with ready-made mesoporous micro- and nano-sized particles (Figure 6a) $[133,137,138]$. While in earlier works $\mathrm{SiO}_{2}$-based mesoporous particles were adopted, $[133,137,138]$ later on also attempts to use other compounds, such as $\mathrm{Al}_{2} \mathrm{O}_{3}$, have been reported [139]. However, the latter compounds exhibited poorer stability in comparison with $\mathrm{SiO}_{2}$. To date, the most promising nanocomposite in terms of stability has been synthesized by the mixture of the colloidal $\mathrm{CsPbBr}_{3}$ PNCs with commercially available mesoporous silica [138]. The solution is then centrifuged and dried in vacuum oven, leading to a light-emitting precipitate with strong resistance to water, UV light, and heat. When the perovskite powder was immersed in water for $120 \mathrm{~h}$ under UV exposure, PL was still observed. Heating to $125^{\circ} \mathrm{C}$ can also still partially preserve the material. After 30 days of storage in ambient conditions, only a slight increase in PL intensity was detected.

One of the easiest ways of producing perovskite-based composites is the integration of PNCs colloidal solution into the protective solid porous media, by the direct placing of the matrix into the solution (Figure $6 \mathrm{~b}$ ). The porosity of the media allows the PNCs to penetrate into its volume and thus be more stable upon environmental exposure. However, the stability of the material remains questionable and strongly depends on the properties of the used matrix, such as the size and the volume of the porous media. Han et al. [134] prepared composite materials by soaking as-prepared 
borosilicate glass in PNCs colloidal solution. They obtained CsPbBr $3 /$ glass, $\mathrm{CsPb}\left(\mathrm{Cl}_{0.5} \mathrm{Br}_{0.5}\right)_{3} / \mathrm{glass}$ and $\mathrm{CsPb}\left(\mathrm{Br}_{0.4} \mathrm{I}_{0.6}\right)_{3} /$ glass composites, whose stabilities were tested. $\mathrm{CsPbBr} /$ /glass composite showed the best performance among all composites. The sample demonstrated relatively high thermal stability (up to $280^{\circ} \mathrm{C}$ ) and more than $12 \mathrm{~h}$ of resistance to UV-light. Integration of the PNCs $\left(\mathrm{CsPbX}_{3}\right.$, where X $=\mathrm{Cl} / \mathrm{Br}, \mathrm{Br}, \mathrm{I})$ into the porous opal matrices, which were grown from amorphous $\mathrm{SiO}_{2}$ spheres, was reported in [136]. The stability of the samples kept in ambient conditions for a month, was investigated by tracking the changes of PL peak position, PL full width at half maximum (FWHM), and average PL lifetime, respectively. All observed changes were insignificant and proved the stability of the materials. Moreover, the double and triple mixtures of PNCs with different compositions were embedded into opal matrix and no considerable change in PL occurred after a month, confirming the absence of anion exchange from the PNCs into the matrix.

Guhrenz et al. [135] showed a method based on the "cold-flow" technique (which refers to the tendency of some solid materials to deform permanently under the long-term influence of mechanical stresses) with halide salts, allowing not only to embed PNCs into protective media but also to perform anion exchange reaction for wavelength tuning (Figure $6 \mathrm{c}$ ). The latter was realized because the matrices were used as the active components of the composites. By changing the halide component in the salt, anion-exchanged PNCs pellets were obtained, emitting at desired wavelengths. Usually, perovskite-based composites demonstrate a decrease in the PLQY in comparison to that of the PNCs in solution [140,141]. Interestingly, in this case a slight increase in PLQY from $77 \%$ to $83 \%$ for $\mathrm{CsPbB}_{3}$ composites was observed. Moreover, while it is well known that PNCs lose about half of their initial PLQY upon anion exchange, [142] in this example PLQY (79\%) did not decrease [135]. The obtained pellets were coated with a protective silicone layer. The stability of the silicone-encapsulated PNCs pellets under ambient condition was heavily dependent on the composition, and was preserved for at least 14 days [135]. Further investigation of "cold-flow" technique with halide PNCs is still required. Nevertheless, only one additional article has been published to date on this topic, [76] in which cation exchange between $\mathrm{CsPBrr}_{3} \mathrm{PNCs}$ and a mixture of $\mathrm{KCl}$ and $\mathrm{MnCl}_{2}$ salt is demonstrated. However, in this article the stability of the proposed material has not been investigated. Moreover, probably due to Mn-doping, PLQY (0.54\%) was lower than the earlier reported values.

The glass encapsulation technique during the glass synthesis is also referred to as the melting-quenching method, which is an established approach for glass manufacturing (Figure 6d). The procedure for producing perovskite glass is as follows: (1) glass ingredients as a raw material are mixed with perovskite precursors; (2) this mixture is melted at high temperature (up to $1100{ }^{\circ} \mathrm{C}$ ) (at this stage perovskite precursors are in the form of ions and dispersed in glass); (3) to remove the residual thermal stress, melt portion is annealed in a muffle furnace and then cooled down; (4) samples are reheated again (at about $400^{\circ} \mathrm{C}$ ) for a long period of time (at this phase perovskite ions absorb energy and form nanocrystals in the glass matrix); (5) final product is cut and polished for future application. Temperatures, time, molar concentration of the compounds, and other conditions may be accordingly tuned to achieve desired properties [143]. Different glass systems have been used with PNCs such as zinc borosilicate $\left(\mathrm{ZnO}-\mathrm{SiO}_{2}-\mathrm{B}_{2} \mathrm{O}_{3}\right)$ [136,144-147], phosphate $\left(\mathrm{P}_{2} \mathrm{O}_{5}-\mathrm{SiO}_{2}-\mathrm{ZnO}\right)$ [148], $\left(\mathrm{P}_{2} \mathrm{O}_{2}-\mathrm{SiO}_{2}-\mathrm{ZnO}\right)$ [149], $\mathrm{GeO}_{2}-\mathrm{B}_{2} \mathrm{O}_{3}-\mathrm{ZnO}-\mathrm{Na}_{2} \mathrm{O}$ [150], tellurite based glasses $\left(\mathrm{TeO}_{2}-\mathrm{Al}_{2} \mathrm{O}_{3}-\mathrm{H}_{3} \mathrm{BO}_{3}-\mathrm{ZnO}-\mathrm{Na}_{2} \mathrm{CO}_{3}\right)$ [151].

\subsection{Polymer Matrix}

Integration into polymer matrix consists in mixing selected polymers with a perovskite solution, containing pre-made PNCs or perovskite precursors. In the latter case, in situ formation of PNCs takes place, which is considered more efficient in terms of quality of surface passivation and dispersity of the NCs. However, the first technique is very common for composites production. For effective connection of the PNCs surface with preferred polymer, a ligand or another polymer can be introduced at the synthesis stage. The selection of the polymer is usually driven by the targeted advantages of the final material, such as flexibility, hydrophobicity, or long-term barrier properties. For further usage in photovoltaics, the obtained colloidal solution is usually cast on a surface and dried out. 
Integration into polymer matrix can be used as a simple and effective way to improve the properties of the perovskite-based materials. Raja et al. [157] revealed that mixing $\left.\mathrm{PNCs}_{(\mathrm{CsPbBr}}\right)$ with poly(styrene-ethylene-butylene-styrene (SEBS) can significantly improve water stability for more than 122 days because of the high contact angle (or, in other words, low wettability) of this polymer. Moreover, SEBS assisted to reduce the toxicity of $\mathrm{Pb}$ in the composition. In fact, the amount of $\mathrm{Pb}$ measured after soaking the samples in water was 200 times smaller than the one contained in unprotected PNCs, reducing the concentration of $\mathrm{Pb}$ to the same values as those contained in drinkable tap water. This work also studied poly(lauryl methacrylate) (PLMA) performance with PNCs. While PLMA-composites were relatively stable in ambient conditions, on the other hand, they demonstrated partial solubility in aqueous solution. Huang et al., dispersed ethylcellulose (EC) in colloidal $\mathrm{CsPb}(\mathrm{Cl} / \mathrm{Br})_{3}$ PNCs [158]. The obtained solution was spin-coated onto an optical glass. Stability was demonstrated up to 6 days in environmental conditions. A self-healing polymer matrix was introduced in [159]. Poly(dimethylsiloxane)-urea (PDMS-urea) copolymer was mixed with $\mathrm{MAPbBr}_{3}$ or $\mathrm{MAPbI}_{3}$ for producing composites. The healing ability was shown by cutting films and monitoring the scratch. The damaged area was completely recovered, and optical properties remained constant after $15 \mathrm{~min}$ after the incision. The healing rates could be accelerated to $5 \mathrm{~min}$ by heating up to $50{ }^{\circ} \mathrm{C}$. The samples also demonstrated significant flexibility and could be stretched up to $500 \%$ of their original length.

In a comprehensive research by Wang et al. [152], the optical properties of several polymers such as (polystyrene (PS), polycarbonate (PC), acrylonitrile butadiene styrene (ABS), cellulose acetate (CA), poly(vinyl chloride) (PVC), and poly(methyl methacrylate) (PMMA)) were studied when combined to

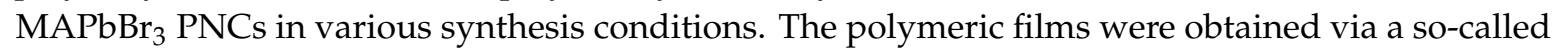
swelling-deswelling technique. This technique enables the polymer to dissolve in a "good" solvent, where the polymer chains can expand upon the sequential solvent evaporation. During the evaporation process, the polymers shrink, leading to strong binding on the PNCs layer (Figure 7a). A set of experiments to reveal the stability of PNCs was conducted. Water treatments showed the enhanced stability of PNCs in PS, PC, ABS and PVC matrices. In fact, only a slight decrease of QY was observed after boiling the PC-based and PS-based films for $30 \mathrm{~min}$. The thermal resistance of the composite generally depends on the thermal stability of the selected polymer and it is rarely measured for polymer-based composite films (Table 2). However, it was shown that PC films can withstand to temperatures up to $180^{\circ} \mathrm{C}$. Wei et al. [160] performed the same technique with pre-made PS beads and $\mathrm{CsPbBr}_{3} \mathrm{PNCs}_{\mathrm{N}}$ using toluene as a good solvent and hexane as a bad one. This method can effectively prevent anion exchange, which was proven after one week followed by the direct mixing of the PNCs/PS powders emitting blue and green light, respectively. The PS beads-based composite can survive more than 9 months in water, which is the best result achieved so far for perovskite/polymer composite (Table 2). The toxicity level of the material was also examined, by stirring the powder in water for $24 \mathrm{~h}$, subsequently separating the composite, and finally drying the residual water. The amount of $\mathrm{Pb}$ found in the supernatant was $1.931 \mathrm{ppm}$, which was even lower than the allowed quantity for drinking water quality standards (10-15 ppm). Extremely high water stability was shown by ethylene vinyl acetate (EVA) mixed with $\mathrm{CsPbBr}_{3}$ precursors [161]. The authors reported that, after $720 \mathrm{~h}$ of storage in water, both the appearance and luminescence property of the films did not remarkably change. Moreover, the material demonstrated high flexibility by withstanding up to 1000 bending cycles with unchanged PL properties. Bright PL was detected after the composite was stretched to $350 \%$ of its original length.

In [153], the PSCs were constructed based on three different polymers, i.e., branched poly(ethyleneimine) (b-PEI), Poly(vinylpyrrolidone) (PVP), and poly(acrylic acid) (PAA) via inter-diffusion method. This approach relies on the formation of the perovskite precursor $\left(\mathrm{PbI}_{2}\right)$ film on the substrate, followed by dripping a mixture of the chosen polymer with the second perovskite precursor (MAI) (Figure 7b). Due to the filter effect, polymer efficiently segregated at the perovskite layer and formed a homogeneous film after annealing. The authors reported a considerable enhancement of 
power conversion efficiency from 16.9\% to $18.8 \%$ in PVP-based PSCs, which was relatively stable at ambient conditions for over 90 days.

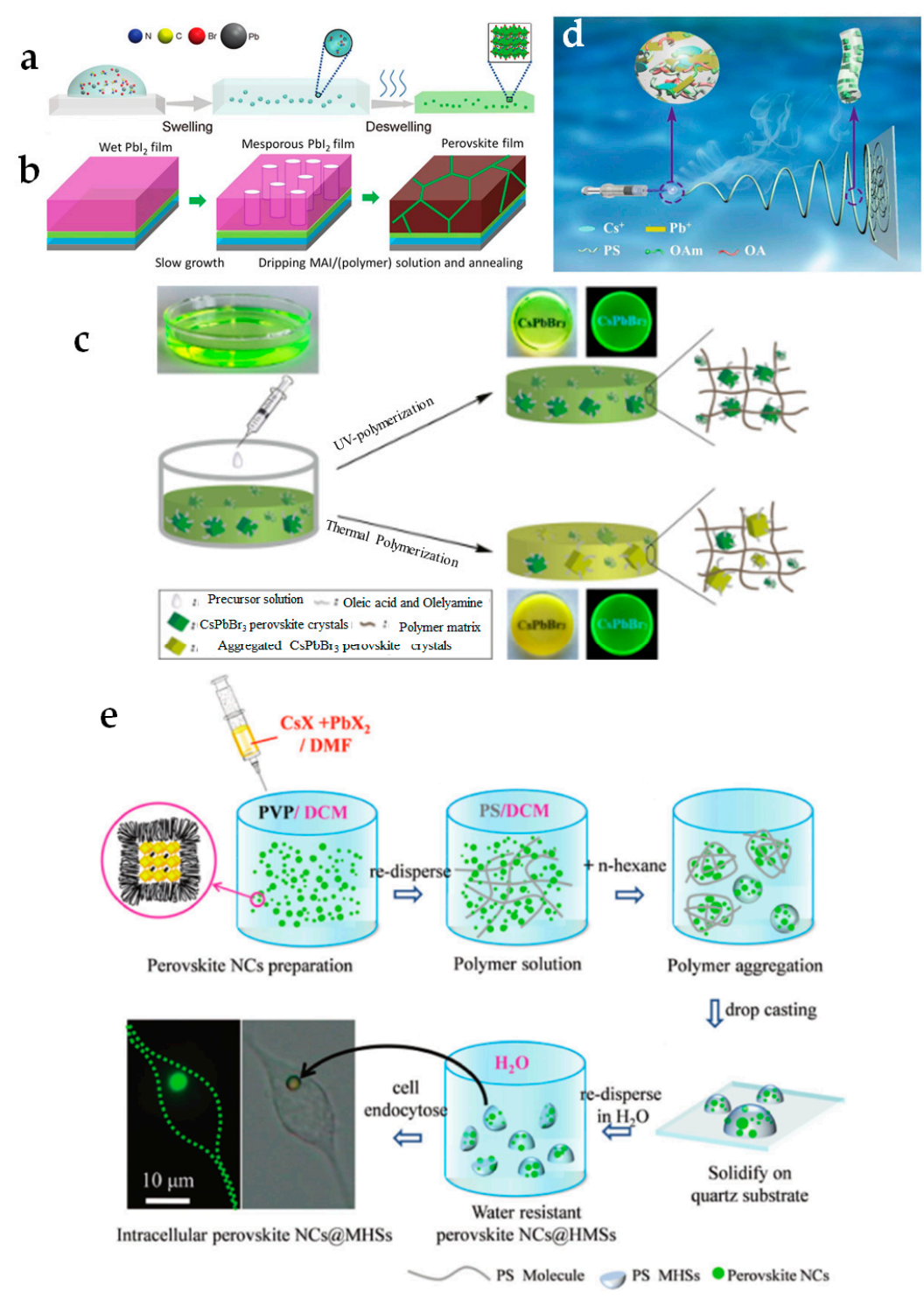

Figure 7. Techniques of integration into polymer matrix. (a) Swelling-deswelling approach. Reproduced with permission [152]; (b) Interdiffusion method. Reproduced with permission [153]; (c) UV or thermal polymerization of composite by adding initiator of polymerization. Reproduced with permission [154]; (d) Perovskite fiber obtained by electrospinning process. Reproduced with permission [155]; (e) PNCs integrated into polystyrene-based microhemispheres. Reproduced with permission [156].

Xin et al. [154] demonstrated the UV polymerization of the composite by addition of UV initiator (diphenyl(2,4,6-trimethylbenzoyl)phosphine oxide (TPO). This method enhanced the quantum yield of the material compared to the thermal polymerization (azobisisobutyronitrile was used as a thermal initiator) (Figure 7c). The concept was proven for PMMA and poly(butyl methacrylate) (PBMA) but it did not work for PS because of the low polymerization constant of styrene. Bagherzadeh et al. [162] embedded PNCs into a polymeric matrix based on the mixture of methyl methacrylate (MMA) and PMMA. For the initiation polymerization process, AIBN was added. The colloidal solution was poured into a casting mold and annealed to form the homogeneous plate. Because the samples were utilized as luminescent solar concentrators, resistance to UV light was investigated via continuous 
measurement of relative PL intensity under UV exposure (9 W). Depending on PNCs concentration, a decrease in brightness up to $25 \%$ after $12 \mathrm{~h}$ of excitation was reported. However, there were no significant changes in PL parameters after $24 \mathrm{~h}$. Zhao et al., incorporated $\mathrm{CsPb}\left(\mathrm{Br}_{x} \mathrm{I}_{1-x}\right)_{3}$ perovskite QDs into the polymer matrix by dispersion of QDs into poly(lauryl methacrylate-co-ethylene glycol dimethacrylate) (PLMA-EGDA) with a UV initiator (TPO). [163] Composites demonstrated outstanding resistance to UV light-no remarkable changes in PL was observed upon four hours of strong UV illumination (100 $\mathrm{mW} / \mathrm{cm}^{2}$, corresponding to 20 sun illumination). Stability under ambient conditions was confirmed up to 5 months of storage.

Another interesting work based on the swelling-deswelling technique has been reported by Liao et al., in [155]. PS was mixed with perovskite precursors and the electrospinning (ES) was utilized to cast fibers (Figure 7d). The authors also confirmed the effectiveness of this approach by synthesizing a series of perovskite films with different composition by adjusting molar ratio of precursors during manufacturing (e.g., $\mathrm{CsPbCl}_{3}, \mathrm{CsPbCl}_{2} \mathrm{Br}_{1}, \mathrm{CsPbCl}_{1.5} \mathrm{Br}_{1.5}, \mathrm{CsPbCl}_{1} \mathrm{Br}_{2}, \mathrm{CsPbBr}_{3}$, $\mathrm{CsPbBr}_{2} \mathrm{I}_{1}, \mathrm{CsPbBr}_{1.5} \mathrm{I}_{1.5}, \mathrm{CsPbBr}_{1} \mathrm{I}_{2}$, and $\mathrm{CsPbI}_{3}$ ) and applied the method also to (poly(vinyl acetate) (PVAc). The stability of $\mathrm{CsPbX}_{3} / \mathrm{PVAc}$ composites was studied, showing a slight decrease to $70 \%$ of the initial PLQY after $192 \mathrm{~h}$ of storage in water and the samples were still fluorescent after 30 days. Continuous heat at $80^{\circ} \mathrm{C}$ for $120 \mathrm{~min}$ led to the reduction of PLQY to $50 \%$ of its initial value. The ES process for producing flexible hydrophobic fibers was also used by Lin et al., [164]. The composites were obtained by mixing PNCs $\left(\mathrm{CsPbX}_{3}\right.$, where $\mathrm{X}=\mathrm{Cl}$, Br, and I) with poly(styrene-butadiene-styrene) (SBS). The dimensions of the fibers were controlled by variable ES parameters. The stability of the materials was investigated upon the influence of water and stretching. Depending on the chemical composition, PL vanished after keeping the samples in water for one hour. However, significant changes in PL brightness were observed for all compositions after already $10 \mathrm{~min}$. RGB light-emitting diode (LED) based on green and red PNCs showed outstanding resistance to stretching (luminescence was detected after $170 \%$ of the strain). A similar approach was applied by Hai et al., using PVP instead, although the authors coated the obtained films by silicone resin for better protection. [165] Moreover, the authors synthesized three different perovskite composites $\left(\mathrm{CsPb}_{3}\right)$ and demonstrated that no anion exchange occurred in a three-compound mixture of them. $\mathrm{CsPbBr}$-based composite demonstrated resistance to water greater than 5 days, resistance to heat higher than $100{ }^{\circ} \mathrm{C}$, and resistance to UV light longer than $120 \mathrm{~h}$ of radiation. Flexible LED based on the mixture of three compounds showed insignificant decrease in PL intensity after storage in ambient conditions.

Zhang et al. [156] embedded PNCs into microhemispheres (MHSs) of polystyrene matrix (Figure 7e). PVP was quickly added into a mixture of perovskite precursors to passivate the surface and to induce the micelles formation. When the mixture of PNCs and PVP was introduced into the PS solution, due to the interfacial tension force PS molecules prefer to aggregate into spherical micelles and then PNCs penetrate into them. After dropping the solution onto a quartz substrate, spherical micelles form microhemispheres for the effect of gravity force.

\subsection{Core/Shell Structure}

Shell coating is a well-established procedure that is extensively used for modifying the properties of QDs and nanocrystals. The shell can effectively prevent the interaction between nanoparticles that causes aggregation and in turn results in non-radiative energy transfer. Moreover, the passivation effect reduces the surface defects leading to trap states and non-radiative relaxation, which negatively influences the corresponding device performance. Various types of shells have been utilized with perovskite, classified into four main categories, namely oxide shell, semiconductor shell (usually another perovskite composition), polymer shell, and multilayer shell.

Oxide shells are usually synthesized via hydrolysis reactions, by an approach also known as sol-gel processing [168]. The most widely applied group of precursors for this purpose are silicon alkoxides (alkoxysilanes) [171]. These precursors are injected into perovskite precursors at synthesis stage, then the mixture is continuously stirred to obtain a hydrolysis reaction. The process can be described as 
wrapping PNCs by the oxide shell (Figure 8a). The result is a composite in the form of gel or precipitate, which can be used further. The main drawback of this approach is the simultaneous growth of certain amount of coreless oxide particles, which are hard to separate from the core/shell PNCs.

(a)

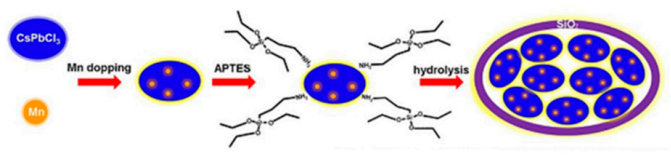

(c)

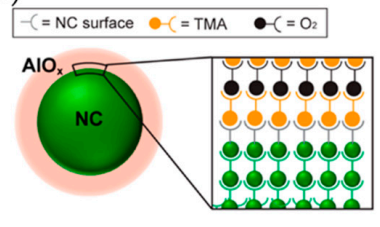

(d)

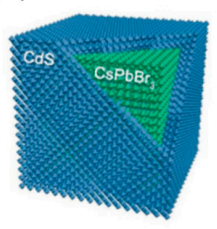

(b)

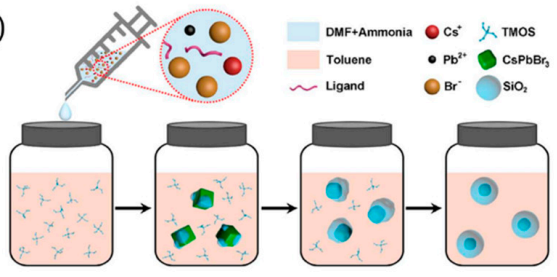

(e)

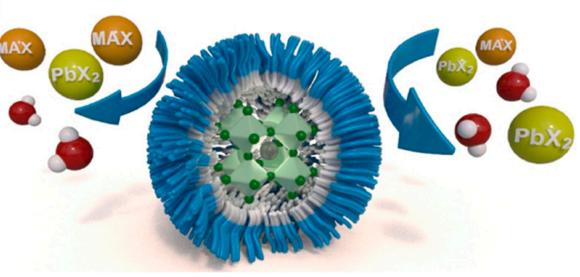

Figure 8. Core/shell approaches utilized with PNCs. (a) Silica-based core/shell perovskite particles. Reproduced with permission [166]; (b) Single silica-based core/shell perovskite particles. Reproduced with permission [167]; (c) $\mathrm{AlO}_{\mathrm{x}}$ shell on top of the PNCs. Reproduced with permission [168]; (d) Semiconductor shell covering PNCs. Reproduced with permission [169]; (e) Polymer-based shell. Reproduced with permission [170].

Sun et al., obtained flexible QDs films due to the one step silanization process using APTES as the silica precursor [140]. Good encapsulation, which was proven by the absence of anion exchange reaction, led to the high resistance of materials towards detrimental exposure. The authors reported about at least one day stability of the composites after immersing them in water. The full degradation due to heat occurred at $90{ }^{\circ} \mathrm{C}$. PL was detected after 22 days of illumination of $450 \mathrm{~nm}$ LED, which is a considerably longer lifetime compared to that of pure QDs. Ding et al., encapsulated $\mathrm{CsPbX}_{3}$ into monodisperse silica nanoplates via the modified Stöber method using tetraethyl orthosilicate (TEOS) [172]. The obtained composites were highly water-soluble and retained their PL during at least $240 \mathrm{~h}$ of storage in water. In ambient conditions, the coated PNCs also demonstrated high stability with practically unchanged PL up to 30 days. Obviously, multiple cores covered by one shell can be less beneficial in terms of their optical properties, leading to aggregation and anion exchange. Zhong et al. [167] demonstrated a method where a single shell covers a single core (Figure $8 \mathrm{~b}$ ). The single core/shell PNCs were obtained by a fast injection of perovskite precursor in tetramethyl orthosilicate (TMOS) (used as silica precursor) solution dissolved in a bad solvent. X-ray diffraction (XRD) analysis, performed in air upon a high humidity level (75\%), confirmed the stability of the composite. To test water resistance, the material was dissolved in water by ultrasonication. Interestingly, after 16 min a clear increase in PL intensity was observed, which can be explained by the enhanced dispersity of PNCs. Even though PL started to decrease after $16 \mathrm{~min}$, its intensity was still slightly higher than the initial one after $40 \mathrm{~min}$. Zhang et al. [173] added L- $\alpha$-phosphatidylcholine (LP) surfactant and silica precursor (TMOS) into PNCs colloidal solution $\left(\mathrm{CsPbr}_{3}\right)$ to form core/shell composite. Multinuclear-coated nanoparticles and mononuclear-coated nanoparticles were found into the precipitate and the supernatant, respectively. Outstanding thermal, water, UV and oxidation resistances were shown by the samples, similar for both types of coating. PL intensity was not varied after the composites were heated up to $120^{\circ} \mathrm{C}$, illuminated for $168 \mathrm{~h}$ of UV radiation, immersed in water for $35 \mathrm{~min}$, or stored for 30 days in ambient conditions.

Other types of oxide shells can be formed on top of the PNCs, too. Loiudice et al. [168] introduced PNCs $\left(\mathrm{CsPbX}_{3}\right.$, were $\left.\mathrm{X}=\mathrm{Br}, \mathrm{I}, \mathrm{Cl}\right)$ which were coated by $\mathrm{AlO}_{x}$ shells with controlled thickness (trimethylaluminum (TMA) was used as aluminium source) (Figure 8c). During the manufacturing process, the pure oxygen was applied to promote the formation of uniform and bright emitting particles. 
By fine-tuning the synthesis conditions and additives concentration, authors achieved an increase of the initial PLQY (75.3\%). PL was still detected after more than 7 days while the particles were immersed in water. Moreover, the applied shell slowed down the anion exchange reaction and allowed studying the structural evolution of PNCs. Li et al. [174] synthesized PNCs core/shell structure by $\mathrm{TiO}_{2}$ coating via mixing titanium precursor (titanium butoxide (TBOT)) with colloidal $\mathrm{CsPbBr}_{3}$. Core/shell PNCs were formed by continuously stirring for $3 \mathrm{~h}$ via hydrolysis reaction followed by annealing to evaporate the excess water and organic matter. A small decrease in the PL intensity was detected after the composite was stored for more than 12 weeks in water or was irradiated with UV light for $24 \mathrm{~h}$. To further investigate the stability properties, anion exchange tests were performed by blending core/shell particles with $\mathrm{Cl}$ and I salts. No significant changes in the PL intensity occurred after 15 days after the mixing, proving the absence of the anion exchange process and the stability enhancement of the structure.

Additional advantages can be found when other semiconductors shells cover the PNCs. Applying a shell with larger bandgap than that of the core can suppress the non-radiative recombination, contributing to the enhancement of the optical properties. Tang et al. [175] developed efficient LEDs based on a $\mathrm{CsPbBr}_{3} / \mathrm{CdS}$ core/shell structure (Figure 8d). However, stability analysis [169] showed a slight decrease of PL intensity after $13.5 \mathrm{~h}$ under high humidity level, dropping down to $40 \%$ after continuous heat up to $60{ }^{\circ} \mathrm{C}$ for $9 \mathrm{~h}$. Wang and co-workers [176] proposed to use rubidium oleate (RbOA) precursor to form $\mathrm{Rb}_{4} \mathrm{PbBr}_{6}$ shell on top of the PNCs. The authors succeeded to increase PLQY from $40 \%$ of the pure PNCs to $85 \%$ of the composite. Photostability was tested under the illumination with UV diode $\left(175 \mathrm{~mW} / \mathrm{cm}^{2}\right)$. In total, $90 \%$ of PLQY was kept even after $42 \mathrm{~h}$, which is a much better result than the one shown by CdSe/CdS QDs measured under the same conditions.

Growing another type of perovskite derivative on top of the PNCs was recently proposed as a convenient method for enhancing their stability while simultaneously improving the optical performance. The shell could be formed by carefully adjusting the synthesis process, such as the precursor concentration, temperature, or time. One example is provided by $\mathrm{CsPbBr}_{3} \mathrm{PNCs}_{\text {covered }}$ with a $\mathrm{CsPb}_{2} \mathrm{Br}_{5}$ layer upon controlling the precursors' concentration and temperature during the synthesis process [177]. Particles demonstrated relatively high PL brightness up to 5 days after being immersed in water. Jia et al. [178] showed a similar approach, forming the perovskite shell on PNCs by adding zinc bromide into perovskite solution. As a result, $\mathrm{CsPbBr} 3 / \mathrm{Cs}_{4} \mathrm{PbBr}_{6}, \mathrm{CsPbCl}_{3} / \mathrm{Cs}_{4} \mathrm{PbCl}_{6}$ and $\mathrm{CsPbI}_{3} / \mathrm{Cs}_{4} \mathrm{PbI}_{6}$ core/shell structures were obtained. Wang et al. [179] developed an amorphous $\mathrm{CsPbBr}_{x}$ shell on the top of $\mathrm{CsPbBr}_{3}$ through a facile hot injection technique and further centrifugation. Due to the amorphous nature of the shell, promising UV protection could be achieved. Xu et al. [180] covered $\mathrm{Mn}^{2+}$-doped $\mathrm{CsPbCl}_{3}$ by undoped $\mathrm{CsPbCl}_{3}$ shell. Relatively high PLQY for Mn-doped PNCs was shown $(40 \%)$, and a slight increase of PL intensity was detected during the heating up to $100{ }^{\circ} \mathrm{C}$, which can be explained by thermal annealing of defects. Bhaumik et al. [181] grew octylammonium $\left(\mathrm{C}_{8} \mathrm{H}_{17} \mathrm{NH}_{3}, \mathrm{OA}\right)$ led bromide $2 \mathrm{~d}$ shell on top of $\mathrm{MAPbBr}_{3}$ by mixing $\mathrm{MABr}$ and $\mathrm{OABr}$ precursors. By optimizing the molar ratio of the components, they obtained perovskite nanoparticles with high PLQY $(92 \%)$, stable under ambient conditions for more than 60 days. The remarkable increase in the PLQY upon semiconductor shell coating demonstrated by the above-mentioned works is a well-recognized strategy that suggests how proper band gap alignment between core and shell contributes to enhanced performance of the composite.

A polymer-based shell was also introduced as one of the routes to form core/shell composite (Figure 8e). Huang et al., formed core/shell structure by coating of $\beta$-cyclodextrin $(\beta-C D)$, which is a cyclic oligosaccharide, on top of the $\mathrm{MAPbBr}_{3}$ [182]. Capping ligand hexylamine was introduced into the system to realize host-guest interaction reaction. Thermal stability was tested by continuous heat at $70{ }^{\circ} \mathrm{C}$. After the first $4 \mathrm{~h}$, PL intensity was increased up to $180 \%$ due to the annealing effect, which resulted in better crystallinity of the $\mathrm{MAPbBr}_{3}$ nanocrystals. Samples demonstrated high resistance to UV light, preserving 55\% of initial PL intensity after $144 \mathrm{~h}$ of UV illumination. Moreover, a relatively high PL intensity was observed after immersing the composite in water for 10 days. Vijila et al. [183] 
mixed PNCs with PMMA solution in order to achieve PNCs covered by the polymer. The composite film was obtained by the solution casting method and dried at $60{ }^{\circ} \mathrm{C}$. Incredible stability was shown under ambient conditions storage. After one year, 13\% of PLQY was retained from the initial value of $88 \%$. To date, this is one of the longest stability tests ever performed. Hintermayr and co-workers introduced an approach in which diblock-copolymer (polystyrene-poly(2-vinlypyridine) (PS-b-P2VP) formed micelles for protecting the PNCs core [170]. Perovskite precursors were added into micelles colloidal solution where, due to the diffusion, they penetrated the micelles and crystallized. This strategy is currently one of the best among the shell-based ones, in terms of resilience of the perovskite composite towards harmful conditions. PL intensity was observed even after 75 days of the immersing samples in water, and after more than 220 days of storage in the environment.

Simultaneous use of different types of materials to obtain multilayer core/shell structures was also

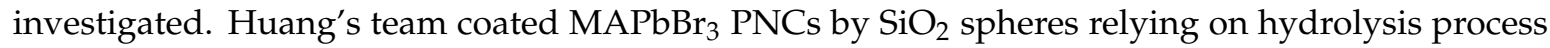
(TMOS was used as silica precursor), then PMMA was added into colloidal solution and thin films were formed [141]. Authors reported high resistance of the composite material against UV light (about $100 \mathrm{~h}$ ), though in this work the samples were tested under high humidity level, therefore being not comparable with other perovskite-based composite materials reported by other researchers.

Figure 9 shows a summary of the key encapsulation methods. Table 2 summarizes the stability properties of composites in the above-mentioned works. The comparison is based on changes in PL intensity.

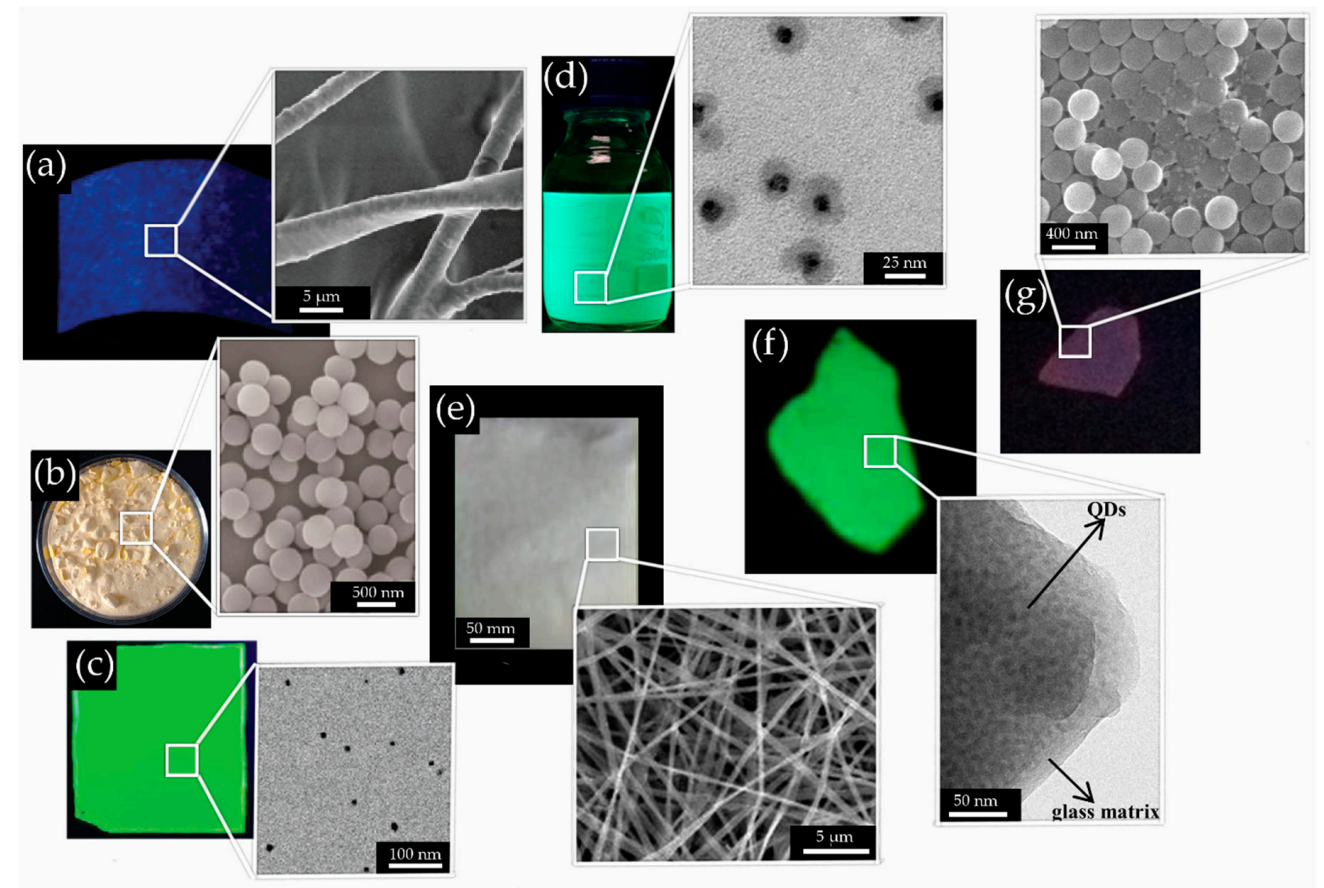

Figure 9. A summary of the key encapsulation methods. (a) Flexible silicone resin (SR)/polyvinylpyrrolidone (PVP)-based composite under UV light. In the inset, SEM images of the material. Reproduced with permission [165]; (b) Photo of PNCs/PS powder. In the inset, SEM image of PNCs into the PS spheres. Reproduced with permission [160]; (c) Photo of $\mathrm{MAPbBr}_{3} / \mathrm{PS}$ film excited by UV light. In the inset, cross-section TEM image. Reproduced with permission [152]; (d) Photo of $\mathrm{CsPbBr} / \mathrm{SiO}_{2}$ core-shell NCs into colloidal solution. In the inset, TEM image of the structure. Reproduced with permission [167]; (e) Photo of $\mathrm{CsPbBr}_{3} / \mathrm{PS}$ composite. In the inset, secondary electron SEM images of $\mathrm{CsPbBr}_{3} / \mathrm{PS}$ fibers. Reproduced with permission [155]; (f) Photo of $\mathrm{CsPbBr}_{3} / \mathrm{TeO}_{2}$-based glass under UV light. In the inset, TEM images of the structure. Reproduced with permission [151]; (g) Photo of PNCs into opal matrix. In the inset, SEM image of the structure. Reproduced with permission [184]. 
Table 2. Comparison the stability properties of PNCs composites. Water stability refers to samples direct placed into water. Dramatic changes imply decreasing of normalized PL to 50\% of its initial value. For UV resistance, the figures in brackets are a power unit of UV radiation. "-" refers to properties not investigated in the work or measured in non-comparable conditions with respect to the others. "**" means that measurements were performed under accelerating aging conditions (high humidity level and/or temperature). “**" means that investigation was performed under sonication.

\begin{tabular}{|c|c|c|c|c|c|c|c|c|c|c|}
\hline \multirow[b]{2}{*}{ Composition } & \multirow[b]{2}{*}{ Method } & \multirow[b]{2}{*}{$\begin{array}{c}\text { PLQY of } \\
\text { Composite, \% }\end{array}$} & \multicolumn{2}{|c|}{ UV Resistance, $h$} & \multicolumn{2}{|c|}{ Thermal Stability, ${ }^{\circ} \mathrm{C}$} & \multicolumn{2}{|c|}{ Water Resistance, $\mathrm{h}$} & \multirow{2}{*}{$\begin{array}{l}\text { Stability under } \\
\text { Ambient } \\
\text { Condition, Days }\end{array}$} & \multirow[b]{2}{*}{ Ref. } \\
\hline & & & $\begin{array}{l}\text { Dramatic } \\
\text { Changes }\end{array}$ & $\begin{array}{c}\text { Full } \\
\text { Degradation }\end{array}$ & $\begin{array}{l}\text { Dramatic } \\
\text { Changes }\end{array}$ & $\begin{array}{c}\text { Full } \\
\text { Degradation }\end{array}$ & $\begin{array}{l}\text { Dramatic } \\
\text { Changes }\end{array}$ & $\begin{array}{c}\text { Full } \\
\text { Degradation }\end{array}$ & & \\
\hline $\mathrm{CsPbBr}_{3}$ & Mesoporous particles $\left(\mathrm{SiO}_{2}\right)$ & 46.2 & $>120$ & $>120$ & 95 & $>125$ & $>120$ & $>120$ & $>30$ & [138] \\
\hline $\mathrm{CsPbBr}_{3}$ & Mesoporous particles $\left(\mathrm{SiO}_{2}\right)$ & - & $>96(6 \mathrm{~W})$ & $>96(6 \mathrm{~W})$ & $>100$ & $>100$ & - & - & & [133] \\
\hline Mn-doped-CsPbBr ${ }_{0.5} \mathrm{I}_{2.5}$ & Mesoporous particles $\left(\mathrm{SiO}_{2}\right)$ & - & -1 & -1 & - & - & - & $>240$ & $>10$ & [139] \\
\hline Mn-doped-CsPbBr $0.5 \mathrm{I}_{2.5}$ & Mesoporous particles $\left(\mathrm{Al}_{2} \mathrm{O}_{3}\right)$ & - & - & - & - & - & - & 72 & 5 & [139] \\
\hline $\mathrm{CsPbr}_{3}$ & & 61 & - & - & - & - & - & $>1680$ & - & [185] \\
\hline $\mathrm{CsPb}\left(\mathrm{Br} / \mathrm{I}_{3}\right.$ & polyhedral-oligomeric-silsesquioxane-(POSS) & 45 & - & - & - & - & - & $>1680$ & - & [185] \\
\hline $\mathrm{CsPbI}_{3}$ & Glass encapsulation $\left(\mathrm{B}_{2} \mathrm{O}_{3}-\mathrm{SiO}_{2}-\mathrm{ZnO}\right)$ & 4.2 & - & - & - & - & - & - & $>8.3 *$ & [144] \\
\hline $\mathrm{CsPbBr}_{3}$ & Glass encapsulation $\left(\mathrm{B}_{2} \mathrm{O}_{3}-\mathrm{SiO}_{2}-\mathrm{ZnO}\right)$ & 42.5 & - & - & - & - & - & - & $>60-$ & [145] \\
\hline $\mathrm{CsPbBr}_{1.5} \mathrm{I}_{1.5}$ & Glass encapsulation $\left(\mathrm{B}_{2} \mathrm{O}_{3}-\mathrm{SiO}_{2}-\mathrm{ZnO}\right)$ & 15.5 & - & - & - & - & - & - & $>60$ & [145] \\
\hline $\mathrm{CsPbI}_{3}$ & Glass encapsulation $\left(\mathrm{B}_{2} \mathrm{O}_{3}-\mathrm{SiO}_{2}-\mathrm{ZnO}\right)$ & 17.6 & - & - & - & - & - & - & $>60$ & [145] \\
\hline $\mathrm{CsPb}_{2} \mathrm{Br}_{5}$ & Glass encapsulation $\left(\mathrm{ZnO}-\mathrm{SiO}_{2}-\mathrm{B}_{2} \mathrm{O}_{3}\right)$ & 30.6 & - & - & 60 & $>160$ & - & - & - & [146] \\
\hline $\mathrm{CsPbBr}_{12} \mathrm{I}_{18}$ & Glass encapsulation $\left(\mathrm{P}_{2} \mathrm{O}_{5}-\mathrm{SiO}_{2}-\mathrm{ZnO}\right)$ & - & $>500$ & $>500$ & 89 & 180 & $>960$ & $>960$ & $>20.8$ & {$[148]$} \\
\hline $\mathrm{CsPbr}_{3}$ & Glass encapsulation $\left(\mathrm{P}_{2} \mathrm{O}_{2}-\mathrm{SiO}_{2}-\mathrm{ZnO}\right)-$ & 42 & $>144$ & $>144$ & $>125$ & $>125$ & 24 & - & $>30$ & [149] \\
\hline $\mathrm{CsPbBr}_{3}$ & $\begin{array}{c}\text { Glass encapsulation } \\
\left(\mathrm{TeO}_{2}-\mathrm{Al}_{2} \mathrm{O}_{2}-\mathrm{H}_{2} \mathrm{BO}_{3}-\mathrm{ZnO}-\mathrm{Na}_{2} \mathrm{CO}_{3}\right)\end{array}$ & 72 & $>20(20 \mathrm{~W})$ & $>20(20 \mathrm{~W})$ & 80 & 180 & $>1080$ & $>1080$ & $>45$ & [151] \\
\hline Mn-doped-CsPbBr ${ }_{10} \mathrm{I}_{20}$ & Glass encapsulation $\left(\mathrm{B}_{2} \mathrm{O}_{3}-\mathrm{SiO}_{2}-\mathrm{ZnO}\right)$ & - & - & - & 81 & $>107$ & - & - & $>70$ & [147] \\
\hline $\mathrm{CsPb}_{0.64} \mathrm{Sn}_{0.36} \mathrm{Br}_{3}$ & Glass encapsulation $\left(\mathrm{B}_{2} \mathrm{O}_{3}-\mathrm{SiO}_{2}-\mathrm{ZnO}\right)$ & 43 & - & - & 140 & $>220$ & - & - & $>100 *$ & [136] \\
\hline $\mathrm{CsPbBr}_{3}$ & $\begin{array}{l}\text { Porous glass encapsulation } \\
\left(\mathrm{SiO}_{2}-\mathrm{B}_{2} \mathrm{O}_{3}-\mathrm{Na}_{2} \mathrm{O}-\mathrm{CaO}\right)\end{array}$ & 28 & $>12(65 \mathrm{~mW})$ & $>12(65 \mathrm{~mW})$ & 77 & 190 & $>0.17$ & - & - & [134] \\
\hline $\mathrm{CsPb}\left(\mathrm{Cl}_{0.5} \mathrm{Br}_{0.5}\right)_{3}$ & $\begin{array}{l}\text { Porous glass encapsulation } \\
\left(\mathrm{SiO}_{2}-\mathrm{B}_{2} \mathrm{O}_{3}-\mathrm{Na}_{2} \mathrm{O}-\mathrm{CaO}\right)\end{array}$ & 2.6 & $8(65 \mathrm{~mW})$ & $>12(65 \mathrm{~mW})$ & 158 & 280 & - & - & - & [134] \\
\hline $\mathrm{CsPb}\left(\mathrm{Br}_{0.4} \mathrm{I}_{0.6}\right)_{3}$ & $\begin{array}{l}\text { Porous glass encapsulation } \\
\left(\mathrm{SiO}_{2}-\mathrm{B}_{2} \mathrm{O}_{3}-\mathrm{Na}_{2} \mathrm{O}-\mathrm{CaO}\right)\end{array}$ & 8.9 & $6(65 \mathrm{~mW})$ & $>6(65 \mathrm{~mW})$ & 54 & 140 & - & - & - & [134] \\
\hline $\mathrm{CsPbX}_{3}(\mathrm{X}=\mathrm{Cl} / \mathrm{Br}, \mathrm{Br}, \mathrm{I})$ & Porous glass encapsulation (opal matrix) & - & - & - & - & - & - & - & $>30$ & [184] \\
\hline $\mathrm{CsPb}\left(\mathrm{Cl}_{0.5} \mathrm{Br}_{0.5}\right)_{3}$ & Polymer matrix (SBS) & 10.8 & - & - & - & - & 0.12 & 1 & - & [164] \\
\hline $\mathrm{CsPb}\left(\mathrm{Br}_{0.8} \mathrm{I}_{0.2}\right)_{3}$ & Polymer matrix (SBS) & 23 & - & - & - & - & 0.17 & 1 & - & [164] \\
\hline $\mathrm{CsPb}\left(\mathrm{Br}_{0.6} \mathrm{~S}_{0.20 .4} \mathrm{I}_{0}\right.$ & Polymer matrix (SBS) & 14.6 & - & - & - & - & 0.1 & 0.5 & - & [164] \\
\hline $\mathrm{CsPb}\left(\mathrm{Br}_{0.4} \mathrm{I}_{0.6} \mathrm{I}_{3}\right.$ & Polymer matrix (SBS) & 12.2 & - & - & - & - & 0.12 & 0.67 & - & [164] \\
\hline$\left(\mathrm{CsPb}(\mathrm{Cl} / \mathrm{Br})_{3}\right)$ & Polymer matrix (ethylcellulose) & - & - & - & - & - & - & - & 6 & [158] \\
\hline $\mathrm{MAPbBr}_{3}$ & Polymer matrix (MMA:PMMA) & - & $12(9 \mathrm{~W})$ & $>24(9 \mathrm{~W})$ & - & - & - & - & - & [162] \\
\hline $\mathrm{CsPbBr}_{3}$ & Polymer matrix (PLMA EGDA) & - & $\begin{array}{r}14(0.1 \\
\left.W / \mathrm{cm}^{2}\right)\end{array}$ & $\begin{array}{l}>14(0.1 \\
\left.\mathrm{W} / \mathrm{cm}^{2}\right)\end{array}$ & - & - & - & - & - & [163] \\
\hline $\mathrm{CsPb}\left(\mathrm{Br}_{0.2} \mathrm{I}_{0.8}\right)_{3}$ & Polymer matrix (PLMA EGDA) & - & $\begin{array}{l}>14(0.1 \\
\left.\mathrm{W} / \mathrm{cm}^{2}\right)\end{array}$ & $\begin{array}{l}>14(0.1 \\
\left.\mathrm{W} / \mathrm{cm}^{2}\right)\end{array}$ & - & - & - & - & $>150$ & [163] \\
\hline $\mathrm{MAPbBr}_{3}$ & Polymer matrix (PS) & 34 & $\begin{array}{c}\left.\mathrm{W} / \mathrm{cm}^{-1}\right) \\
-\end{array}$ & $\begin{array}{c}\mathrm{W} / \mathrm{Cm}^{-1} \\
-\end{array}$ & 70 & $>100$ & - & $>1440$ & $>150$ & [152] \\
\hline $\mathrm{MAPbBr}_{3}$ & Polymer matrix (PC) & 31 & - & - & 60 & $>180$ & - & $>1440$ & $>150$ & [152] \\
\hline $\mathrm{MAPbBr}_{3}$ & Polymer matrix (ABS) & 48 & - & - & 75 & $>100$ & - & $>1440$ & $>150$ & [152] \\
\hline $\mathrm{MAPbBr}_{3}$ & Polymer matrix (CA) & 47 & - & - & - & - & - & $>48$ & $>150$ & [152] \\
\hline $\mathrm{MAPbBr}_{3}$ & Polymer matrix (PVC) & 16 & - & - & - & - & - & $>1440$ & $>150$ & [152] \\
\hline $\mathrm{MAPbBr}_{3}$ & Polymer matrix (PMMA) & - & - & - & - & - & - & 0 & 1 & [152] \\
\hline
\end{tabular}


Table 2. Cont.

\begin{tabular}{|c|c|c|c|c|c|c|c|c|c|c|}
\hline \multirow[b]{2}{*}{ Composition } & \multirow[b]{2}{*}{ Method } & \multirow[b]{2}{*}{$\begin{array}{c}\text { PLQY of } \\
\text { Composite, } \%\end{array}$} & \multicolumn{2}{|c|}{ UV Resistance, $\mathrm{h}$} & \multicolumn{2}{|c|}{ Thermal Stability, ${ }^{\circ} \mathrm{C}$} & \multicolumn{2}{|c|}{ Water Resistance, $\mathrm{h}$} & \multirow{2}{*}{$\begin{array}{l}\text { Stability under } \\
\text { Ambient } \\
\text { Condition, Days }\end{array}$} & \multirow[b]{2}{*}{ Ref. } \\
\hline & & & $\begin{array}{l}\text { Dramatic } \\
\text { Changes }\end{array}$ & $\begin{array}{c}\text { Full } \\
\text { Degradation }\end{array}$ & $\begin{array}{l}\text { Dramatic } \\
\text { Changes }\end{array}$ & $\begin{array}{c}\text { Full } \\
\text { Degradation }\end{array}$ & $\begin{array}{l}\text { Dramatic } \\
\text { Changes }\end{array}$ & $\begin{array}{c}\text { Full } \\
\text { Degradation }\end{array}$ & & \\
\hline $\mathrm{MAPbBr}_{3}$ & Polymer matrix (PDMS-urea) & 23.8 & - & - & - & - & $>216$ & - & - & [159] \\
\hline $\mathrm{MAPbI}_{3}$ & Polymer matrix (PDMS-urea) & - & - & - & - & - & 24 & $>48$ & - & [159] \\
\hline $\mathrm{CsPbBr}_{3}$ & Polymer matrix (EVA) & 40.5 & $>54$ & - & 65 & $>75$ & $>240$ & $>720$ & $>8$ & [161] \\
\hline $\mathrm{CsPbBr}_{3}$ & Polymer matrix (PS) & 48 & - & - & - & - & - & $>720$ & - & [155] \\
\hline $\mathrm{CsPbBr}_{3}$ & Polymer matrix (PVP/silicone resin) & 24 & $>120$ & - & $>100$ & - & - & $>4$ & $>5$ & [165] \\
\hline $\mathrm{CsPbBr}_{3}$ & Polymer matrix (PVP/PS) & 27 & $>10$ & - & - & - & - & - & - & [156] \\
\hline $\mathrm{CsPbBr}_{3}$ & Polymer matrix (SEBS) & - & - & $\begin{array}{l}>2.8 \times 10^{-4} \\
\left(50 \mathrm{~kW} / \mathrm{cm}^{2}\right)\end{array}$ & - & - & - & $>2928$ & - & [157] \\
\hline $\mathrm{CsPbBr}_{3}$ & Polymer matrix (PS) & 68 & $288(16 \mathrm{~W})$ & $>384(16 \mathrm{~W})$ & - & - & 528 & $>6480$ & - & [160] \\
\hline $\mathrm{CsPbBr}_{3}$ & Polymer matrix (PMMA) & 54.6 & - & - & - & $>80$ & $>48$ & - & $>30$ & [154] \\
\hline $\mathrm{CsPbBr}_{3}$ & Polymer matrix (PBMA) & 62.2 & - & - & - & - & $>48$ & $>720$ & $>30$ & [154] \\
\hline $\mathrm{MAPbBr}_{3}$ & Polymer matrix (PVA) & - & $>2(2 \mathrm{pW})$ & - & - & - & - & - & - & [186] \\
\hline $\mathrm{MAPbBr}_{3}$ & Polymer matrix (PVDF) & 94.6 & -2 & $>400(6 \mathrm{~W})$ & - & - & - & $>400$ & $>9 *$ & [187] \\
\hline $\mathrm{MAPb}_{3}$ & Polymer matrix (PEG) & - & - & - & - & - & - & - & $>12.5^{*}$ & [188] \\
\hline $\mathrm{MAPbI}_{3}$ & Polymer matrix (P123) & - & - & - & - & - & - & - & $>20 *$ & [189] \\
\hline $\mathrm{MA}_{0.7} \mathrm{FA}_{0.3} \mathrm{PbI}_{3}$ & Polymer matrix (F127) & - & - & - & - & - & - & - & $>10$ & [190] \\
\hline $\mathrm{CsPbMCl}_{3}$ & Core/Shell $\left(\mathrm{SiO}_{2}\right)$ & 55.4 & - & - & $>100$ & $>100$ & - & - & $>15$ & [166] \\
\hline $\mathrm{CsPbX}_{3}$ & Core/Shell $\left(\mathrm{SiO}_{2}\right)$ & 60 & 360 & $>528$ & 50 & 90 & $>24$ & - & - & [140] \\
\hline $\mathrm{CsPbCl}_{3}$ & Core/Shell $\left(\mathrm{SiO}_{2}\right)$ & 11.2 & - & - & - & - & - & - & $>30$ & [172] \\
\hline $\mathrm{CsPbBr}_{3}$ & Core/Shell $\left(\mathrm{SiO}_{2}\right)$ & 84 & - & - & - & - & - & - & $>30$ & [172] \\
\hline $\mathrm{CsPbI}_{3}$ & Core/Shell $\left(\mathrm{SiO}_{2}\right)$ & 45 & - & - & - & - & - & - & $>60$ & [172] \\
\hline $\mathrm{CsPb}\left(\mathrm{Cl}_{0.5} / \mathrm{Br}_{0.5}\right)_{3}$ & Core/Shell $\left(\mathrm{SiO}_{2}\right)$ & - & - & - & - & - & 2 & $>240$ & - & [172] \\
\hline $\mathrm{CsPbBr}_{3}$ & Core/Shell $\left(\mathrm{SiO}_{2}\right)$ & - & - & - & - & - & 2 & $>240$ & - & [172] \\
\hline $\mathrm{CsPb}\left(\mathrm{Br}_{0.3} / \mathrm{I}_{0.7}\right)_{3}$ & Core/Shell $\left(\mathrm{SiO}_{2}\right)$ & - & - & - & - & - & 1.3 & $>240$ & - & [172] \\
\hline $\mathrm{CsPbr}_{3}$ & Core/Shell $\left(\mathrm{SiO}_{2}\right)$ & 90 & & - & - & & $>0.7$ ** & & $>28^{*}$ & [167] \\
\hline $\mathrm{CsPbBr}_{3}$ & Core/Shell $\left(\mathrm{LP} / \mathrm{SiO}_{2}\right)$ & 90.5 & $>168(8 \mathrm{~W})$ & - & 60 & 120 & & $>0.6$ & $>30$ & [173] \\
\hline $\mathrm{CsPbBr}_{3}$ & Core/Shell $\left(\mathrm{TiO}_{2}\right)$ & - & $>24$ & - & - & - & $>2160$ & - & - & [174] \\
\hline $\mathrm{CsPbBr}_{3}$ & Core/Shell $\left(\mathrm{AlO}_{\mathrm{x}}\right)$ & 75.3 & - & - & - & - & - & $>168$ & - & [168] \\
\hline $\mathrm{CsPbBr}_{3}$ & Core/Shell $\left(\mathrm{CsPb}_{2} \mathrm{Br}_{5}\right)$ & - & - & - & - & - & $>72$ & $>120$ & - & [177] \\
\hline $\mathrm{CsPbI}_{3}$ & Core/Shell $\left(\mathrm{Cs}_{4} \mathrm{PbI}_{6}\right)$ & - & - & - & - & - & - & - & $>7$ & [178] \\
\hline $\mathrm{CsPbBr}_{3}$ & Core/Shell (amorphous $\mathrm{CsPbBr}_{\mathrm{x}}$ ) & 84 & - & - & - & - & - & - & - & [179] \\
\hline $\mathrm{CsPbBr}_{3}$ & Core/Shell $\left(\mathrm{Rb}_{4} \mathrm{PbBr}_{6}\right)$ & 85 & $\begin{array}{l}>10(175 \\
\left.\mathrm{mW} / \mathrm{cm}^{2}\right)\end{array}$ & - & - & - & - & - & - & [176] \\
\hline $\mathrm{Mn}^{2+}$-doped $\mathrm{CsPbCl}_{3}$ & Core/Shell $\left(\mathrm{CsPbCl}_{3}\right)$ & 40 & mortari & - & $>110$ & - & - & - & - & [180] \\
\hline $\mathrm{MAPbBr}_{3}$ & Core/Shell $\left(\left(\mathrm{C}_{8} \mathrm{H}_{17} \mathrm{NH}_{3}\right)_{2} \mathrm{PbBr}_{4}\right)$ & 92 & - & - & - & - & - & - & $>60$ & [181] \\
\hline $\mathrm{CsPbBr}_{3}$ & Core/Shell (PMA) & 53 & $>12$ & - & - & - & - & - & - & [191] \\
\hline $\mathrm{MAPbBr}_{3}$ & Core/Shell (PMMA) & 88 & $>7$ & - & - & - & - & $>18$ & $>365$ & [183] \\
\hline $\mathrm{MAPbBr}_{3}$ & Core/Shell ( $\beta$-cyclodextrin) & 89.7 & $>144$ & - & - & - & $>240$ & & - & [182] \\
\hline $\mathrm{MAPbI}_{3}$ & Core/Shell (PS-b-P2VP)) & 55 & - & - & - & - & 312 & 1800 & $>220$ & [170] \\
\hline
\end{tabular}

Abbreviations: PVDF-Poly(vinylidene floride); PEG-Poly(ethylene glycol); P123-Poly(ethylene glycol)-poly(propylene glycol)-poly(ethylene glycol) (PEG-PPG-PEG); F127-Poly(ethylene oxide)-poly(propylene oxide)-poly(ethylene oxide) (PEO-PPO-PEO). 


\section{Conclusions and Future Outlook}

Metal halide perovskites have recently emerged as the key materials for the development of highly efficient, low-cost, and printable photovoltaics (PVs). However, their poor stability, lagging well behind that of traditional PVs materials (e.g., silicon), is seriously restricting any practical utilization of this technology. Colloidal PNCs allow us exploiting the attractive optoelectronic properties of bulk metal halide perovskites with quantum confinement effects at the nanoscale. Similarly, as their bulk counterparts, PNCs also suffer from the mediocre intrinsic stability. This challenge could be addressed in many ways, including but not limited to optimizing the synthesis conditions, developing new perovskites compositions, or post-synthetic treatments. Furthermore, when exposed to environmental conditions such as heat, moisture, oxygen, and/or UV light, measures should be taken to improve PNCs' extrinsic stability.

There are several well-established PNCs synthesis approaches, such as hot-injection and LARP. Though widely adopted worldwide, further work is needed to overcome the limited size and morphology control, the necessity of purification, and the complexity in view of large-scale manufacturing. It is expected that the optimization in the synthesis techniques will also influence the stability of the obtained nanocrystals. Due to the difficulty of the manufacturing process and poorer photovoltaic performance, $\mathrm{Pb}$-free perovskite compositions are still underrepresented in the literature compared to the $\mathrm{Pb}$-based ones. First works related to $\mathrm{Pb}$-free PNCs have been reported only recently. However, the future development of PNCs can no longer ignore $\mathrm{Pb}$ toxicity. Therefore, future research should focus more intensively on establishing novel approaches for $\mathrm{Pb}$-free compositions that, ideally, are also intrinsically stable. One promising direction in this context is the development of halide double perovskites, though the field is still in its early infancy and their utilization in PVs has so far resulted in devices with significantly lower efficiency compared to that of $\mathrm{Pb}$-based perovskite devices. On the other hand, popular $\mathrm{Sn}^{2+}$ based PNCs have led so far to the best device performance among Pb-free perovskite candidates. Yet, $\mathrm{Sn}^{2+}$ is easily oxidized to $\mathrm{Sn}^{4+}$ in ambient conditions. To take advantage of the promising properties of $\mathrm{Sn}$ and simultaneously achieve reasonable stability, $\mathrm{Sn}^{2+}$ could be mixed with other air-stable divalent metal cations, such as $\mathrm{Mg}^{2+}, \mathrm{Mn}^{2+}$, and some other transition metals like $\mathrm{Fe}^{2+}$ or $\mathrm{Zn}^{2+}$.

Based on this review on the up-to-date multiple approaches to stabilize PNCs, we propose several key strategies to tackle PNCs degradation. First, from PNCs composition point of view, all-inorganic metal halide PNCs should be always prioritized, with accurate tuning at A-site (e.g., Cs, K, Rb) and $\mathrm{B}$-site ( $\mathrm{Pb}$-free) metal cations towards symmetric nanostructures. As additional strategy, various surface (ligands) passivation methods should be continuously investigated for high quality and highly stable PNCs. Several properties of ideal ligands, including strong electron-withdrawing ability with steric hindrance and high hydrophobicity, [50] should be considered as selection criteria to effectively passivate the surface of PNCs against oxidization and moisture. Moreover, halogen or hydrogen bonding could be exploited as powerful strategies to passivate the PNCs surface. Since it has been found out that the surface ligands influence the stability of PNCs and their PLQYs in an opposite way, a trade-off needs to be found in order to achieve both stable and highly performing PNCs [15]. Another important strategy to effectively protect PNCs is the so-called core/shell structure. The shell materials can be either organic (e.g., polymers), [162] or inorganic or even another type of perovskite (as reported in the case of $\mathrm{Cs}_{4} \mathrm{PbBr}_{6}$ [178]) suggesting an alternative direction for future stability enhancement studies in this field.

Finally, a careful design of composite materials has proven to be beneficial in tackling the degradation issues by boosting the material's resistance to ambient exposure while enhancing the optoelectronic performance at the same time. The synthesis of PNCs into glass systems or in polymer matrices, in addition to the above-mentioned core/shell structure, has been recently proposed to this aim. Despite the success in terms of stability, all these techniques require further optimization. Generally, glass encapsulation demonstrates better water stability and UV-resistance, while the polymer matrix approach is the most convenient and eco-friendly way to obtain composite PNCs structures with 
improved photovoltaic characteristics with respect to those of pristine PNCs. Therefore, when designing a composite material, it is essential to consider its future utilization and environmental impact.

Funding: This research was funded by Jane and Aatos Erkko foundation, project "ASPIRE", and by Business Finland, project "SolarWAVE". This work is part of the Academy of Finland Flagship Programme's Photonics Research and Innovation (PREIN), decision No. 320165.

Conflicts of Interest: The authors declare no conflict of interest.

\section{References}

1. Kumar Jena, A.; Kulkarni, A.; Miyasaka, T. Halide Perovskite Photovoltaics: Background, Status, and Future Prospects. Chem. Rev. 2019, 119, 3036-3103. [CrossRef]

2. Fu, Y.; Zhu, H.; Chen, J.; Hautzinger, M.P.; Zhu, X.-Y.; Jin, S. Metal halide perovskite nanostructures for optoelectronic applications and the study of physical properties. Nat. Rev. Mater. 2019, 4, 169-188. [CrossRef]

3. NREL. Best Research-Cell Efficiencies. 2019. Available online: https:/www.nrel.gov/pv/assets/pdfs/bestresearch-cell-efficiencies.20190923.pdf (accessed on 25 September 2019).

4. Talapin, D.V.; Lee, J.-S.; Kovalenko, M.V.; Shevchenko, E.V. Prospects of Colloidal Nanocrystals for Electronic and Optoelectronic Applications. Chem. Rev. 2010, 110, 389-458. [CrossRef] [PubMed]

5. Li, Y.; Zhang, X.; Huang, H.; Kershaw, S.V.; Rogach, A.L. Advances in metal halide perovskite nanocrystals: Synthetic strategies, growth mechanisms, and optoelectronic applications. Mater. Today 2019. In press. [CrossRef]

6. Liu, M.; Zhang, H.; Gedamu, D.; Fourmont, P.; Rekola, H.; Hiltunen, A.; Cloutier, S.G.; Nechache, R.; Priimagi, A.; Vivo, P. Halide Perovskite Nanocrystals for Next-Generation Optoelectronics. Small 2019, 15, 1900801. [CrossRef] [PubMed]

7. Polavarapu, L.; Zhang, Q.; Krahne, R. Nanoscale \& Nanoscale Advances joint themed collection on halide perovskite nanocrystals. Nanoscale 2019, 11, 8648-8650. [PubMed]

8. Brittman, S.; Luo, J. A Promising Beginning for Perovskite Nanocrystals: A Nano Letters Virtual Issue. Nano Lett. 2018, 18, 2747-2750. [CrossRef] [PubMed]

9. Wang, Q.; Phung, N.; Di Girolamo, D.; Vivo, P.; Abate, A. Enhancement in lifespan of halide perovskite solar cells. Energy Environ. Sci. 2019, 12, 865-886. [CrossRef]

10. Kovalenko, M.V.; Protesescu, L.; Bodnarchuk, M.I. Properties and potential optoelectronic applications of lead halide perovskite nanocrystals. Science 2017, 358, 745-750. [CrossRef] [PubMed]

11. Aristidou, N.; Eames, C.; Sanchez-Molina, I.; Bu, X.; Kosco, J.; Islam, M.S.; Haque, S.A. Fast oxygen diffusion and iodide defects mediate oxygen-induced degradation of perovskite solar cells. Nat. Commun. 2017, 8, 15218. [CrossRef] [PubMed]

12. Ghosh, S.; Pradhan, B. Lead-Free Metal Halide Perovskite Nanocrystals: Challenges, Applications, and Future Aspects. ChemNanoMat 2019, 5, 300-312. [CrossRef]

13. Shamsi, J.; Urban, A.S.; Imran, M.; de Trizio, L.; Manna, L. Metal Halide Perovskite Nanocrystals: Synthesis, Post-Synthesis Modifications, and Their Optical Properties. Chem. Rev. 2019, 119, 3296-3348. [CrossRef] [PubMed]

14. He, X.; Qiu, Y.; Yang, S. Fully-Inorganic Trihalide Perovskite Nanocrystals: A New Research Frontier of Optoelectronic Materials. Adv. Mater. 2017, 29, 1700775. [CrossRef] [PubMed]

15. Dong, Y.; Zhao, Y.; Zhang, S.; Dai, Y.; Liu, L.; Li, Y.; Chen, Q. Recent advances toward practical use of halide perovskite nanocrystals. J. Mater. Chem. A 2018, 6, 21729-21746. [CrossRef]

16. Chan, S.; Liu, M.; Latham, K.; Haruta, M.; Kurata, H.; Teranishi, T.; Tachibana, Y. Monodisperse and size-tunable PbS colloidal quantum dots via heterogeneous precursors. J. Mater. Chem. C 2017, 5, 2182-2187. [CrossRef]

17. Protesescu, L.; Yakunin, S.; Bodnarchuk, M.I.; Krieg, F.; Caputo, R.; Hendon, C.H.; Yang, R.X.; Walsh, A.; Kovalenko, M.V. Nanocrystals of Cesium Lead Halide Perovskites $\left(\mathrm{CsPbX}_{3}, \mathrm{X}=\mathrm{Cl}, \mathrm{Br}\right.$, and I): Novel Optoelectronic Materials Showing Bright Emission with Wide Color Gamut. Nano Lett. 2015, 15, 3692-3696. [CrossRef] [PubMed]

18. Song, J.; Li, J.; Li, X.; Xu, L.; Dong, Y.; Zeng, H. Quantum Dot Light-Emitting Diodes Based on Inorganic Perovskite Cesium Lead Halides $\left(\mathrm{CsPbX}_{3}\right)$. Adv. Mater. 2015, 27, 7162-7167. [CrossRef] [PubMed] 
19. Pan, A.; He, B.; Fan, X.; Liu, Z.; Urban, J.J.; Alivisatos, A.P.; He, L.; Liu, Y. Insight into the Ligand-Mediated Synthesis of Colloidal $\mathrm{CsPbr}_{3}$ Perovskite Nanocrystals: The Role of Organic Acid, Base, and Cesium Precursors. ACS Nano 2016, 10, 7943-7954. [CrossRef] [PubMed]

20. De Roo, J.; Ibáñez, M.; Geiregat, P.; Nedelcu, G.; Walravens, W.; Maes, J.; Martins, J.C.; Van Driessche, I.; Kovalenko, M.V.; Hens, Z. Highly Dynamic Ligand Binding and Light Absorption Coefficient of Cesium Lead Bromide Perovskite Nanocrystals. ACS Nano 2016, 10, 2071-2081. [CrossRef] [PubMed]

21. Song, J.; Xu, L.; Li, J.; Xue, J.; Dong, Y.; Li, X.; Zeng, H. Monolayer and Few-Layer All-Inorganic Perovskites as a New Family of Two-Dimensional Semiconductors for Printable Optoelectronic Devices. Adv. Mater. 2016, 28, 4861-4869. [CrossRef] [PubMed]

22. Li, G.; Wang, H.; Zhang, T.; Mi, L.; Zhang, Y.; Zhang, Z.; Zhang, W.; Jiang, Y. Solvent-Polarity-Engineered Controllable Synthesis of Highly Fluorescent Cesium Lead Halide Perovskite Quantum Dots and Their Use in White Light-Emitting Diodes. Adv. Funct. Mater. 2016, 26, 8478-8486. [CrossRef]

23. Yang, B.; Chen, J.; Hong, F.; Mao, X.; Zheng, K.; Yang, S.; Li, Y.; Pullerits, T.; Deng, W.; Han, K. Lead-Free, Air-Stable All-Inorganic Cesium Bismuth Halide Perovskite Nanocrystals. Angew. Chem. Int. Ed. 2017, 56, 12471-12475. [CrossRef] [PubMed]

24. Jellicoe, T.C.; Richter, J.M.; Glass, H.F.J.; Tabachnyk, M.; Brady, R.; Dutton, S.E.; Rao, A.; Friend, R.H.; Credgington, D.; Greenham, N.C.; et al. Synthesis and Optical Properties of Lead-Free Cesium Tin Halide Perovskite Nanocrystals. J. Am. Chem. Soc. 2016, 138, 2941-2944. [CrossRef] [PubMed]

25. Wang, A.; Yan, X.; Zhang, M.; Sun, S.; Yang, M.; Shen, W.; Pan, X.; Wang, P.; Deng, Z. Controlled Synthesis of Lead-Free and Stable Perovskite Derivative $\mathrm{Cs}_{2} \mathrm{SnI}_{6}$ Nanocrystals via a Facile Hot-Injection Process. Chem. Mater. 2016, 28, 8132-8140. [CrossRef]

26. Zhang, Y.; Yin, J.; Parida, M.R.; Ahmed, G.H.; Pan, J.; Bakr, O.M.; Brédas, J.-L.; Mohammed, O.F. Direct-Indirect Nature of the Bandgap in Lead-Free Perovskite Nanocrystals. J. Phys. Chem. Lett. 2017, 8, 3173-3177. [CrossRef] [PubMed]

27. Pradhan, B.; Kumar, G.S.; Sain, S.; Dalui, A.; Ghorai, U.K.; Pradhan, S.K.; Acharya, S. Size Tunable Cesium Antimony Chloride Perovskite Nanowires and Nanorods. Chem. Mater. 2018, 30, 2135-2142. [CrossRef]

28. De Mello Donegá, C.; Liljeroth, P.; Vanmaekelbergh, D. Physicochemical Evaluation of the Hot-Injection Method, a Synthesis Route for Monodisperse Nanocrystals. Small 2005, 1, 1152-1162. [CrossRef] [PubMed]

29. Swarnkar, A.; Marshall, A.R.; Sanehira, E.M.; Chernomordik, B.D.; Moore, D.T.; Christians, J.A.; Chakrabarti, T.; Luther, J.M. Quantum dot-induced phase stabilization of $\alpha-\mathrm{CsPI}_{3}$ perovskite for high-efficiency photovoltaics. Science 2016, 354, 92-95. [CrossRef] [PubMed]

30. Van Embden, J.; Chesman, A.S.R.; Jasieniak, J.J. The Heat-Up Synthesis of Colloidal Nanocrystals. Chem. Mater. 2015, 27, 2246-2285. [CrossRef]

31. Li, X.; Wu, Y.; Zhang, S.; Cai, B.; Gu, Y.; Song, J.; Zeng, H. CsPbX 3 Quantum Dots for Lighting and Displays: Room- Temperature Synthesis, Photoluminescence Superiorities, Underlying Origins and White Light-Emitting Diodes. Adv. Funct. Mater. 2016, 2435-2445. [CrossRef]

32. Wei, S.; Yang, Y.; Kang, X.; Wang, L.; Huang, L.; Pan, D. Room-temperature and gram-scale synthesis of $\mathrm{CsPbX}_{3}(\mathrm{X}=\mathrm{Cl}, \mathrm{Br}$, I) perovskite nanocrystals with 50-85\% photoluminescence quantum yields. Chem. Commun. 2016, 52, 7265-7268. [CrossRef] [PubMed]

33. Schmidt, L.C.; Pertegás, A.; González-Carrero, S.; Malinkiewicz, O.; Agouram, S.; Mínguez Espallargas, G.; Bolink, H.J.; Galian, R.E.; Pérez-Prieto, J. Nontemplate Synthesis of $\mathrm{CH}_{3} \mathrm{NH}_{3} \mathrm{PbBr}_{3}$ Perovskite Nanoparticles. J. Am. Chem. Soc. 2014, 136, 850-853. [CrossRef] [PubMed]

34. Akkerman, Q.A.; Motti, S.G.; Srimath Kandada, A.R.; Mosconi, E.; D’Innocenzo, V.; Bertoni, G.; Marras, S.; Kamino, B.A.; Miranda, L.; De Angelis, F. Solution Synthesis Approach to Colloidal Cesium Lead Halide Perovskite Nanoplatelets with Monolayer-Level Thickness Control. J. Am. Chem. Soc. 2016, 138, 1010-1016. [CrossRef] [PubMed]

35. Huang, H.; Zhao, F.; Liu, L.; Zhang, F.; Wu, X.; Shi, L.; Zou, B.; Pei, Q.; Zhong, H. Emulsion Synthesis of Size-Tunable $\mathrm{CH}_{3} \mathrm{NH}_{3} \mathrm{PbBr}_{3}$ Quantum Dots: An Alternative Route toward Efficient Light-Emitting Diodes. ACS Appl. Mater. Interfaces 2015, 7, 28128-28133. [CrossRef] [PubMed]

36. Zhang, F.; Zhong, H.; Chen, C.; Wu, X.; Hu, X.; Huang, H.; Han, J.; Zou, B.; Dong, Y. Brightly Luminescent and Color-Tunable Colloidal $\mathrm{CH}_{3} \mathrm{NH}_{3} \mathrm{PbX}_{3}(\mathrm{X}=\mathrm{Br}, \mathrm{I}, \mathrm{Cl})$ Quantum Dots: Potential Alternatives for Display Technology. ACS Nano 2015, 9, 4533-4542. [CrossRef] [PubMed] 
37. Sun, S.; Yuan, D.; Xu, Y.; Wang, A.; Deng, Z. Ligand-Mediated Synthesis of Shape-Controlled Cesium Lead Halide Perovskite Nanocrystals via Reprecipitation Process at Room Temperature. ACS Nano 2016, 10, 3648-3657. [CrossRef] [PubMed]

38. Leng, M.; Yang, Y.; Zeng, K.; Chen, Z.; Tan, Z.; Li, S.; Li, J.; Xu, B.; Li, D.; Hautzinger, M.P. All-Inorganic Bismuth-Based Perovskite Quantum Dots with Bright Blue Photoluminescence and Excellent Stability. Adv. Funct. Mater. 2018, 28, 1704446. [CrossRef]

39. Zhang, J.; Yang, Y.; Deng, H.; Farooq, U.; Yang, X.; Khan, J.; Tang, J.; Song, H. High Quantum Yield Blue Emission from Lead-Free Inorganic Antimony Halide Perovskite Colloidal Quantum Dots. ACS Nano 2017, 11, 9294-9302. [CrossRef] [PubMed]

40. Ng, C.K.; Wang, C.; Jasieniak, J.J. Synthetic Evolution of Colloidal Metal Halide Perovskite Nanocrystals. Langmuir 2019, 35, 11609-11628. [CrossRef] [PubMed]

41. Imran, M.; Di Stasio, F.; Dang, Z.; Canale, C.; Khan, A.H.; Shamsi, J.; Brescia, R.; Prato, M.; Manna, L. Colloidal Synthesis of Strongly Fluorescent $\mathrm{CsPbBr}_{3}$ Nanowires with Width Tunable down to the Quantum Confinement Regime. Chem. Mater. 2016, 28, 6450-6454. [CrossRef] [PubMed]

42. Boles, M.A.; Ling, D.; Hyeon, T.; Talapin, D.V. The surface science of nanocrystals. Nat. Mater. 2016, 15, 141-153. [CrossRef] [PubMed]

43. Akkerman, Q.A.; Rainò, G.; Kovalenko, M.V.; Manna, L. Genesis, challenges and opportunities for colloidal lead halide perovskite nanocrystals. Nat. Mater. 2018, 17, 394-405. [CrossRef] [PubMed]

44. Li, J.; Xu, L.; Wang, T.; Song, J.; Chen, J.; Xue, J.; Dong, Y.; Cai, B.; Shan, Q.; Han, B. 50-Fold EQE Improvement up to $6.27 \%$ of Solution-Processed All-Inorganic Perovskite $\mathrm{CsPbB}_{3}$ QLEDs via Surface Ligand Density Control. Adv. Mater. 2017, 29, 1603885. [CrossRef] [PubMed]

45. Kirakosyan, A.; Yun, S.; Yoon, S.-G.; Choi, J. Surface engineering for improved stability of $\mathrm{CH}_{3} \mathrm{NH}_{3} \mathrm{PbBr}_{3}$ perovskite nanocrystals. Nanoscale 2018, 10, 1885-1891. [CrossRef] [PubMed]

46. Ripka, E.G.; Deschene, C.R.; Franck, J.M.; Bae, I.-T.; Maye, M.M. Understanding the Surface Properties of Halide Exchanged Cesium Lead Halide Nanoparticles. Langmuir 2018, 34, 11139-11146. [CrossRef] [PubMed]

47. Ravi, V.K.; Santra, P.K.; Joshi, N.; Chugh, J.; Singh, S.K.; Rensmo, H.; Ghosh, P.; Nag, A. Origin of the Substitution Mechanism for the Binding of Organic Ligands on the Surface of $\mathrm{CsPbBr}_{3}$ Perovskite Nanocubes. J. Phys. Chem. Lett. 2017, 8, 4988-4994. [CrossRef] [PubMed]

48. Luo, B.; Pu, Y.-C.; Lindley, S.A.; Yang, Y.; Lu, L.; Li, Y.; Li, X.; Zhang, J.Z. Organolead Halide Perovskite Nanocrystals: Branched Capping Ligands Control Crystal Size and Stability. Angew. Chem. Int. Ed. 2016, 55, 8864-8868. [CrossRef] [PubMed]

49. Liu, F.; Zhang, Y.; Ding, C.; Kobayashi, S.; Izuishi, T.; Nakazawa, N.; Toyoda, T.; Ohta, T.; Hayase, S.; Minemoto, T.; et al. Highly Luminescent Phase-Stable CsPbI 3 Perovskite Quantum Dots Achieving Near 100\% Absolute Photoluminescence Quantum Yield. ACS Nano 2017, 11, 10373-10383. [CrossRef] [PubMed]

50. Wang, A.; Guo, Y.; Muhammad, F.; Deng, Z. Controlled Synthesis of Lead-Free Cesium Tin Halide Perovskite Cubic Nanocages with High Stability. Chem. Mater. 2017, 29, 6493-6501. [CrossRef]

51. Suh, Y.-H.; Kim, T.; Choi, J.W.; Lee, C.-L.; Park, J. High-Performance CsPbX 3 Perovskite Quantum-Dot Light-Emitting Devices via Solid-State Ligand Exchange. ACS Appl. Nano Mater. 2018, 1, 488-496. [CrossRef]

52. Pan, J.; Shang, Y.; Yin, J.; De Bastiani, M.; Peng, W.; Dursun, I.; Sinatra, L.; El-Zohry, A.M.; Hedhili, M.N.; Emwas, A.-H. Bidentate Ligand-Passivated $\mathrm{CsPbI}_{3}$ Perovskite Nanocrystals for Stable Near-Unity Photoluminescence Quantum Yield and Efficient Red Light-Emitting Diodes. J. Am. Chem. Soc. 2018, 140, 562-565. [CrossRef] [PubMed]

53. Ravi, V.K.; Scheidt, R.A.; Nag, A.; Kuno, M.; Kamat, P.V. To Exchange or Not to Exchange. Suppressing Anion Exchange in Cesium Lead Halide Perovskites with $\mathrm{PbSO}_{4}-$ Oleate Capping. ACS Energy Lett. 2018, 3, 1049-1055. [CrossRef]

54. Huang, S.; Wang, B.; Zhang, Q.; Li, Z.; Shan, A.; Li, L. Postsynthesis Potassium-Modification Method to Improve Stability of $\mathrm{CsPbBr}_{3}$ Perovskite Nanocrystals. Adv. Opt. Mater. 2018, 6, 1701106. [CrossRef]

55. Nedelcu, G.; Protesescu, L.; Yakunin, S.; Bodnarchuk, M.I.; Grotevent, M.J.; Kovalenko, M.V. Fast Anion-Exchange in Highly Luminescent Nanocrystals of Cesium Lead Halide Perovskites $\left(\mathrm{CsPb}_{3}\right.$, $\mathrm{X}=\mathrm{Cl}, \mathrm{Br}, \mathrm{I})$. Nano Lett. 2015, 15, 5635-5640. [CrossRef] [PubMed] 
56. Li, G.; Wang, H.; Zhu, Z.; Chang, Y.; Zhang, T.; Song, Z.; Jiang, Y. Shape and phase evolution from $\mathrm{CsPbBr}_{3}$ perovskite nanocubes to tetragonal $\mathrm{CsPb}_{2} \mathrm{Br}_{5}$ nanosheets with an indirect bandgap. Chem. Commun. 2016, 52, 11296-11299. [CrossRef] [PubMed]

57. Li, J.; Zhang, H.; Wang, S.; Long, D.; Li, M.; Wang, D.; Zhang, T. Inter-Conversion between Different Compounds of Ternary Cs-Pb-Br System. Materials 2018, 11, 717. [CrossRef] [PubMed]

58. Balakrishnan, S.K.; Kamat, P.V. Ligand Assisted Transformation of Cubic $\mathrm{CsPbBr}_{3}$ Nanocrystals into Two-Dimensional $\mathrm{CsPb}_{2} \mathrm{Br}_{5}$ Nanosheets. Chem. Mater. 2018, 30, 74-78. [CrossRef]

59. Palazon, F.; Almeida, G.; Akkerman, Q.A.; De Trizio, L.; Dang, Z.; Prato, M.; Manna, L. Changing the Dimensionality of Cesium Lead Bromide Nanocrystals by Reversible Postsynthesis Transformations with Amines. Chem. Mater. 2017, 29, 4167-4171. [CrossRef] [PubMed]

60. Udayabhaskararao, T.; Houben, L.; Cohen, H.; Menahem, M.; Pinkas, I.; Avram, L.; Wolf, T.; Teitelboim, A.; Leskes, M.; Yaffe, O. A Mechanistic Study of Phase Transformation in Perovskite Nanocrystals Driven by Ligand Passivation. Chem. Mater. 2018, 30, 84-93. [CrossRef]

61. Chen, X.; Chen, D.; Li, J.; Fang, G.; Sheng, H.; Zhong, J. Tunable CsPbBr $3 / \mathrm{Cs}_{4} \mathrm{PbBr}_{6}$ phase transformation and their optical spectroscopic properties. Dalton Trans. 2018, 47, 5670-5678. [CrossRef] [PubMed]

62. Liu, Z.; Bekenstein, Y.; Ye, X.; Nguyen, S.C.; Swabeck, J.; Zhang, D.; Lee, S.-T.; Yang, P.; Ma, W.; Alivisatos, A.P. Ligand Mediated Transformation of Cesium Lead Bromide Perovskite Nanocrystals to Lead Depleted $\mathrm{Cs}_{4} \mathrm{PbBr}_{6}$ Nanocrystals. J. Am. Chem. Soc. 2017, 139, 5309-5312. [CrossRef] [PubMed]

63. Palazon, F.; Urso, C.; De Trizio, L.; Akkerman, Q.; Marras, S.; Locardi, F.; Nelli, I.; Ferretti, M.; Prato, M.; Manna, L. Postsynthesis Transformation of Insulating $\mathrm{Cs}_{4} \mathrm{PbBr}_{6}$ Nanocrystals into Bright Perovskite $\mathrm{CsPbB}_{3}$ through Physical and Chemical Extraction of CsBr. ACS Energy Lett. 2017, 2, 2445-2448. [CrossRef] [PubMed]

64. Palazon, F.; Dogan, S.; Marras, S.; Locardi, F.; Nelli, I.; Rastogi, P.; Ferretti, M.; Prato, M.; Krahne, R.; Manna, L. From $\mathrm{CsPbBr}_{3}$ Nano-Inks to Sintered $\mathrm{CsPbBr}_{3}-\mathrm{CsPb}_{2} \mathrm{Br}_{5}$ Films via Thermal Annealing: Implications on Optoelectronic Properties. J. Phys. Chem. C 2017, 121, 11956-11961. [CrossRef] [PubMed]

65. Shen, W.; Ruan, L.; Shen, Z.; Deng, Z. Reversible light-mediated compositional and structural transitions between $\mathrm{CsPbBr}_{3}$ and $\mathrm{CsPb}_{2} \mathrm{Br}_{5}$ nanosheets. Chem. Commun. 2018, 54, 2804-2807. [CrossRef] [PubMed]

66. Wu, L.; Hu, H.; Xu, Y.; Jiang, S.; Chen, M.; Zhong, Q.; Yang, D.; Liu, Q.; Zhao, Y.; Sun, B. From Nonluminescent $\mathrm{Cs}_{4} \mathrm{PbX}_{6}(\mathrm{X}=\mathrm{Cl}, \mathrm{Br}, \mathrm{I})$ Nanocrystals to Highly Luminescent $\mathrm{CsPbX}_{3}$ Nanocrystals: Water-Triggered Transformation through a CsX-Stripping Mechanism. Nano Lett. 2017, 17, 5799-5804. [CrossRef] [PubMed]

67. Turedi, B.; Lee, K.J.; Dursun, I.; Alamer, B.; Wu, Z.; Alarousu, E.; Mohammed, O.F.; Cho, N.; Bakr, O.M. Water-Induced Dimensionality Reduction in Metal-Halide Perovskites. J. Phys. Chem. C 2018, 122, 14128-14134. [CrossRef]

68. Long, Z.; Ren, H.; Sun, J.; Ouyang, J.; Na, N. High-throughput and tunable synthesis of colloidal CsPbX 3 perovskite nanocrystals in a heterogeneous system by microwave irradiation. Chem. Commun. 2017, 53, 9914-9917. [CrossRef] [PubMed]

69. Zhang, D.; Yang, Y.; Bekenstein, Y.; Yu, Y.; Gibson, N.A.; Wong, A.B.; Eaton, S.W.; Kornienko, N.; Kong, Q.; Lai, M. Synthesis of Composition Tunable and Highly Luminescent Cesium Lead Halide Nanowires through Anion-Exchange Reactions. J. Am. Chem. Soc. 2016, 138, 7236-7239. [CrossRef] [PubMed]

70. Li, M.; Zhang, X.; Lu, S.; Yang, P. Phase transformation, morphology control, and luminescence evolution of cesium lead halide nanocrystals in the anion exchange process. RSC Adv. 2016, 6, 103382-103389. [CrossRef]

71. Akkerman, Q.A.; D'Innocenzo, V.; Accornero, S.; Scarpellini, A.; Petrozza, A.; Prato, M.; Manna, L. Tuning the optical properties of cesium lead halide perovskite nanocrystals by anion exchange reactions. J. Am. Chem. Soc. 2015, 137, 10276-10281. [CrossRef] [PubMed]

72. Protesescu, L.; Yakunin, S.; Kumar, S.; Bär, J.; Bertolotti, F.; Masciocchi, N.; Guagliardi, A.; Grotevent, M.; Shorubalko, I.; Bodnarchuk, M.I. Dismantling the "Red Wall" of Colloidal Perovskites: Highly Luminescent Formamidinium and Formamidinium-Cesium Lead Iodide Nanocrystals. ACS Nano 2017, 11, 3119-3134. [CrossRef] [PubMed]

73. Van der Stam, W.; Geuchies, J.J.; Altantzis, T.; van den Bos, K.H.W.; Meeldijk, J.D.; Van Aert, S.; Bals, S.; Vanmaekelbergh, D.; de Mello Donega, C. Highly Emissive Divalent-Ion-Doped Colloidal $\mathrm{CsPb}_{1-x} \mathrm{M}_{x} \mathrm{Br}_{3}$ Perovskite Nanocrystals through Cation Exchange. J. Am. Chem. Soc. 2017, 139, 4087-4097. [CrossRef] [PubMed]

74. Mondal, N.; De, A.; Samanta, A. Achieving Near-Unity Photoluminescence Efficiency for Blue-Violet-Emitting Perovskite Nanocrystals. ACS Energy Lett. 2019, 4, 32-39. [CrossRef] 
75. Huang, G.; Wang, C.; Xu, S.; Zong, S.; Lu, J.; Wang, Z.; Lu, C.; Cui, Y. Postsynthetic Doping of $\mathrm{MnCl}_{2}$ Molecules into Preformed $\mathrm{CsPBr}_{3}$ Perovskite Nanocrystals via a Halide Exchange-Driven Cation Exchange. Adv. Mater. 2017, 29, 1700095. [CrossRef] [PubMed]

76. Xu, W.; Li, F.; Lin, F.; Chen, Y.; Cai, Z.; Wang, Y.; Chen, X. Synthesis of $\mathrm{CsPbCl}_{3}-\mathrm{Mn}$ Nanocrystals via Cation Exchange. Adv. Opt. Mater. 2017, 1700520. [CrossRef]

77. Saliba, M. Polyelemental, Multicomponent Perovskite Semiconductor Libraries through Combinatorial Screening. Adv. Energy Mater. 2019, 9, 1803754. [CrossRef]

78. Linaburg, M.R.; McClure, E.T.; Majher, J.D.; Woodward, P.M. $\mathrm{Cs}_{1-x} \mathrm{Rb}_{x} \mathrm{PbCl}_{3}$ and $\mathrm{Cs}_{1-x} \mathrm{Rb}_{x} \mathrm{PbBr}_{3}$ Solid Solutions: Understanding Octahedral Tilting in Lead Halide Perovskites. Chem. Mater. 2017, 29, 3507-3514. [CrossRef]

79. Lim, D.-H.; Ramasamy, P.; Kwak, D.-H.; Lee, J.-S. Solution-phase synthesis of rubidium lead iodide orthorhombic perovskite nanowires. Nanotechnology 2017, 28, 255601. [CrossRef] [PubMed]

80. Amgar, D.; Binyamin, T.; Uvarov, V.; Etgar, L. Near ultra-violet to mid-visible band gap tuning of mixed cation $\mathrm{Rb}_{\mathrm{x}} \mathrm{Cs}_{1-\mathrm{x}} \mathrm{PbX}_{3}(\mathrm{X}=\mathrm{Cl}$ or $\mathrm{Br})$ perovskite nanoparticles. Nanoscale 2018, 10, 6060-6068. [CrossRef] [PubMed]

81. Saidaminov, M.I.; Mohammed, O.F.; Bakr, O.M. Low-Dimensional-Networked Metal Halide Perovskites: The Next Big Thing. ACS Energy Lett. 2017, 2, 889-896. [CrossRef]

82. Fan, Q.; Biesold-McGee, G.V.; Xu, Q.; Pan, S.; Peng, J.; Ma, J.; Lin, Z. Lead-Free Halide Perovskite Nanocrystals: Crystal Structures, Synthesis, Stabilities, and Optical Properties. Angew. Chem. 2019, 1904862.

83. Qiu, L.; Ono, L.K.; Qi, Y. Advances and challenges to the commercialization of organic-inorganic halide perovskite solar cell technology. Mater. Today Energy 2018, 7, 169-189. [CrossRef]

84. Giustino, F.; Snaith, H.J. Toward Lead-Free Perovskite Solar Cells. ACS Energy Lett. 2016, 1, $1233-1240$. [CrossRef]

85. Lyu, M.; Yun, J.-H.; Chen, P.; Hao, M.; Wang, L. Addressing Toxicity of Lead: Progress and Applications of Low-Toxic Metal Halide Perovskites and Their Derivatives. Adv. Energy Mater. 2017, 7, 1602512. [CrossRef]

86. Shi, Z.; Guo, J.; Chen, Y.; Li, Q.; Pan, Y.; Zhang, H.; Xia, Y.; Huang, W. Lead-Free Organic-Inorganic Hybrid Perovskites for Photovoltaic Applications: Recent Advances and Perspectives. Adv. Mater. 2017, 29, 1605005. [CrossRef] [PubMed]

87. Hoefler, S.F.; Trimmel, G.; Rath, T. Progress on lead-free metal halide perovskites for photovoltaic applications: A review. Monatshefte Für Chem. Chem. Mon. 2017, 148, 795-826. [CrossRef] [PubMed]

88. Sun, J.; Yang, J.; Lee, J.I.; Cho, J.H.; Kang, M.S. Lead-Free Perovskite Nanocrystals for Light-Emitting Devices. J. Phys. Chem. Lett. 2018, 9, 1573-1583. [CrossRef] [PubMed]

89. Khalfin, S.; Bekenstein, Y. Advances in lead-free double perovskite nanocrystals, engineering band-gaps and enhancing stability through composition tunability. Nanoscale 2019, 11, 8665-8679. [CrossRef] [PubMed]

90. Bekenstein, Y.; Dahl, J.C.; Huang, J.; Osowiecki, W.T.; Swabeck, J.K.; Chan, E.M.; Yang, P.; Alivisatos, A.P. The Making and Breaking of Lead-Free Double Perovskite Nanocrystals of Cesium Silver-Bismuth Halide Compositions. Nano Lett. 2018, 18, 3502-3508. [CrossRef] [PubMed]

91. Swarnkar, A.; Ravi, V.K.; Nag, A. Beyond Colloidal Cesium Lead Halide Perovskite Nanocrystals: Analogous Metal Halides and Doping. ACS Energy Lett. 2017, 2, 1089-1098. [CrossRef]

92. Scaife, D.E.; Weller, P.F.; Fisher, W.G. Crystal preparation and properties of cesium tin(II) trihalides. J. Solid State Chem. 1974, 9, 308-314. [CrossRef]

93. Yamada, K.; Kawaguchi, H.; Matsui, T.; Okuda, T.; Ichiba, S. Structural Phase Transition and Electrical Conductivity of the Perovskite $\mathrm{CH}_{3} \mathrm{NH}_{3} \mathrm{Sn}_{1-}{ }_{x} \mathrm{~Pb}_{x} \mathrm{Br}_{3}$ and $\mathrm{CsSnBr}_{3}$. Bull. Chem. Soc. Jpn. 1990, 63, 2521-2525. [CrossRef]

94. Qiu, X.; Cao, B.; Yuan, S.; Chen, X.; Qiu, Z.; Jiang, Y.; Ye, Q.; Wang, H.; Zeng, H.; Liu, J. From unstable CsSnI 3 to air-stable $\mathrm{Cs}_{2} \mathrm{SnI}_{6}$ : A lead-free perovskite solar cell light absorber with bandgap of $1.48 \mathrm{eV}$ and high absorption coefficient. Sol. Energy Mater. Sol. Cells 2017, 159, 227-234. [CrossRef]

95. Leng, M.; Chen, Z.; Yang, Y.; Li, Z.; Zeng, K.; Li, K.; Niu, G.; He, Y.; Zhou, Q.; Tang, J. Lead-Free, Blue Emitting Bismuth Halide Perovskite Quantum Dots. Angew. Chem. Int. Ed. 2016, 55, 15012-15016. [CrossRef] [PubMed]

96. Nelson, R.D.; Santra, K.; Wang, Y.; Hadi, A.; Petrich, J.W.; Panthani, M.G. Synthesis and optical properties of ordered-vacancy perovskite cesium bismuth halide nanocrystals. Chem. Commun. 2018, 54, 3640-3643. [CrossRef] [PubMed] 
97. Lou, Y.; Fang, M.; Chen, J.; Zhao, Y. Formation of highly luminescent cesium bismuth halide perovskite quantum dots tuned by anion exchange. Chem. Commun. 2018, 54, 3779-3782. [CrossRef] [PubMed]

98. Pal, J.; Manna, S.; Mondal, A.; Das, S.; Adarsh, K.V.; Nag, A. Colloidal Synthesis and Photophysics of $\mathrm{M}_{3} \mathrm{Sb}_{2} \mathrm{I}_{9}(\mathrm{M}=\mathrm{Cs}$ and $\mathrm{Rb})$ Nanocrystals: Lead-Free Perovskites. Angew. Chem. Int. Ed. 2017, 56, 14187-14191. [CrossRef] [PubMed]

99. Zhao, X.-G.; Yang, J.-H.; Fu, Y.; Yang, D.; Xu, Q.; Yu, L.; Wei, S.-H.; Zhang, L. Design of Lead-Free Inorganic Halide Perovskites for Solar Cells via Cation-Transmutation. J. Am. Chem. Soc. 2017, 139, 2630-2638. [CrossRef] [PubMed]

100. Yang, B.; Mao, X.; Hong, F.; Meng, W.; Tang, Y.; Xia, X.; Yang, S.; Deng, W.; Han, K. Lead-Free Direct Bandgap Double Perovskite Nanocrystals with Bright Dual-Color Emission. J. Am. Chem. Soc. 2018, 140, 17001-17006. [CrossRef] [PubMed]

101. Ke, W.; Stoumpos, C.C.; Kanatzidis, M.G. “Unleaded” Perovskites: Status Quo and Future Prospects of Tin-Based Perovskite Solar Cells. Adv. Mater. 2018, 1803230. [CrossRef] [PubMed]

102. Shao, S.; Liu, J.; Portale, G.; Fang, H.-H.; Blake, G.R.; ten Brink, G.H.; Koster, L.J.A.; Loi, M.A. Highly Reproducible Sn-Based Hybrid Perovskite Solar Cells with 9\% Efficiency. Adv. Energy Mater. 2018, 8, 1702019. [CrossRef]

103. Babayigit, A.; Duy Thanh, D.; Ethirajan, A.; Manca, J.; Muller, M.; Boyen, H.-G.; Conings, B. Assessing the toxicity of $\mathrm{Pb}$ - and $\mathrm{Sn}$-based perovskite solar cells in model organism Danio rerio. Sci. Rep. 2016, 6, 18721. [CrossRef] [PubMed]

104. Chen, M.; Ju, M.-G.; Garces, H.F.; Carl, A.D.; Ono, L.K.; Hawash, Z.; Zhang, Y.; Shen, T.; Qi, Y.; Grimm, R.L. Highly stable and efficient all-inorganic lead-free perovskite solar cells with native-oxide passivation. Nat. Commun. 2019, 10, 16. [CrossRef] [PubMed]

105. Liu, M.; Pasanen, H.; Ali-Löytty, H.; Lahtonen, K.; Qudsia, S.; Smått, J.H.; Valden, M.; Tkachenko, N.V.; Vivo, P. All-inorganic Tin-Germanium Perovskite Nanocubes: Towards Highly Efficient Lead-free Perovskite Nanocrystals-based Solar Cells. J. Am. Chem. Soc. 2019. under peer review.

106. Zhou, Y.; Zhao, Y. Chemical stability and instability of inorganic halide perovskites. Energy Environ. Sci. 2019, 12, 1495-1511. [CrossRef]

107. Xiao, Z.; Zhou, Y.; Hosono, H.; Kamiya, T.; Padture, N.P. Bandgap Optimization of Perovskite Semiconductors for Photovoltaic Applications. Chem. A Eur. J. 2018, 24, 2305-2316. [CrossRef] [PubMed]

108. Ravi, V.K.; Singhal, N.; Nag, A. Initiation and future prospects of colloidal metal halide double-perovskite nanocrystals: $\mathrm{Cs}_{2} \mathrm{AgBiX}_{6}(\mathrm{X}=\mathrm{Cl}, \mathrm{Br}, \mathrm{I})$. J. Mater. Chem. A 2018, 6, 21666-21675. [CrossRef]

109. McClure, E.T.; Ball, M.R.; Windl, W.; Woodward, P.M. $\mathrm{Cs}_{2} \operatorname{AgBiX}_{6}(\mathrm{X}=\mathrm{Br}, \mathrm{Cl})$ : New Visible Light Absorbing, Lead-Free Halide Perovskite Semiconductors. Chem. Mater. 2016, 28, 1348-1354. [CrossRef]

110. Slavney, A.H.; Hu, T.; Lindenberg, A.M.; Karunadasa, H.I. A Bismuth-Halide Double Perovskite with Long Carrier Recombination Lifetime for Photovoltaic Applications. J. Am. Chem. Soc. 2016, 138, 2138-2141. [CrossRef] [PubMed]

111. Yang, B.; Chen, J.; Yang, S.; Hong, F.; Sun, L.; Han, P.; Pullerits, T.; Deng, W.; Han, K. Lead-Free Silver-Bismuth Halide Double Perovskite Nanocrystals. Angew. Chem. Int. Ed. 2018, 57, 5359-5363. [CrossRef] [PubMed]

112. Dahl, J.C.; Osowiecki, W.T.; Cai, Y.; Swabeck, J.K.; Bekenstein, Y.; Asta, M.; Chan, E.M.; Alivisatos, A.P. Probing the Stability and Band Gaps of $\mathrm{Cs}_{2} \mathrm{AgInCl}_{6}$ and $\mathrm{Cs}_{2} \mathrm{AgSbCl}_{6}$ Lead-Free Double Perovskite Nanocrystals. Chem. Mater. 2019, 31, 3134-3143. [CrossRef]

113. Li, X.; Li, B.; Chang, J.; Ding, B.; Zheng, S.; Wu, Y.; Yang, J.; Yang, G.; Zhong, X.; Wang, J. $\left(\mathrm{C}_{6} \mathrm{H}_{5} \mathrm{CH}_{2} \mathrm{NH}_{3}\right)_{2} \mathrm{CuBr}_{4}$ : A Lead-Free, Highly Stable Two-Dimensional Perovskite for Solar Cell Applications. ACS Appl. Energy Mater. 2018, 1, 2709-2716. [CrossRef]

114. Vargas, B.; Ramos, E.; Pérez-Gutiérrez, E.; Alonso, J.C.; Solis-Ibarra, D. A Direct Bandgap Copper-Antimony Halide Perovskite. J. Am. Chem. Soc. 2017, 139, 9116-9119. [CrossRef] [PubMed]

115. Liu, P.; Chen, W.; Wang, W.; Xu, B.; Wu, D.; Hao, J.; Cao, W.; Fang, F.; Li, Y.; Zeng, Y. Halide-Rich Synthesized Cesium Lead Bromide Perovskite Nanocrystals for Light-Emitting Diodes with Improved Performance. Chem. Mater. 2017, 29, 5168-5173. [CrossRef]

116. Woo, J.Y.; Kim, Y.; Bae, J.; Kim, T.G.; Kim, J.W.; Lee, D.C.; Jeong, S. Highly Stable Cesium Lead Halide Perovskite Nanocrystals through in Situ Lead Halide Inorganic Passivation. Chem. Mater. 2017, 29, 7088-7092. [CrossRef] 
117. Imran, M.; Caligiuri, V.; Wang, M.; Goldoni, L.; Prato, M.; Krahne, R.; De Trizio, L.; Manna, L. Benzoyl Halides as Alternative Precursors for the Colloidal Synthesis of Lead-Based Halide Perovskite Nanocrystals. J. Am. Chem. Soc. 2018, 140, 2656-2664. [CrossRef] [PubMed]

118. Creutz, S.E.; Crites, E.N.; De Siena, M.C.; Gamelin, D.R. Colloidal Nanocrystals of Lead-Free Double-Perovskite (Elpasolite) Semiconductors: Synthesis and Anion Exchange To Access New Materials. Nano Lett. 2018, 18, 1118-1123. [CrossRef] [PubMed]

119. Noh, J.H.; Im, S.H.; Heo, J.H.; Mandal, T.N.; Seok, S. Il Chemical Management for Colorful, Efficient, and Stable Inorganic-Organic Hybrid Nanostructured Solar Cells. Nano Lett. 2013, 13, 1764-1769. [CrossRef] [PubMed]

120. Akkerman, Q.A.; Meggiolaro, D.; Dang, Z.; De Angelis, F.; Manna, L. Fluorescent Alloy $\mathrm{CsPb}_{x} \mathrm{Mn}_{1-x} \mathrm{I}_{3}$ Perovskite Nanocrystals with High Structural and Optical Stability. ACS Energy Lett. 2017, 2, 2183-2186. [CrossRef] [PubMed]

121. Zou, S.; Liu, Y.; Li, J.; Liu, C.; Feng, R.; Jiang, F.; Li, Y.; Song, J.; Zeng, H.; Hong, M.; et al. Stabilizing Cesium Lead Halide Perovskite Lattice through Mn(II) Substitution for Air-Stable Light-Emitting Diodes. J. Am. Chem. Soc. 2017, 139, 11443-11450. [CrossRef] [PubMed]

122. Liu, H.; Wu, Z.; Shao, J.; Yao, D.; Gao, H.; Liu, Y.; Yu, W.; Zhang, H.; Yang, B. $\mathrm{CsPb}_{x} \mathrm{Mn}_{1-x} \mathrm{Cl}_{3}$ Perovskite Quantum Dots with High Mn Substitution Ratio. ACS Nano 2017, 11, 2239-2247. [CrossRef] [PubMed]

123. Liu, W.; Lin, Q.; Li, H.; Wu, K.; Robel, I.; Pietryga, J.M.; Klimov, V.I. Mn ${ }^{2+}$-Doped Lead Halide Perovskite Nanocrystals with Dual-Color Emission Controlled by Halide Content. J. Am. Chem. Soc. 2016, 138, 14954-14961. [CrossRef] [PubMed]

124. Mir, W.J.; Jagadeeswararao, M.; Das, S.; Nag, A. Colloidal Mn-Doped Cesium Lead Halide Perovskite Nanoplatelets. ACS Energy Lett. 2017, 2, 537-543. [CrossRef]

125. Chen, D.; Fang, G.; Chen, X. Silica-Coated Mn-Doped $\mathrm{CsPb}(\mathrm{Cl} / \mathrm{Br})_{3}$ Inorganic Perovskite Quantum Dots: Exciton-to-Mn Energy Transfer and Blue-Excitable Solid-State Lighting. ACS Appl. Mater. Interfaces 2017, 9 , 40477-40487. [CrossRef] [PubMed]

126. Begum, R.; Parida, M.R.; Abdelhady, A.L.; Murali, B.; Alyami, N.M.; Ahmed, G.H.; Hedhili, M.N.; Bakr, O.M.; Mohammed, O.F. Engineering Interfacial Charge Transfer in $\mathrm{CsPbr}_{3}$ Perovskite Nanocrystals by Heterovalent Doping. J. Am. Chem. Soc. 2017, 139, 731-737. [CrossRef] [PubMed]

127. Chen, D.; Fang, G.; Chen, X.; Lei, L.; Zhong, J.; Mao, Q.; Zhou, S.; Li, J. Mn-Doped CsPbCl 3 perovskite nanocrystals: Solvothermal synthesis, dual-color luminescence and improved stability. J. Mater. Chem. C 2018, 6, 8990-8998. [CrossRef]

128. Wang, C.; Zhang, Y.; Wang, A.; Wang, Q.; Tang, H.; Shen, W.; Li, Z.; Deng, Z. Controlled Synthesis of Composition Tunable Formamidinium Cesium Double Cation Lead Halide Perovskite Nanowires and Nanosheets with Improved Stability. Chem. Mater. 2017, 29, 2157-2166. [CrossRef]

129. Mosconi, E.; Azpiroz, J.M.; De Angelis, F. Ab Initio Molecular Dynamics Simulations of Methylammonium Lead Iodide Perovskite Degradation by Water. Chem. Mater. 2015, 27, 4885-4892. [CrossRef]

130. Fu, Y.; Zhu, H.; Schrader, A.W.; Liang, D.; Ding, Q.; Joshi, P.; Hwang, L.; Zhu, X.-Y.; Jin, S. Nanowire Lasers of Formamidinium Lead Halide Perovskites and Their Stabilized Alloys with Improved Stability. Nano Lett. 2016, 16, 1000-1008. [CrossRef] [PubMed]

131. Asuo, I.M.; Gedamu, D.; Ka, I.; Gerlein, L.F.; Fortier, F.-X.; Pignolet, A.; Cloutier, S.G.; Nechache, R. High-performance pseudo-halide perovskite nanowire networks for stable and fast-response photodetector. Nano Energy 2018, 51, 324-332. [CrossRef]

132. Yuan, H.; Debroye, E.; Janssen, K.; Naiki, H.; Steuwe, C.; Lu, G.; Moris, M.; Orgiu, E.; Uji-i, H.; De Schryver, F.; et al. Degradation of Methylammonium Lead Iodide Perovskite Structures through Light and Electron Beam Driven Ion Migration. J. Phys. Chem. Lett. 2016, 7, 561-566. [CrossRef] [PubMed]

133. Wang, H.C.; Lin, S.Y.; Tang, A.C.; Singh, B.P.; Tong, H.C.; Chen, C.Y.; Lee, Y.C.; Tsai, T.L.; Liu, R.S. Mesoporous Silica Particles Integrated with All-Inorganic $\mathrm{CsPbBr}_{3}$ Perovskite Quantum-Dot Nanocomposites (MP-PQDs) with High Stability and Wide Color Gamut Used for Backlight Display. Angew. Chem. Int. Ed. 2016, 55, 7924-7929. [CrossRef] [PubMed]

134. Han, Y.; Sun, J.; Ye, S.; Zhang, Q. A stimuli responsive material of perovskite quantum dots composited nano-porous glass. J. Mater. Chem. C 2018, 6, 11184-11192. [CrossRef]

135. Guhrenz, C.; Benad, A.; Ziegler, C.; Haubold, D.; Gaponik, N.; Eychmüller, A. Solid-State Anion Exchange Reactions for Color Tuning of $\mathrm{CsPbX}_{3}$ Perovskite Nanocrystals. Chem. Mater. 2016, 28, 9033-9040. [CrossRef] 
136. Liu, S.; Shao, G.; Ding, L.; Liu, J.; Xiang, W.; Liang, X. Sn-doped CsPbBr 3 QDs glasses with excellent stability and optical properties for WLED. Chem. Eng. J. 2019, 361, 937-944. [CrossRef]

137. Di, X.; Jiang, J.; Hu, Z.; Zhou, L.; Li, P.; Liu, S.; Xiang, W.; Liang, X. Stable and brightly luminescent all-inorganic cesium lead halide perovskite quantum dots coated with mesoporous silica for warm WLED. Dye. Pigment. 2017, 146, 361-367. [CrossRef]

138. Di, X.; Shen, L.; Jiang, J.; He, M.; Cheng, Y.; Zhou, L.; Liang, X.; Xiang, W. Efficient white LEDs with bright green-emitting $\mathrm{CsPbBr} 3$ perovskite nanocrystal in mesoporous silica nanoparticles. J. Alloy. Compd. 2017, 729, 526-532. [CrossRef]

139. He, M.; Liu, S.; Ding, L.; Zhang, Z.; Liu, J.; Xiang, W.; Liang, X. SiO 2 -improved stability of Mn-doped $\mathrm{CsPbBr}_{0.5} \mathrm{I}_{2.5} \mathrm{NC}$ and their application for white LED. J. Am. Ceram. Soc. 2019, 102, 930-935.

140. Sun, C.; Shen, X.; Zhang, Y.; Wang, Y.; Chen, X.; Ji, C.; Shen, H.; Shi, H.; Wang, Y.; Yu, W.W. Highly luminescent, stable, transparent and flexible perovskite quantum dot gels towards light-emitting diodes. Nanotechnology 2017, 28, 36. [CrossRef] [PubMed]

141. Huang, S.; Li, Z.; Kong, L.; Zhu, N.; Shan, A.; Li, L. Enhancing the Stability of $\mathrm{CH}_{3} \mathrm{NH}_{3} \mathrm{PbBr}_{3}$ Quantum Dots by Embedding in Silica Spheres Derived from Tetramethyl Orthosilicate in "waterless" Toluene. J. Am. Chem. Soc. 2016, 138, 5749-5752. [CrossRef] [PubMed]

142. Milstein, T.J.; Kluherz, K.T.; Kroupa, D.M.; Erickson, C.S.; Yoreo, J.J.D.; Gamelin, D.R. Anion Exchange and the Quantum-Cutting Energy Threshold in Ytterbium-Doped $\mathrm{CsPb}\left(\mathrm{Cl}_{1-\mathrm{x}} \mathrm{Br}_{\mathrm{x}}\right)_{3}$ Perovskite Nanocrystals. Nano Lett. 2019, 19, 1931-1937. [CrossRef] [PubMed]

143. Kaur, G.; Pandey, O.P.; Singh, K.; Homa, D.; Scott, B.; Pickrell, G. A review of bioactive glasses: Their structure, properties, fabrication and apatite formation. J. Biomed. Mater. Res. Part A 2014, 102, 254-274. [CrossRef] [PubMed]

144. Liu, S.; Luo, Y.; He, M.; Liang, X.; Xiang, W. Novel CsPbI ${ }_{3}$ QDs glass with chemical stability and optical properties. J. Eur. Ceram. Soc. 2017, 38, 1998-2004. [CrossRef]

145. Diodes, M.L.; Br, C.X.; Dots, I.Q. Multicolour Light-emitting Diodes Based on $\mathrm{CsPbX}_{3}(\mathrm{X}=\mathrm{Br}, \mathrm{I})$ Quantum Dots Glasses Solid Materials. Mater. Lett. 2018, 229, 290-292.

146. Li, P.; Cheng, Y.; Zhou, L.; Yu, X.; Jiang, J.; He, M.; Liang, X.; Xiang, W. Photoluminescence properties and device application of $\mathrm{CsPb}_{2} \mathrm{Br}_{5}$ quantum dots in glasses. Mater. Res. Bull. 2018, 105, 63-67. [CrossRef]

147. He, M.; Ding, L.; Liu, S.; Shao, G.; Zhang, Z.; Liang, X.; Xiang, W. Superior fluorescence and high stability of B-Si-Zn glasses based on Mn-doped $\mathrm{CsPbBr}_{\mathrm{x}} \mathrm{I}_{3-\mathrm{x}}$ nanocrystals. J. Alloy. Compd. 2018, 780, 318-325. [CrossRef]

148. Jiang, J.; Shao, G.; Zhang, Z.; Ding, L.; Zhang, H.; Liu, J.; Chen, Z.; Xiang, W.; Liang, X. Ultrastability and color-tunability of $\mathrm{CsPb}(\mathrm{Br} / \mathrm{I})_{3}$ nanocrystals in P-Si-Zn glass for white LEDs. Chem. Commun. 2018, 54, 12302-12305. [CrossRef] [PubMed]

149. Di, X.; Hu, Z.; Jiang, J.; He, M.; Zhou, L.; Xiang, W.; Liang, X. Use of long-term stable CsPbBr 3 perovskite quantum dots in phospho-silicate glass for highly efficient white LEDs. Chem. Commun. 2017, 53, 11068-11071. [CrossRef] [PubMed]

150. Zhang, W.; Ye, Y.; Liu, C.; Zhao, Z.; Wang, J.; Han, J.; Zhao, X. Revealing the Effects of Defects on Ultrafast Carrier Dynamics of $\mathrm{CsPbI}_{3}$ Nanocrystals in Glass. J. Phys. Chem. C 2019, 123, 15851-15858. [CrossRef]

151. Yuan, S.; Chen, D.; Li, X.; Zhong, J.; Xu, X. Functional Inorganic Materials and Devices In Situ Crystallization Synthesis of $\mathrm{CsPbBr}_{3}$ Perovskite Quantum Dots Embedded Glasses with Improved Stability for Solid-State-Lighting and Random Upconverted Lasing. ACS Appl. Mater. Interfaces 2018, 10, 18918-18926. [CrossRef] [PubMed]

152. Wang, Y.; He, J.; Chen, H.; Chen, J.; Zhu, R.; Ma, P.; Towers, A.; Lin, Y.; Gesquiere, A.J.; Wu, S.T. Ultrastable, Highly Luminescent Organic-Inorganic Perovskite-Polymer Composite Films. Adv. Mater. 2016, 28, 10710-10717. [CrossRef] [PubMed]

153. Zuo, L.; Guo, H.; DeQuilettes, D.W.; Jariwala, S.; De Marco, N.; Dong, S.; DeBlock, R.; Ginger, D.S.; Dunn, B.; Wang, M. Polymer-modified halide perovskite films for efficient and stable planar heterojunction solar cells. Sci. Adv. 2017, 3, 1700106. [CrossRef] [PubMed]

154. Xin, Y.; Zhao, H.; Zhang, J. Highly Stable and Luminescent Perovskite-Polymer Composites from a Convenient and Universal Strategy. ACS Appl. Mater. Interfaces 2018, 10, 4971-4980. [CrossRef] [PubMed]

155. Liao, H.; Guo, S.; Cao, S.; Wang, L.; Gao, F.; Yang, Z.; Zheng, J.; Yang, W. A General Strategy for In Situ Growth of All-Inorganic $\mathrm{CsPbX}_{3}(\mathrm{X}=\mathrm{Br}, \mathrm{I}$, and $\mathrm{Cl})$ Perovskite Nanocrystals in Polymer Fibers toward Significantly Enhanced Water/Thermal Stabilities. Adv. Opt. Mater. 2018, 6, 1800346. [CrossRef] 
156. Zhang, H.; Wang, X.; Liao, Q.; Xu, Z.; Li, H.; Zheng, L.; Fu, H. Embedding Perovskite Nanocrystals into a Polymer Matrix for Tunable Luminescence Probes in Cell Imaging. Adv. Funct. Mater. 2017, 27, 1604382. [CrossRef]

157. Raja, S.N.; Bekenstein, Y.; Koc, M.A.; Fischer, S.; Zhang, D.; Lin, L.; Ritchie, R.O.; Yang, P.; Alivisatos, A.P. Encapsulation of Perovskite Nanocrystals into Macroscale Polymer Matrices: Enhanced Stability and Polarization. ACS Appl. Mater. Interfaces 2016, 8, 35523-35533. [CrossRef] [PubMed]

158. Huang, G.; Huang, Y.; Xu, W.; Yao, Q.; Liu, X.; Ding, C.; Chen, X. Cesium lead halide perovskite nanocrystals for ultraviolet and blue light blocking. Chin. Chem. Lett. 2018, 30, 1021-1023. [CrossRef]

159. Fang, M.; Huang, S.; Li, D.; Jiang, C.; Tian, P.; Lin, H.; Luo, C.; Yu, W.; Peng, H. Stretchable and self-healable organometal halide perovskite nanocrystal-embedded polymer gels with enhanced luminescence stability. Nanophotonics 2018, 7, 1949-1958. [CrossRef]

160. Wei, Y.; Deng, X.; Xie, Z.; Cai, X.; Liang, S.; Ma, P.; Hou, Z.; Cheng, Z.; Lin, J. Enhancing the Stability of Perovskite Quantum Dots by Encapsulation in Crosslinked Polystyrene Beads via a Swelling-Shrinking Strategy toward Superior Water Resistance. Adv. Funct. Mater. 2017, 27, 1703535. [CrossRef]

161. Li, Y.; Lv, Y.; Guo, Z.; Dong, L.; Zheng, J.; Chai, C.; Chen, N.; Lu, Y.; Chen, C. One-Step Preparation of Long-Term Stable and Flexible $\mathrm{CsPbB}_{3}$ Perovskite Quantum Dots/Ethylene Vinyl Acetate Copolymer Composite Films for White Light-Emitting Diodes. ACS Appl. Mater. Interfaces 2018, 10, 15888-15894. [CrossRef] [PubMed]

162. Bagherzadeh-Khajehmarjan, E.; Nikniazi, A.; Olyaeefar, B.; Ahmadi-Kandjani, S.; Nunzi, J.-M. Bulk luminescent solar concentrators based on organic-inorganic $\mathrm{CH}_{3} \mathrm{NH}_{3} \mathrm{PbBr}_{3}$ perovskite fluorophores. Sol. Energy Mater. Sol. Cells 2019, 192, 44-51. [CrossRef]

163. Zhao, H.; Zhou, Y.; Benetti, D.; Ma, D.; Rosei, F. Perovskite quantum dots integrated in large-area luminescent solar concentrators. Nano Energy 2017, 37, 214-223. [CrossRef]

164. Lin, C.C.; Jiang, D.H.; Kuo, C.C.; Cho, C.J.; Tsai, Y.H.; Satoh, T.; Su, C. Water-Resistant Efficient Stretchable Perovskite-Embedded Fiber Membranes for Light-Emitting Diodes. ACS Appl. Mater. Interfaces 2018, 10, 2210-2215. [CrossRef] [PubMed]

165. Hai, J.; Li, H.; Zhao, Y.; Chen, F.; Peng, Y.; Wang, B. Designing of blue, green, and red $\mathrm{CsPbX}_{3}$ perovskite-codoped flexible films with water resistant property and elimination of anion-exchange for tunable white light emission. Chem. Commun. 2017, 53, 5400-5403. [CrossRef] [PubMed]

166. Chen, W.; Shi, T.; Du, J.; Zang, Z.; Yao, Z.; Li, M.; Sun, K.; Hu, W.; Leng, Y.; Tang, X. Highly Stable Silica-Wrapped Mn-Doped $\mathrm{CsPbCl}_{3}$ Quantum Dots for Bright White Light-Emitting Devices. ACS Appl. Mater. Interfaces 2018, 10, 43978-43986. [CrossRef] [PubMed]

167. Zhong, Q.; Cao, M.; Hu, H.; Yang, D.; Chen, M.; Li, P.; Wu, L.; Zhang, Q. One-pot synthesis of highly stable $\mathrm{CsPbBr}_{3} @ \mathrm{SiO}_{2}$ core-shell nanoparticles. ACS Nano 2018, 12, 8579-8587. [CrossRef] [PubMed]

168. Loiudice, A.; Strach, M.; Saris, S.; Chernyshov, D.; Buonsanti, R. Universal Oxide Shell Growth Enables in Situ Structural Studies of Perovskite Nanocrystals during the Anion Exchange Reaction. J. Am. Chem. Soc. 2019, 141, 8254-8263. [CrossRef] [PubMed]

169. Tang, X.; Yang, J.; Li, S.; Liu, Z.; Hu, Z.; Hao, J.; Du, J.; Leng, Y.; Qin, H.; Lin, X. Single Halide Perovskite/Semiconductor Core/Shell Quantum Dots with Ultrastability and Nonblinking Properties. Adv. Sci. 2019, 6, 1900412. [CrossRef] [PubMed]

170. Hintermayr, V.; Lampe, C.; Löw, M.; Roemer, J.; Vanderlinden, W.; Gramlich, M.; Böhm, A.X.; Sattler, C.; Nickel, B.; Lohmueller, T. Polymer nanoreactors shield perovskite nanocrystals from degradation. Nano Lett. 2019, 19, 4928-4933. [CrossRef] [PubMed]

171. Innocenzi, P. The Sol to Gel Transition; Briefs Mater; Springer: Berlin, Germany, 2016.

172. Ding, N.; Zhou, D.; Sun, X.; Xu, W.; Xu, H.; Pan, G.; Li, D.; Zhang, S.; Dong, B.; Song, H. Highly stable and water-soluble monodisperse $\mathrm{CsPbX}_{3} / \mathrm{SiO}_{2}$ nanocomposites for white-LED and cells imaging. Nanotechnology 2018, 29, 34. [CrossRef] [PubMed]

173. Zhang, F.; Shi, Z.; Li, S.; Ma, Z.; Li, Y.; Wang, L.; Wu, D.; Tian, Y.; Du, G.; Li, X. Synergetic Effect of the Surfactant and Silica Coating on the Enhanced Emission and Stability of Perovskite Quantum Dots for Anticounterfeiting. ACS Appl. Mater. Interfaces 2019, 11, 28013-28022. [CrossRef] [PubMed]

174. Li, Z.J.; Hofman, E.; Li, J.; Davis, A.H.; Tung, C.H.; Wu, L.Z.; Zheng, W. Photoelectrochemically active and environmentally stable $\mathrm{CsPbBr} / \mathrm{TiO}_{2}$ core/shell nanocrystals. Adv. Funct. Mater. 2018, 28, 1704288. [CrossRef] 
175. Tang, X.; Yang, J.; Li, S.; Chen, W.; Hu, Z.; Qiu, J. CsPbBr $3 /$ CdS Core/Shell Structure Quantum Dots for Inverted Light-Emitting Diodes Application. Front. Chem. 2019, 7, 499. [CrossRef] [PubMed]

176. Wang, B.; Zhang, C.; Huang, S.; Li, Z.; Kong, L.; Jin, L.; Wang, J.; Wu, K.; Li, L. Postsynthesis Phase Transformation for $\mathrm{CsPbBr}_{3} / \mathrm{Rb}_{4} \mathrm{PbBr}_{6}$ Core/Shell Nanocrystals with Exceptional Photostability. ACS Appl. Mater. Interfaces 2018, 10, 23303-23310. [CrossRef] [PubMed]

177. Qiao, B.; Song, P.; Cao, J.; Zhao, S.; Shen, Z.; Di, G.; Liang, Z.; Xu, Z.; Song, D.; Xu, X. Water-resistant, monodispersed and stably luminescent $\mathrm{CsPbBr} 3 / \mathrm{CsPb}_{2} \mathrm{Br}_{5}$ core-shell-like structure lead halide perovskite nanocrystals. Nanotechnology 2017, 28, 44. [CrossRef] [PubMed]

178. Jia, C.; Li, H.; Meng, X.; Li, H. CsPbX $3 / \mathrm{Cs}_{4} \mathrm{PbX}_{6}$ core/shell perovskite nanocrystals. Chem. Commun. 2018, 54, 6300-6303. [CrossRef] [PubMed]

179. Wang, S.; Bi, C.; Yuan, J.; Zhang, L.; Tian, J. Original Core-Shell Structure of Cubic $\mathrm{CsPbBr}_{3} @ \mathrm{Amorphous}$ $\mathrm{CsPbBr}$ Perovskite Quantum Dots with a High Blue Photoluminescence Quantum Yield of over 80\%. ACS Energy Lett. 2018, 3, 245-251. [CrossRef]

180. Xu, K.; Lin, C.C.; Xie, X.; Meijerink, A. Efficient and Stable Luminescence from $\mathrm{Mn}^{2+}$ in Core and Core-Isocrystalline Shell $\mathrm{CsPbl}_{3}$ Perovskite Nanocrystals. Chem. Mater. 2017, 29, 4265-4272. [CrossRef] [PubMed]

181. Bhaumik, S.; Veldhuis, S.A.; Ng, Y.F.; Li, M.; Muduli, S.K.; Sum, T.C.; Damodaran, B.; Mhaisalkar, S.; Mathews, N. Highly stable, luminescent core-shell type methylammonium-octylammonium lead bromide layered perovskite nanoparticles. Chem. Commun. 2016, 52, 7118-7121. [CrossRef] [PubMed]

182. Huang, S.; Zhang, T.; Jiang, C.; Qi, R. Luminescent $\mathrm{CH}_{3} \mathrm{NH}_{3} \mathrm{PbBr}_{3} / \beta$-cyclodextrin Core/Shell Nanodots with Controlled Size and Ultrastability Through Host-guest Interaction. ChemNanoMat. 2019, 1900381.

183. Mary Vijila, C.V.; Rajeev Kumar, K.; Jayaraj, M.K. Stokes shift engineered, stable core-shell perovskite nanoparticle - Poly(methyl methacrylate) composites with high photoluminescence quantum yield. Opt. Mater. 2019, 94, 241-248. [CrossRef]

184. Ushakova, E.; Matuhina, A.; Sokolova, A.; Cherevkov, S.A.; Dubavik, A.; Medvedev, O.; Litvin, A.; Kurdyukov, D.; Golubev, V.; Baranov, A.V. Enhanced stability of the optical responses from the all-inorganic perovskite nanocrystals embedded in synthetic opal matrix. Nanotechnology 2019, 30, 40. [CrossRef] [PubMed]

185. Huang, H.; Chen, B.; Wang, Z.; Hung, T.F.; Susha, A.S.; Zhong, H.; Rogach, A.L. Water resistant CsPbX 3 nanocrystals coated with polyhedral oligomeric silsesquioxane and their use as solid state luminophores in all-perovskite white light-emitting devices. Chem. Sci. 2016, 7, 5699-5703. [CrossRef] [PubMed]

186. Mirershadi, S.; Ahmadi-Kandjani, S. Efficient thin luminescent solar concentrator based on organometal halide perovskite. Dye. Pigment. 2015, 120,15-21. [CrossRef]

187. Zhou, Q.; Bai, Z.; Lu, W.G.; Wang, Y.; Zou, B.; Zhong, H. In Situ Fabrication of Halide Perovskite Nanocrystal-Embedded Polymer Composite Films with Enhanced Photoluminescence for Display Backlights. Adv. Mater. 2016, 28, 9163-9168. [CrossRef] [PubMed]

188. Zhao, Y.; Wei, J.; Li, H.; Yan, Y.; Zhou, W.; Yu, D.; Zhao, Q. A polymer scaffold for self-healing perovskite solar cells. Nat. Commun. 2016, 7, 10228. [CrossRef] [PubMed]

189. Zong, Y.; Zhou, Y.; Zhang, Y.; Li, Z.; Zhang, L.; Ju, M.G.; Chen, M.; Pang, S.; Zeng, X.C.; Padture, N.P. Continuous Grain-Boundary Functionalization for High-Efficiency Perovskite Solar Cells with Exceptional Stability. Chem 2018, 4, 1404-1415. [CrossRef]

190. Wang, C.; Song, Z.; Zhao, D.; Awni, R.A.; Li, C.; Shrestha, N.; Chen, C.; Yin, X.; Li, D.; Ellingson, R.J. Improving Performance and Stability of Planar Perovskite Solar Cells through Grain Boundary Passivation with Block Copolymers. Sol. RRL 2019, 3, 1900078. [CrossRef]

191. Meyns, M.; Perálvarez, M.; Heuer-Jungemann, A.; Hertog, W.; Ibáñez, M.; Nafria, R.; Genç, A.; Arbiol, J.; Kovalenko, M.V.; Carreras, J. Polymer-Enhanced Stability of Inorganic Perovskite Nanocrystals and Their Application in Color Conversion LEDs. ACS Appl. Mater. Interfaces 2016, 8, 19579-19586. [CrossRef] [PubMed]

(C) 2019 by the authors. Licensee MDPI, Basel, Switzerland. This article is an open access article distributed under the terms and conditions of the Creative Commons Attribution (CC BY) license (http://creativecommons.org/licenses/by/4.0/). 